\title{
Measuring the "Free" Digital Economy within the GDP and Productivity Accounts
}

Leonard Nakamura ${ }^{1}$, Jon Samuels ${ }^{2}$, and Rachel Soloveichik ${ }^{3}$

${ }^{1}$ Federal Reserve Bank of Philadelphia, ${ }^{2,3}$ U.S. Bureau of Economic Analysis

ESCoE Discussion Paper 2017-03

December 2017 


\section{About the Economic Statistics Centre of Excellence (ESCoE)}

The Economic Statistics Centre of Excellence provides research that addresses the challenges of measuring the modern economy, as recommended by Professor Sir Charles Bean in his Independent Review of UK Economics Statistics. ESCoE is an independent research centre sponsored by the Office for National Statistics (ONS). Key areas of investigation include: National Accounts and Beyond GDP, Productivity and the Modern economy, Regional and Labour Market statistics.

ESCoE is made up of a consortium of leading institutions led by the National Institute of Economic and Social Research (NIESR) with King's College London, innovation foundation Nesta, University of Cambridge, Warwick Business School (University of Warwick) and Strathclyde Business School.

ESCoE Discussion Papers describe research in progress by the author(s) and are published to elicit comments and to further debate. Any views expressed are solely those of the author(s) and so cannot be taken to represent those of the ESCoE, its partner institutions or the ONS.

For more information on ESCoE see www.escoe.ac.uk.

\section{Contact Details}

Economic Statistics Centre of Excellence

2 Dean Trench St

London SW1P 3HE

United Kingdom

T: +44 (0)207222 7665

E: escoeinfo@niesr.ac.uk
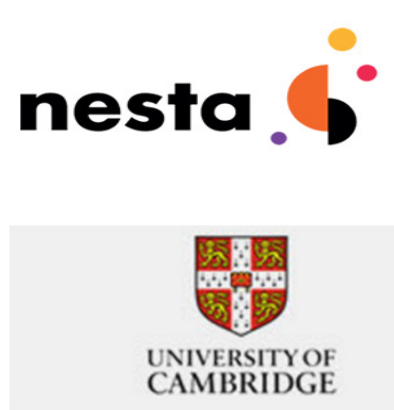
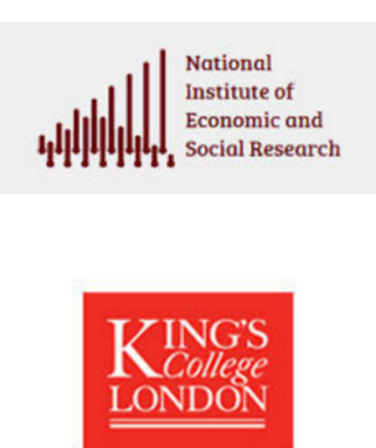

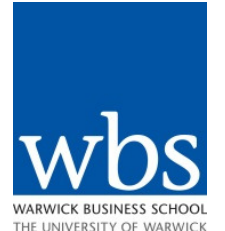

University of Business
School 


\title{
Measuring the "Free" Digital Economy within the GDP and Productivity Accounts
}

\author{
Leonard Nakamura ${ }^{1}$, Jon Samuels ${ }^{2}$, and Rachel Soloveichik ${ }^{3},{ }^{4}$ \\ ${ }^{1}$ Federal Reserve Bank of Philadelphia, ${ }^{2,3}$ U.S. Bureau of Economic Analysis
}

\begin{abstract}
We develop an experimental methodology that values "free" digital content through the lens of a production account and is consistent with the framework of the national accounts. We build upon the work in Nakamura, et al. (2016) by combining marketing- and advertising-supported content and find that the impact of "free" digital content on U.S. gross domestic product (GDP) has accelerated in recent years, particularly since 2005. However, the explosion in "free" digital content is partially offset by a decrease in "free" print content like newspapers. Including these, real GDP growth would grow at 1.53 percent a year from 2005 to 2015 rather than the official growth rate of 1.42 percent, a tenth of a percent faster. Thus, there is a substantive impact on 2005 to 2015 real growth, even when we do not measure the full consumer surplus benefits of free goods. In addition, from 1995 to 2005, real GDP growth, including "free" content, would grow 0.07 percentage point faster, and in the earlier period, from 1929 to $1995,0.01$ percentage point faster. We further find that the personal consumption expenditures (PCE) and core PCE deflators would have risen about 0.1 percentage point slower from 2005 to 2015. To analyze the impact of "free" content on measured private business total factor productivity (TFP) growth, we account for inputs of "free" content used in production. We find that TFP would grow faster by 0.07 percentage point per year from 2005 to 2014 and faster by 0.07 percentage point from 1995 to 2005.
\end{abstract}

Key words: Internet, productivity, advertising, marketing, measurement, GDP

JEL classification: C82, L81, M37, and O3

\section{Contact Details}

Rachel Soloveichik

Bureau of Economic Analysis (BEA)

4600 Silver Hill Rd.

Washington, DC 20233, USA

Email: ${ }^{1}$ leonard.nakamura@phil.frb.org, ${ }^{2}$ jon.samuels@bea.gov,

${ }^{3}$ rachel.soloveichik@bea.gov

This ESCoE paper was first published in December 2017.

(C) Leonard Nakamura, Jon Samuels and Rachel Soloveichik

\footnotetext{
4 Leonard Nakamura is a vice president and economist in the Research Department at the Federal Reserve Bank of Philadelphia, Ten Independence Mall, Philadelphia, PA 19106-1574; Jon Samuels and Rachel Soloveichik are research economists at the U.S. Bureau of Economic Analysis. The views expressed here are those of the authors and do not represent those of the U.S. Bureau of Economic Analysis, the U.S. Department of Commerce, the Federal Reserve Bank of Philadelphia, or the Federal Reserve System. This paper is also available free of charge at www.philadelphiafed.org/research-and-data/publications/working-papers and https://www.bea.gov/papers/working_papers.htm
} 


\section{Introduction}

"Free" digital content is pervasive. Yet, unlike the majority of output produced by the private business sector, many facets of the digital economy (e.g., Google, Facebook, Candy Crush) are provided without a market transaction between the final user of the content and the producer of the content. For those used to thinking about GDP from the expenditure side, this raises immediate concerns that the value of this content is not only unmeasured within the current GDP and productivity statistics, but is fundamentally unmeasurable within the current framework. Furthermore, because these technologies are so pervasive and have induced large changes in consumer behavior and business practice, these open questions have evolved into arguments that the exclusion of these technologies from the national accounts leads to a significant downward bias in official estimates of growth and productivity.

The first contribution of this paper is to provide an argument that, yes, it is possible to measure many aspects of the "free" digital economy via the lens of a production account. In particular, we modify the production account to separate the costs of producing "free" digital content and equate these costs to their value. The output side of the production account corresponds to GDP and measures the production of goods and services, while the input side corresponds to gross domestic income (GDI) and includes payments to the inputs used in production. The ratio of the quantity of output to the quantity of input is defined as TFP, and this provides the link between the GDP and productivity accounts. The motivations for framing our analysis within the production account are that 1) the other components of GDP and productivity are measured within a production account, and 2) it highlights important consistency issues between the outputs of "free" content and the inputs used to produce the content. To be clear at the outset, this approach does not provide a willingness to pay or welfare valuation of the "free" content. But this approach does provide an estimate of the value of the content that is consistent with national accounting estimates of production.

We model the provision of "free" content as a barter transaction. Consumers and businesses receive content in exchange for exposure to advertising or marketing. Our approach reduces to treating the provision of the "free" digital content as payment in kind for viewership services produced by households and businesses. Put differently, the national accounts currently ignore the role of households in the production of advertising and marketing. In our methodology, households are active producers of viewership services that they barter for consumer entertainment.

Our experimental methodology has at its heart two balancing components. On the expenditure side, we impute content purchases equal to the cost of providing content services. These costs are paid by advertisers or marketers, so "free" content is actually advertising-supported media or marketingsupported information that could have been supplied through other funding methods. Indeed, "free" content can be thought of as having been bid away from alternatives. For example, driving directions can be downloaded from an advertising-supported Web site like Google or a subscriber-supported Web 
site like PCmiler. Similarly, when a journal like Science accepts advertising, it is enabled to provide more information services to the businesses that subscribe. This approach requires no major conceptual changes to the international guidelines for national accounts (System of National Accounts 2008 or SNA 2008), and thus could be implemented without the major lag that usually accompanies revisions to international economic accounting standards.

The second contribution of this paper is to assess the empirical impact of the "free" digital economy on measures of output, value added, and productivity at the aggregate and industry levels. We focus on two types of "free" content: advertising-supported media and marketing-supported information. ${ }^{2}$ Advertising-supported media includes digital content like Google search, but also more traditional content like print media and broadcast television. Marketing-supported information includes digital content like so-called freemium games for smartphones or recipes from BettyCrocker.com, but also more traditional content like print newsletters and audiovisual marketing. Conceptually, the barter transaction between the producer and user of "free" information is nearly identical to that with advertising-supported media. The main difference is that advertising viewership is almost exclusively "purchased" by media companies from the general public and then resold to outside companies. In contrast, the marketing viewership that is exchanged for "free" information is generally "purchased" by nonmedia companies from potential customers and used in-house.

To assess the industry origins of the digital economy and its impact across industries that use "free" content as an input into production, we extend our basic barter transaction model to distinguish between the use of "free" content by households and private businesses. The identity of the user determines both the terminology we use and also the impact on measured GDP. When households use "free" content, we call it "consumer entertainment" in the case of advertising media and "consumer information" in the case of marketing supported information. ${ }^{3}$ In this case, we add the value of that entertainment or information to PCE and GDP. Balancing that additional PCE, we impute income to viewers that are, in effect, paid to view advertising or marketing, with those payments being equal to the cost of providing entertainment or information programs. This additional income precisely equals the additional PCE, so there is no change in household savings.

When private businesses use "free" content, we call it "business information" and add the value of that information to intermediate inputs. Balancing that additional intermediate input, we impute business output for ad viewership. This additional business output precisely equals the additional expenditures on intermediate inputs, so measured nominal value added by industry and nominal GDP do not change in the case of business use. However, measured real value added by industry and measured productivity

\footnotetext{
${ }^{2}$ Both advertising-supported media and marketing-supported information are often offered at a subsidized price rather than a zero price. For example, newspapers and magazines typically charge a subscription cost lower than their actual prices. Similarly, freemium games offer basic features for free but require payment for extras.

${ }^{3}$ Historically, marketing-supported consumer information has focused on relatively boring topics like product attributes or household production tips. For these topics, the description of marketing-supported content as information appears uncontroversial. However, we also include fun marketing like "free" games or celebrity Twitter accounts in the category "consumer information"
} 
by industry may change because the newly recognized outputs have a different price trend than the newly recognized inputs.

We estimate the contribution of "free" content from the supply side by measuring the costs of production. That is, we do not capture a welfare measure of the value of Google Maps, but only measure the cost of providing it. This could be viewed as an underestimate of the contribution of this "free" content to output and productivity-but it is consistent with the standard national accounting methodologies for estimating industry output and input. Therefore, our supply-side numbers are consistent with the concept of domestic production, but they differ in scope from other approaches to measuring the economic impact of digital goods. ${ }^{4}$

When we calculate private business TFP, we separate the viewership sector's value added from the private business sector's value added. Note that nominal value added in the private business sector is unchanged by our methodology, as the two sides of the barter transaction cancel out. However, the real quantity of value added changes, since the real quantity of viewership output (think of these as marketing exposures) contributed to marketing differs from the real quantity of content (priced at cost) supplied-the terms of trade in the barter relationship have changed over time.

In this paper, we study only the United States, so all references to GDP and PCE are to GDP and PCE for the entire U.S. economy. And when we refer to TFP, we mean private business TFP.

We are particularly interested in the analysis of "free" digital content beginning in 1995 because that year has been previously identified as an inflection point in the production of information technology (IT) equipment (Jorgenson 2001). Moreover, that is when the Internet emerged as a significant source of "free" content. We calculate that, from 1995 to 2014, our experimental methodology applied to digital content annually raises nominal GDP growth by 0.036 percentage point, real GDP growth by 0.089 percentage point, and TFP growth 0.048 percentage point. The growth of digital content is partially offset by a decrease in "free" print content like newspapers. From 1995 to 2014, all "free" content categories together annually raise nominal GDP growth by 0.033 percentage point, raise real GDP growth by 0.080 percentage point, and raise TFP growth by 0.073 percentage point. From 1929 to 1995, the impact of "free" content is small. From 1949 to 1995, all "free" content categories together annually raise nominal GDP growth by 0.008 percentage point, raise real GDP growth by 0.010 percentage point, and raise TFP growth by 0.024 percentage point. These revised numbers slightly ameliorate the recent slowdown in economic growth-but not nearly enough to reverse the slowdown.

It is also of interest to divide the period from 1995 to 2015 into halves, -the relatively high-productivity decade from 1995 to 2005 and the relatively low-productivity decade from 2005 to 2014. When we do so, we find the impact of "free" content is to accelerate real GDP growth by just 0.027 percentage point and TFP growth by just 0.003 percentage point in the second decade relative to the first. Thus, while these data tend to show acceleration for real GDP and TFP after 1995, they do little to affect the dramatic slowdown in both after 2005.

\footnotetext{
${ }^{4}$ Our approach is fully consistent with the approach to GDP in Hulten and Nakamura (2017).
} 
Figures 1 and 2 show the impact on real GDP by content type and funding source, year by year. An important result from our analysis is that most of the impact is due to marketing-supported content. Therefore, the focus of prior literature on advertising-supported media underestimates the true value of "free" content. Our results also show that most of the impact on real GDP of "free" content occurs from 1995 to 2015. For example, relative to a 2009 base year, we see that real GDP would have been lower by 1.1 percent in 1995 and higher by 0.6 percent in 2005. And we can readily see that online content was almost entirely the reason, with print content and audiovisual content roughly cancelling one another out.

Another implication of our treatment is the effect on measured inflation as shown in table 2. GDP price inflation between 1995 and 2015 slows by about 0.07 percentage point. A slightly larger effect is on PCE and core PCE inflation: PCE inflation and core PCE inflation fall by 0.09 percentage point and 0.10 percentage point, respectively. This occurs because of the fairly rapid deflation rate of online content, which falls at an 11 percent annual rate during this period while online nominal content is expanding rapidly. As a consequence, from 2005 to 2015, the PCE deflator falls from 1.73 percent annual growth to 1.64 percent annual growth.

The remainder of the paper proceeds as follows. Section 2 describes the current treatment of advertising-supported content and marketing-supported content, respectively, in the official U.S. GDP accounts. Within these sections, we introduce the alternative formulation that we think better captures the transactions present in the "free" digital economy. In section 3, we compare our approach to other noncash payments included in the official national accounts. Section 4 covers the nominal production of advertising-supported media, while section 5 covers the nominal production of marketing-supported information. Section 6 compares our results with the existing industry literature on "free" content and advertising and marketing. Section 7 covers the deflators we use to transform the nominal values to quantity indexes and then uses these deflators to calculate real GDP growth when "free" content is included in final output. Section 8 calculates input prices for advertising and marketing viewership and total factor productivity when "free" content is included in the input-output accounts. We give our concluding remarks in Section 9.

\section{2. "Free" Content Within the Production Account}

In the SNA 2008 and the U.S. Bureau of Economic Analysis (BEA) national income and product accounts, advertising-supported media is treated as an intermediate input to the production of advertising viewership. If we think of soap as being the advertised good, then a YouTube video produced to entertain households is an expense of the media company, which then sells the advertising viewership to the soap manufacturer. In turn, the cost of the advertising viewership is an intermediate expense of the soap manufacturer similar to the cost of physical inputs such as lye or fat. In this treatment, there is no directly measured part of personal consumption expenditures that represents the entertainment provided on YouTube, except to the extent that the consumer pays for the hardware and services associated with receiving the entertainment, such as the computer and Internet service. Moreover, as 
Goolsbee and Klenow (2006) point out, Internet users in 2005 spent 10 percent of their leisure on the Internet but only 0.33 percent of their expenditures on the Internet service, suggesting that Internet users derive utility disproportionate to their measured expenditures.

Conceptually, marketing-supported information is nearly identical to advertising-supported media. The main difference is that media companies resell viewership and marketers use it in-house. Because marketing viewership is not resold, it is not tracked as an intermediate input in the input-output (I-O) accounts. Instead, the labor, capital, and intermediate inputs used to produce YouTube videos are combined with the labor, capital, and intermediate inputs used elsewhere in the production process. Regardless of whether viewership is tracked in the I-O accounts, there is no directly measured part of personal consumption expenditures that represents the information provided on corporate Web sites or social media accounts.

The difficulty of the current treatment is highlighted when television or the Internet bids entertainment or content providers, such as baseball teams, away from the paid entertainment sector into the advertising-supported sector. Under the current treatment, these sports teams would cease to be providing consumer recreation services and would become advertising instead. Similarly, marketers bid content providers such as Betty Crocker away from the paid information sector into marketingsupported information. ${ }^{5}$ Under the current treatment, Betty Crocker would cease to be providing consumer information services and would become marketing instead. A consequence is that in the 1950s, for example, spending on real consumer recreation services rose only 2 percent per year, much slower than the overall increase in real personal consumption, because households switched from movies to television as their prime source of entertainment. Another way to think about this is to consider how the value of a smartphone to the consumer is affected by an increase in the number of advertising-supported Web sites published or marketing-supported apps released. The increased content variety increases consumer choice and therefore welfare. Should this improvement in welfare be reflected in the quality-adjusted price for smartphones? Holding nominal output fixed, this decline in quality-adjusted prices for smartphones would result in a real output increase for the smartphoneproducing industry, even if there is no change in the direct product or process of smartphone equipment production. The method that we propose in this paper avoids the problem of trying to capture the value of "free" content in quality-adjusted prices of existing goods by treating the production and use of "free" content as a new economic transaction.

It is useful to clarify the conundrum with the following highly stylized model. We consider a soap manufacturer, an entertainer, and households. The soap manufacturer must spend money on sales before households buy the soap. Initially, the soap manufacturer spends $\$ 550$ to make the soap, spends $\$ 250$ on selling costs with no value to households, and sells 800 bars of soap for $\$ 1$ each. The entertainer sells 100 tickets to her online show for $\$ 2$ each. One hundred households each spend $\$ 8$ for soap and $\$ 2$ for entertainment. Now, suppose the soap manufacturer pays the entertainer $\$ 200$ to include an announcement for soap in her program and cuts other selling costs by $\$ 200$. If the

\footnotetext{
${ }^{5}$ Betty Crocker is not a real person. She was created in the 1920s as a human face for the chefs and customer service representatives employed at General Mills. A variety of actresses have portrayed Betty Crocker in public.
} 
entertainer is an independent contractor, then her show is now considered advertising-supported media. Conversely, if she is an employee of the soap company, then her show is now considered marketing-supported information. Regardless of the precise employment details, the effect on households is identical. The entertainer now allows the same 100 households to watch her act without charging for tickets. The 100 households receive the soap and the entertainment but pay only the \$8 per household for soap (and listen to a soap announcement). For simplicity, we assume that the demand for entertainment is unaffected by this switch. In other words, households act as if they were paying \$2 for the entertainment, but instead, they are viewing the advertising and marketing, and they appear to perceive that viewing the advertising and marketing costs them \$2 each. Roughly speaking, the households consume the same amount but pay less out of pocket.

In the current treatment within the national income and product accounts, measured output drops when entertainment is supported by either advertising or marketing. The entertainment is no longer measured as part of personal consumption, only the soap is. In the initial case, \$1,000 in economic resources was used to produce $\$ 1,000$ in consumption output. With advertising- or marketingsupported content, $\$ 1,000$ is used to produce $\$ 800$ of consumption output and $\$ 200$ of intermediate input. Effectively, $\$ 200$ has disappeared from consumption output. However, this appears to be a misrepresentation in that the households are still consuming the same amount of entertainment, but it has disappeared from measured output.

One possible treatment would be to view the entertainment with advertising as having the same real value but falling in price to zero; that is, nominal output is $\$ 800$, but real output is $\$ 1,000$. While we do not actually observe the market value to the consumer of the entertainment in most cases, we can impute the market value from the payment to the entertainer. But zero prices have conceptual and practical issues. For example, it is difficult to explain why consumers sometimes pay to avoid advertising if the price for advertising-supported media is zero. Furthermore, if the situation should reverse and a price be paid, the rate of inflation for that item cannot be calculated.

The treatment we pursue in this paper is to consider the transaction as a barter trade of entertainment received by the consumer in exchange for which the consumer agrees to view the advertising and marketing. We record a dollar as paid by the consumer to the soap manufacturer for the entertainment, and the soap manufacturer would pay it back to the consumer for viewing the advertising and marketing. In this treatment, both advertising-supported media and marketing-supported information are reflected in the real income and consumption of the consumer. ${ }^{6}$ The value of "free" content (not the total spending by advertisers or marketers) is the pertinent value for the barter transaction. To measure the nominal "free" content, we first measure total spending by advertisers and marketers and then extract the value of "free" content by subtracting out noncontent expenses such as administrative costs for billing advertisers or printing costs for the glossy-ad sections placed within newspapers. This approach follows the data available. Conceptually, the costs of producing and distributing advertising

\footnotetext{
${ }^{6}$ A similar alternative was recently proposed by Charles Hulten. He argued that "free" content can be viewed as a gift from companies to consumers. Conceptually, this is parallel to the treatment of nonprofit organizations serving households. This treatment has the same impact on measured GDP as our proposed barter transaction. But it is unclear how to attribute output gains when businesses receive inputs as gifts from other businesses.
} 
and marketing should be disregarded. Only the cost of the wanted "free" content that is bundled with advertising or marketing is tracked in the barter transaction. Similarly, we entirely disregard marketing that are not bundled with wanted "free" content, such as telemarketing or junk mail.

\section{Noncash Payments in GDP}

Our experimental methodology does not require any major conceptual changes to SNA. In this paper, we treat "free" content as a payment in-kind for services produced by households and business. SNA 2008 already counts noncash payments to workers as labor income (Section 7.51). SNA also imputes cash values for barter transactions (Section 3.75), owner-occupied housing (Section 6.34), and financial services indirectly measured (Section 6.163). Just as with those transactions, we impute a value for "free" content based on estimated costs. However, since the household is not "employed" by the content producer, we treat the household production of advertising and marketing viewership as a form of production by an unincorporated household enterprise. To minimize the deviation from BEA's official accounts, we do not consider the production process for this advertising and marketing viewership. ${ }^{7}$ As a result, when we analyze the impact of our methodology on measured TFP (which requires outputs and inputs), we do this only for the private business sector and not the aggregate economy. However, on the expenditure side of the production account, we are able to analyze the full GDP. In practice, the reason for this is that our methodology yields estimates of viewership output produced by the household sector, which is in final expenditures, but does not reveal the complete production process that is used by households to produce viewership output.

Our paper is not the first to discuss treating advertising-supported media as payment in-kind. Imputation for advertising-supported media was first raised in The National Income - 1954 Edition and was extensively discussed in the 1970s (Ruggles and Ruggles 1970; Okun 1971; Jaszi 1971; Juster 1973; Eisner 1978; and Kendrick 1979). Cremeans (1980) estimated that advertising-supported media was worth $\$ 28$ billion in 1976. ${ }^{8}$ Vanoli discusses this issue in A History of National Accounting (2005). More recently, Bloomberg Businessweek published an article in 2013 (Ito) and The Wall Street Journal published an article in 2015 (Aeppel) suggesting the BEA's GDP numbers for should include "free" online media. In addition, we have previously written papers studying advertising-supported media and advocating it be treated as a barter transaction (Nakamura 2015; Soloveichik 2014; and Nakamura and Soloveichik 2015).

Our joint research extends the earlier research on advertising-supported media by developing productivity accounts by industry and by media category. This decomposition allows researchers and policymakers to better understand the sources of GDP growth and the impact of different categories on perceived biases in the official measures. The production account approach recognizes that "free"

\footnotetext{
${ }^{7}$ We do assume that advertising and marketing viewership is produced only using capital and labor, without any intermediate expenses. Therefore, gross output is equal to value added.

${ }^{8}$ For the same year, we estimate that advertising-supported entertainment added only \$8 billion to GDP. The main reason for the difference is our exclusion of nonmedia costs and business information from final output.
} 
aspects of the digital economy resemble both a consumption good present in personal consumption expenditures and an input into production. When a business uses Google as an input into production, in our barter transaction, the using business provides viewership of advertising in return. This generates both new industry output (viewership) and new industry input ("free" content) leaving private value added unchanged. When a media producing company makes "free" content, this generates previously unrecognized output (advertising-supported media) using previously unrecognized input (household viewership). While these balance in nominal terms, a contribution of this paper is to introduce price indexes for the outputs and inputs, allowing us to assess the productivity impact of these implicit transactions. These productivity accounts were first developed for advertising-supported media in a previous paper completed last year (Nakamura, Samuels, and Soloveichik 2016).

A major extension that we make in this paper is to include marketing-supported information in "free" content together with advertising-supported media. To the best of our knowledge, our paper is the first to propose treating marketing-supported information as a barter transaction and the first to recalculate GDP when marketing-supported information is included in final output. Furthermore, by including marketing-supported information, we capture the exchange of value that occurs under the ubiquity first, revenues later economic model. Spending on building ubiquity, for example, embeds a barter transaction of content in exchange for building a network of users.

Because marketing is produced by so many industries, it is more difficult to track than advertising. Appendix $B$ of this paper contains a detailed discussion of the complex calculations and multiple datasets necessary to track marketing-supported information. Most of those datasets did not exist during the 1970s, when the literature on advertising-supported media was at its peak. This lack of data may explain why the earlier literature did not examine marketing-supported information. We estimate in table 1 that in 2015 in nominal terms, nonadvertising marketing expenditure totaled \$389 billion while advertising totaled $\$ 215$ billion. Of this, we estimate that nonadvertising marketing would contribute $\$ 189$ billion to PCE in nominal terms, and advertising would add $\$ 122$ billion to PCE. Adding marketing considerably increases the potential GDP impact of our experimental work on "free" content.

\section{Nominal Advertising-Supported Media}

\subsection{Total Output of Advertising-Supported Media}

When measuring advertising-supported media, we categorize media into three separate sub-categories: a) printed newspapers, magazines, and directories; b) radio, television, and other audiovisual content ${ }^{9}$, and c) digital content like blogs or search engines. These sub-categories were chosen because each has a different production process, and each may be affected differently by technological innovations, video cameras, or computers. In addition, previous researchers and policymakers have focused on digital content-so it is useful to provide numbers for digital content alone. Note that we are not attempting to measure the out-of-pocket costs paid by customers for media such as Internet access charges or cable

\footnotetext{
${ }^{9}$ This category includes online video channels hosted on YouTube and online radio stations like Pandora. We exclude online audiovisual content from the digital category, so there is no double-counting.
} 
subscription fees. Appendix B contains detailed information on the datasets used to track nominal advertising revenue and the benchmarking procedures. As a reminder, the key mechanism is that advertising revenue ${ }^{10}$ embeds the value of the "free" media to viewers because this content has been bid away from the producers of the content. Thus, in our model, viewers receive the "free" content in return for exposure to the advertising. That is, the content providers receive the advertising revenue in exchange for providing a product that yields advertising viewership.

Advertising revenue by media category over time as a share of GDP is shown in Figure 3. Since 1995, online media has grown from almost nothing to 0.36 percent of nominal GDP. Over the same time period, print advertising shrank from 0.63 percent to 0.16 percent of nominal GDP. The growth of the Internet is almost certainly responsible for most of the print decline. Classified advertising has moved from newspaper sections to Web sites and printed Yellow Pages are being replaced by Web search. Between 1995 and 2015, audiovisual advertising, that is, radio and television advertising, rose from 0.50 percent to 0.59 percent of nominal GDP. The increase in "free" audiovisual content took place even as spending on subscription television rose from 0.32 percent to 0.48 percent of nominal GDP.

\subsection{Opportunity Costs of In-House Advertising Usage}

The Economic Census focuses on revenue from the sale of advertising viewership and ignores the opportunity cost of using advertising viewership in-house. Freemium games like Candy Crush are the best known category of in-house advertising viewership. These games are free to download and play, but they offer extra lives and other bonuses for purchase. In other words, the "free" game is basically advertising for the premium products that make money. The vast majority of this advertising viewership is used within the company, so the viewership represents an opportunity cost of forgone ad sales rather than out-of-pocket expenditures that would be recorded in the Economic Census. Similarly, cable networks devote a large share of their advertising to their own shows, movie theaters show trailers for upcoming films, and newspapers run ads encouraging readers to renew their subscriptions.

Figure 4 shows the opportunity cost for in-house advertising viewership over time. The most important result is that the opportunity cost of in-house advertising viewership is very small relative to the revenue from sold advertising viewership. Americans may be spending enormous amounts of time playing freemium games like Candy Crush-but they rarely buy expensive items while playing those games. When measuring GDP using our experimental methodology, we account for "free" entertainment based on the resource input rather than the time used or happiness created. As a result, we assign a very low value to Candy Crush despite the possibility it creates enormous consumer surplus. Because opportunity cost advertising is so small, we will not track it separately in the remainder of this paper. Instead, we combine it with the advertising revenue shown in Figure 3. More details on the construction of opportunity costs by media are given in Appendix B.

\footnotetext{
${ }^{10}$ Some media companies also earn money from collecting personal data and reselling it to third parties. This data collection is particular common for freemium games. We will include this data revenue together with ad revenue.
} 


\subsection{Share of Advertising Devoted to "Free" Entertainment}

Not all of the advertising revenue shown in Figures 3 and 4 is used to produce media that is of value to consumers and businesses. Media companies need a sales staff to reach out to advertisers, plan the exact format of the ads, and bill the advertisers afterward. Moreover, physical costs of printing marketing inserts account for a substantial share of print advertising expenditures. In earlier research, we estimated that nonmedia costs account for 50 percent of print newspaper advertising; 72 percent of print magazine advertising (Nakamura 2015); approximately 55 percent for print directory advertising; and 25 percent of television, radio, and online advertising (Soloveichik and Wasshausen 2013; and Soloveichik 2013 a, b, c, d and e). When calculating nonmedia costs, we assume that the nonmedia cost share for each category is fixed from 1929 until $2015 .{ }^{12}$

Figures 3 and 4 show that print media has been steadily declining relative to both audiovisual media and digital media.. Print media also has much higher noncontent costs than the other two categories. Accordingly, we calculate that the average content share of advertising-supported media grew from 45 percent in 1929 to 70 percent in 2015. To reiterate, this content share reflects the estimated cost of providing advertising-supported media relative to advertising revenue, not the full consumer surplus that users enjoy. Just like much of consumer surplus, this value over expenditure is not counted in either GDP or TFP. Furthermore, the estimated cost is an imperfect proxy for the market price that might have been charged. This problem has been studied previously for government output, nonprofit output, and other items in which GDP methodology uses costs as a proxy for value.

\subsection{Media Usage by Consumers vs. Businesses}

As we discussed in the introduction, the identity of the user determines both the terminology used and also the impact of the barter transaction on measured GDP. To fix ideas, let us consider a driver using Google Maps or Waze to plan a trip. If the driver is working for a bakery, the driver is obtaining information from the Web site, and this becomes an input into the firm's activity and baked goods output. In exchange, the driver is viewing advertisements, and the firm is paying the driver to provide advertising viewership in exchange for the information. These activities are intermediate inputs on both sides-for the advertiser and for the bakery, and neither constitutes an addition to final expenditure. On the other hand, when the same driver is planning a vacation trip at home, the information becomes part of personal consumption expenditures and therefore adds to GDP. The driver's viewership in this case also adds to the income side of the account.

Accordingly, it is crucial to determine the share of advertising-supported media used by consumers relative to that used by businesses. Unfortunately, it is difficult to find data splitting advertisingsupported media between consumer advertising and business advertising. ${ }^{13}$ In a few cases, the products

\footnotetext{
${ }^{12}$ As a robustness check, we collected summary data from the internal revenue service tracking (total expenditures) relative to (total revenue) by industry and by year. We found that adjusting for this variation increases the value of online media during the dot com bubble and reduces volatility over the business cycle slightly-but it has little impact on long-term results.

${ }^{13}$ In some parts of its data collection, the U.S. Census Bureau asks businesses the proportion revenues from various customer categories. The list of customer categories includes "households and individuals" as well as multiple business sectors. Such questions are harder to answer when the "customers" do not make payments.
} 
advertised provide some clue about the likely industry of the user. For example, hospitals are the main purchasers of X-ray machines-so magazines with ads boasting low prices for X-ray machines are probably targeting hospital executives. But most Web sites target a general audience and have advertising unrelated to the precise media services provided. In correspondence, Hal Varian, chief economist at Google, said that Google does not have much information on whether consumers or businesses are viewing their ads. To the best of our knowledge, no company or researcher has published any estimates of the consumer share for "free" Web sites, advertising-supported print, or other media.

This paper uses a variety of data sources to split media usage between consumers and businesses. For online media, we use survey data from Forrester Research. Since 2007, Forrester Research has asked survey respondents to report both "work Internet" time and "personal Internet" time. We use this data to estimate the consumer entertainment share of online media. For print media, we use genre data reported in the Economic Census and other sources to split consumers and businesses. For example, we assume that scientific journals are used for work rather than leisure. Finally, we assume that radio, television, and freemium games are almost entirely targeted towards consumers for leisure use. More information on the procedures used is given in Appendix B of this paper.

Figure 5 shows that advertising-supported online entertainment has grown rapidly in the past decade and now accounts for 0.15 percent of nominal GDP. However, this nominal growth is largely canceled out by a decrease in advertising-supported print entertainment. Total advertising-supported entertainment only rose from 0.60 percent of GDP in 1995 to 0.68 percent of GDP in 2015. As a result, nominal GDP growth increases only slightly when "free" media is included in final output. Between 1929 and 2015, advertising-supported entertainment has hovered around 0.5 percent of nominal GDP. Therefore, long-term nominal GDP growth is almost unchanged by our experimental inclusion of advertising-supported entertainment in final output. Advertising-supported business information is much smaller than advertising-supported consumer entertainment. Despite the size differences, recent patterns are very similar.

In sharp contrast to this result, we document in the next section that marketing-supported content as a whole has grown rapidly in nominal terms in the past 20 years. This growth of content-led by growth in online and audiovisual marketing-contributes to our finding that "free" content has a substantive effect on real output and private business productivity.

\section{Nominal Information Production and Consumer Information}

\subsection{Total Output of Marketing-Supported Information}

Marketing output that flows through advertising agencies is not the only marketing output that supports content that is useful to consumers and businesses. The main difference is the greater difficulty of measuring marketing outside of advertising. With advertising, there is a clear transaction that provides an arms-length measure of the nominal output. Yet, as we shall see, nonadvertising marketing has been growing as a proportion of marketing and of GDP, so when we ignore this part of marketing, we miss out on its extraordinary dynamism and, in turn, on the growth of content supported by marketing. 
We estimate total output in two basic steps. First, we use the Economic Census to estimate business expenditures on purchased marketing services from 2002 until 2012. Next, we use the Occupational Employment Survey (OES) to impute the value of marketing services produced in-house. We then calculate total marketing output by adding the two series.

We start out by using the Economic Census to estimate business expenditures on purchased marketing services. The Economic Census reports product-line sales across all businesses with employees in 2012, 2007, and 2002. ${ }^{15}$ We identified seven product lines of interest: (1) media representation services in NAICS 5418; (2) public relations services in NAICS 5418; (3) advertising planning, creation and placement services in NAICS 5418; (4) remaining marketing-supported information in NAICS 5418; (5) Web site development and hosting in NAICS 518 and 5415; (6) commercial photography in NAICS 5419; (7) event sponsorship in NAICS 711. In total, these seven product lines accounted for $\$ 119$ billion worth of sales in 2012. Only a small portion of the $\$ 119$ billion in product-line sales is for completed marketing campaigns that are ready for public consumption immediately. Instead, most companies combine purchased marketing inputs with in-house marketing production before rolling out a completed marketing campaign.

Next, we use the Occupational Employment Survey (OES) to impute a value for in-house marketing service production. That survey reports employment and earnings for selected industry and occupation combinations. The OES does not track individuals who are employed producing in-house marketing directly, but we have identified a list of occupations that are likely to be involved with marketing production. For example, a writer employed at a car manufacturing company probably works for the marketing department. We use that data to estimate total expenditures on in-house marketing using a two-step procedure. First, we calculate total earnings for marketing professionals who are employed outside the marketing sector. Next, we multiply those earnings by an adjustment ratio to estimate total expenditures on in-house marketing. ${ }^{16}$ Our expenditure estimates are an attempt to measure total costs and therefore include labor costs for marketing professionals, labor costs for support staff, nonlabor intermediate expenses, and a return on capital. In 2012, we calculate that the U.S. private business sector produced $\$ 247$ billion of marketing services in-house. This $\$ 247$ billion includes $\$ 70$ billion in forgone profits that companies might have earned if they had sold their marketing output rather than using it in-house. ${ }^{17}$

\footnotetext{
${ }^{15}$ The Economic Census does not require businesses without employees to report product-line detail. In addition, some businesses may underreport or misreport revenue to the Economic Census. When calculating GDP, BEA adjusts for all of these issues. We use BEA's preexisting adjustments for 2007 to calculate total sales.

${ }^{16}$ This ratio grew from 4.49 in 2002 to 6.62 in 2012. We don't explore the reasons for the growth in this paper.

${ }^{17}$ Our ratio of operating expenses to revenue is taken from the Service Annual Survey, which tracks operating expenses by industry. At first glance, the low ratio of operating expenses to revenue might suggest that marketers are reselling creative services produced by others and therefore double-counting those designs in revenue. We thank Jonathan Haskel for this point. In fact, advertising agencies (NAICS 54181) earn similar profit rates as publishers (NAICS 511) and broadcasters (NAICS 515). Instead, it appears that creative industries genuinely do earn substantial profits. These profits might be compensation for risk, a return on intangible capital, or due to monopoly power. We will impute the same profits for in-house production of marketing.
} 
The conceptual framework makes no distinction between marketing-supported information purchased from outside companies and marketing-supported information produced in-house. Accordingly, we will combine both production methods in all of our figures and discussion. This treatment is consistent with our previous treatment of advertising-supported media, (Nakamura, et al. 2016), in which we tracked the aggregate value of "free" media content without distinguishing between media programs licensed from specialty producers and media programs produced in-house.

In total, we calculate that U.S. businesses created $\$ 366$ billion of marketing output in 2012 . This number appears very large-but it is consistent with the industry literature. The research firm Outsell publishes an annual report that tracks spending by category. They report that U.S. businesses spent $\$ 218$ billion on marketing in 2012. ${ }^{18}$ We also experimented with using corporate filing data from Compustat to estimate marketing-supported information. Based on the Compustat data, we calculate that U.S. businesses spent approximately $\$ 4.5$ trillion on sales, general, and administrative (SG\&A) in 2012 . The industry literature suggests that total marketing accounts for approximately 30 percent of total SG\&A or $\$ 1.35$ trillion. We then subtracted expenditures on advertising-supported media, expenditures on unwanted marketing, and compensation for salespeople to calculate a residual value for marketingsupported information. Based on this residual methodology, we estimate that marketing-supported information accounted for approximately 16 percent of that $\$ 1.35$ trillion or $\$ 210$ billion. So, our estimate of $\$ 296$ billion in out-of-pocket spending and $\$ 70$ billion in opportunity costs is somewhat higher than the industry literature, but within a similar order of magnitude.

The OES goes back to the late 1980s, but many of the occupation codes and classification methodologies changed around 1998. Furthermore, the OES only covered a rotating sample of industries from 1988 until 1995. As a result of all these changes, it is difficult to use the same datasets to measure marketingsupported information before 1998. We use the reported revenue from sold marketing services in the Economic Census, decennial population Census, and other datasets to estimate expenditures on marketing-supported information for selected years. Appendix B contains more details on the data.

Figure 6 shows output of marketing relative to GDP over time. We find that marketing-supported information output is currently larger than advertising-supported media output and has grown faster over time. In 1929, businesses created $\$ 520$ million on marketing-supported information, approximately 0.5 percent of aggregate nominal GDP. In 2015, businesses created $\$ 389$ billion on marketing-supported information, approximately 2.2 percent of aggregate GDP. Over the same time period, expenditures on advertising-supported media have hovered around 1 percent of nominal GDP. Yet, advertisingsupported media receives the vast majority of policymaker and researcher attention. This paper aims to rectify the imbalance by tracking both components of "free" content.

It is informative to decompose the nominal growth into its components. By construction, nominal growth is explained by three factors: (1) price change for marketing-supported information, (2) quantities of marketing viewership, and (3) ratio of marketing-supported information quantities to marketing viewership quantities. Later in the paper, we will show that content production costs have

${ }^{18}$ Outsell reports total spending on advertising and marketing of $\$ 397$ billion in 2012 . Based on the data underlying Figure 3, we calculate that companies spent $\$ 179$ billion on advertising in 2012, leaving \$218 billion for marketing. 
roughly tracked overall GDP prices and quantities of marketing viewership have risen only slightly faster than overall GDP quantities. This implies that the main contributor to the dramatic growth shown in Figure 6 is an increase in marketing-supported information per unit of marketing viewership. This suggests that users of marketing-supported information may have enjoyed significant consumption growth that is not captured in the current GDP or TFP statistics. By introducing price indexes for the barter transactions (discussed below), our experimental methodology captures the increased "consumption" of marketing-supported information.

\subsection{Marketing-Supported Output by Subcategory}

Just like advertising-supported media, we split marketing-supported information into three categories: (1) print, (2) audiovisual, and (3) digital. Neither the product line information provided by the Economic Census nor the occupation codes provided by the OES specify precisely what type of marketingsupported information is being produced. For example, a "writer" might write a column for a print newsletter, contribute to a corporate blog, or write dialogue for a filmed ad. Many "writers" do all three simultaneously. As a result, it is extremely hard to split total expenditures on marketing-supported information between possible subcategories. Instead, we purchased reports from the research firm Outsell that covered the time period 2007 to 2015. Before then, we use a variety of sources to estimate spending by subcategory. Appendix B contains details on dataset construction techniques. ${ }^{19}$

Figure 6 shows our best estimate of marketing output by category. We find that that marketingsupported information grew dramatically over the past decade, and this growth is entirely driven by digital marketing. Web sites account for the largest portion of this digital marketing, but companies are also spending heavily on social media outreach like Facebook pages and Twitter feeds. In recent years, companies have also started developing smartphone apps and other mobile marketing. Despite the recent explosion in online marketing, the overall growth rate for total marketing-supported information in the past decade is not exceptional. Instead, marketing-supported information has steadily increased its nominal GDP share by 0.034 percent per year after 1975, but it was relatively steady before 1975 . We have not yet fully identified a reason for the trend break in 1975, but online marketing was very rare before 1995 and so does not contribute to growth from 1975 to 1995 . One observation is that most of the increase in the proportion of investment in intellectual property products in GDP occurs after 1975 when the proportion rises from 1.6 percent to 4.0 percent. To the extent that an important value of marketing lies in introducing innovative products to potential customers, rising innovation may be associated with rising marketing expenses.

\subsection{Content Creation Costs for Marketing-Supported Information}

Like total advertising revenue, not all of the marketing output shown in Figure 5 is of value to the information users. Companies spend significant resources printing the marketing material that is bundled together with marketing-supported in-person and print information; clearly, the users do not

\footnotetext{
${ }^{19}$ Note that the precise split between marketing categories has no effect on aggregate marketing output. However, each information category has its own physical production costs and its own consumer share. As a result, the adjustment to measured nominal GDP is influenced by the split. Furthermore, each information category has its own price index, so the rate of real GDP growth is also influenced by the split.
} 
value the bundled marketing component in and of itself. Fewer resources are necessary to distribute audiovisual and online marketing, but there are still costs for distribution. We have not been able to find any data directly measuring the costs of printing and distributing marketing. However, there is a vast marketing literature comparing viewership of media content with marketing content like television commercials. The general result is that marketing viewership is only slightly lower than media content viewership (Danaher 1995; Rose, Generali, and Coleman 2006; Nielsen 2015). Technologies like the remote control or DVR have increased commercial skipping somewhat, but the effect is relatively small. The most plausible explanation for the equal viewership is that users value a minute of marketingsupported information almost as much as they value a minute of advertising-supported media. Furthermore, the marketing output statistics discussed in Appendix B suggest that per-minute costs are similar for marketing-supported information and advertising-supported media. Taken together, these two facts suggest that the ratio of user value to creation costs is similar for marketing-supported information and advertising-supported media. Based on our results for advertising-supported media, we set noninformation costs equal to 60 percent of print marketing costs, 25 percent of audiovisual marketing costs, and 25 percent of online marketing costs. We assume that these marketing-cost shares are fixed over time and across customer categories.

Note that the marketing distribution costs estimated above can be thought of as a lower bound on the true (noninformation) costs of marketing. For example, marketers generally frame the information presented so that their product is placed in the best possible light. This framing provides little value to users, so the costs of framing should be subtracted from overall marketing expenditures. Take the case of a car company that spends enormous resources designing road tests that favor their brands. These design costs are not included in the marketing distribution costs given above, but may be included in our estimate of spending on marketing. ${ }^{20}$ Unfortunately, we were not able to find any data on these framing costs, so, we do not subtract them in this draft. As a result, the estimated values for marketingsupported information might be seen as an upper bound.

From 1929 to 2015, the information content share of marketing grew from 45 percent to 70 percent. This steady increase is caused by a composition shift. Like advertising-supported print media, marketingsupported print information has been growing slower than overall GDP. This same category also devotes a much larger share of costs to noncontent, so it has less money available to subsidize wanted information. As a result, marketing-supported information has grown faster than overall marketing output.

\subsection{Information Usage by Consumers Versus Businesses}

Like advertising-supported media, it is difficult to split marketing-supported consumer information from marketing-supported business information. To start out, we assign marketing bundled together with media using the same allocations discussed earlier for advertising-supported media. In particular, we allocate TV and radio commercials, public relations spokespeople interviewed on TV and radio, and sponsored sports aired on TV and radio using the same business and consumer split developed earlier

\footnotetext{
${ }^{20}$ The cost of framing information is not necessarily positive. For a variety of reasons, corporate cultures generally encourage workers to be loyal to their company's products and report good news whenever possible.
} 
for TV and radio media. Similarly, we allocate print commercials and public relations spokespeople interviewed in print journals using the same business and consumer split developed earlier for newspaper, magazine, and directory media. Finally, we allocate online commercials and public relations spokespeople interviewed online using the split developed earlier for online media.

Next, we use research purchased from the firm Outsell to split other marketing (that is, not bundled with media). For each year, they publish two separate reports: one tracking business-to-consumer marketing (B2C) and one tracking business-to-business marketing (B2B). Their annual data are somewhat noisy, so we averaged across all the reports purchased. ${ }^{21}$ For print and audiovisual media, the consumer share has remained relatively constant over time. Accordingly, we believe the average reported in Outsell's data is probably a reasonable proxy for the consumer share back to 1929. On the other hand, Internet access started in the business sector and only spread to the consumer sector later. As a result, we impute a growing consumer share for online marketing over time. For 2015, we calculate that consumers receive 51 percent of separated print marketing, 81 percent of separated audiovisual marketing, and 57 percent of separated online marketing. We then combine those consumer shares for separated marketing with the consumer shares for marketing embedded in media. We find that the consumer share has hovered around 70 percent throughout the entire time period. There is a little variation caused by shifting marketing categories, but this variation is small and does not appear to be associated with obvious economic or social changes. Measured GDP and other summary statistics would not change significantly if we fixed the consumer share at exactly 70 percent throughout the entire time period.

Figure 7 shows the increase in nominal GDP from including marketing-supported consumer information. Consistent with Brynjolfsson's research, online consumer information has grown enormously in the past decade and now accounts for 0.55 percent of nominal GDP. However, some of this increase is offset by decreases in other types of marketing-supported consumer entertainment. Accordingly, nominal GDP growth over the past decade increases by 0.035 percentage point per year when we include "free" information in final expenditures. This is not a trivial change, but it is not nearly enough to reverse the recent slowdown in GDP growth. Marketing-supported business information displays similar patterns as marketing-supported consumer information. To save space, we will not show it here.

Table 3 shows the data for nominal "free" content, by medium, back to 1930. This long, historical sweep enables us to see that the contribution of content in 1930 was 0.6 percent of nominal GDP, almost entirely from print. By 1965, audiovisual media has become larger than print, at a point when TV dominates leisure time. Yet, combined "free" content is still only 0.8 percent of nominal GDP in 1965. The total GDP share for "free" content did not start rising until 1975, long after TV had become nearly universal. It is interesting as well that, while the combination of online and the Great Recession wallops print content in nominal terms beginning in 2006, audiovisual content continues to grow quite strongly and adds nearly as much nominal content between then and the present as online does. The extreme importance of online for real growth is due to the rapid decline of input costs for online content.

\footnotetext{
${ }^{21}$ Like most surveys, Outsell treats owner-occupied housing as part of the consumer sector. In contrast, BEA treats it as part of the business sector when measuring GDP. We use our best judgment to adjust for this difference.
} 


\section{Comparing Our Results to the Industry Literature}

\subsection{Research Valuing "Free" Online Content}

In 2011, we estimate that "free" online content added \$100 billion to the U.S. GDP, \$17 billion of advertising-supported media and $\$ 83$ billion of marketing-supported information. This is not a trivial amount, but it is far lower than alternative estimates. For 2011, Brynjolfsson and Oh (2012) estimated a value of $\$ 376$ billion based on time use data. ${ }^{22}$ The Boston Consulting Group (Dean, Digrande, Field, Lundmark, O'Day, Pineda, and Zwillenberg 2012) estimated a value of $\$ 500$ billion in 2011, based on consumer surveys and an economic model. More recently, Brynjolfsson, et al. (2017a) use willingnessto-accept estimates to show that the median consumer in 2016 valued online search at $\$ 14,760$ per year and valued the rest of the Internet at $\$ 10,937$ per year. Across the entire U.S. population, that adds up to $\$ 8.3$ trillion in total consumer surplus. Consistent with that high valuation for search engines, the paper "A Day Without a Search Engine" (Chen, Jeon, and Kim 2014) finds that research offline takes triple the time (22 minutes versus 7 minutes), so online search saves an enormous amount of time in aggregate. The much higher numbers in these studies are a consequence of different methodologies and different (but related) research questions. All four studies use indirect methods to estimate the consumer utility gained from leisure time spent online. This paper is trying to estimate only the cost of producing online information, which our results indicate is much lower than consumer surplus.

Another measure of consumer surplus was conducted by Noll et al. (1973). They examine how much viewers were willing to pay for access to the three major TV networks in areas of the U.S. outside the broadcast range of these networks in 1969 (these are payments for no-frills community cable TV). This permits them to estimate that the willingness of U.S. TV viewers to pay was close to $\$ 20$ billion in nominal terms. This is substantially higher than the $\$ 2.4$ billion value we estimated for "free" television content in 1969. If the same ten-fold ratio of consumer surplus to production costs applies to online media, then our estimate of $\$ 100$ billion in production costs implies $\$ 1$ trillion in consumer surplus. Similarly, Brynjolfsson et al. (2017b) use willingness-to-accept estimates to value access to prescription drugs at $\$ 50,000$ per year per person, approximately forty-fold BEA's estimates of prescription drug spending in 2016 and to value access to medical care at $\$ 600,000$ per person per year, approximately seventy-fold BEA's estimates of health care spending in $2016 .{ }^{23}$ If the same ratio of consumer-surplusto-production costs applies to online media, then the $\$ 8.3$ trillion value for the Internet implies spending of $\$ 118$ billion- $\$ 208$ billion per year. This range matches well with our estimated $\$ 150$ billion in "free" content available online in $2016 .{ }^{24} \mathrm{~A}$ large difference between consumer spending and willingness to pay

\footnotetext{
${ }^{22}$ Brynjolfsson and Oh's paper (2012) values free Web sites, which is broader than the "free" digital content covered in this paper, but that only explains a portion of the difference.

${ }^{23} \mathrm{BEA}^{\prime}$ s estimates for prescription drugs are from NIPA table 2.4.4U, line 121 and the estimates for total health care spending are from NIPA table 2.4.4, lines 40,60, and 93.

${ }^{24}$ Our paper only reports data up until 2015. However, we were able to use reports from IAB and Outsell to estimate growth rates from 2015 to 2016. Based on those growth rates, we estimate \$150 billion in 2016 . Our
} 
is common in many other sectors of the economy. For example, sleeping occupies about a third of total time and provides enormous utility, yet, beds represent a very small fraction of consumer spending.

Our estimates of online content value are similar to preexisting estimates of the consumer value for high-speed Internet. Greenstein and McDevitt (2011) estimated that in 2006 U.S. households received $\$ 20$ billion to $\$ 22$ billion of value from broadband Internet. In comparison, we estimated that U.S. households enjoyed $\$ 41$ billion of marketing-supported online information and $\$ 10$ billion of advertising-supported online media in 2006. In other words, we estimate that the total value of "free" Web sites was larger than the value of broadband Internet.

\subsection{Other Research Studying Advertising and Marketing}

Previous researchers have studied why advertising exists and calculated how much firms should optimally spend on advertising (Dorfman and Steiner 1954 and Nerlove and Arrow 1962). In addition, the literature on the measurement of investment on intangible assets has argued that advertising increases sales over the long run, and therefore, advertising expenditures should be considered an investment in brand equity (Nakamura 2015; Corrado, Hulten, and Sichel 2009). These papers can be seen as another avenue by which these expenditures should be included in final expenditures in the national accounts: some advertising and marketing could be viewed as gross investment. ${ }^{25}$ All of these papers are focused on the companies that use advertising and marketing to sell products and build brand equity. Because the focus is on companies, the advertising and marketing expenditures studied in these papers include unwanted marketing, like junk mail or telemarketing, in addition to the wanted content studied here. In contrast, our research is focused on the users who produce viewership and then barter it for wanted content. None of the results in this paper depends on how companies use bartered viewership in their production process or the useful lifespan for bartered viewership. The only thing that matters is that companies want advertising and marketing viewership and are willing to provide "free" content in exchange.

Despite the different theoretical viewpoint, our empirical data work is quite similar to related research. In particular, we use many of the same data sets as the paper "Brands as Productive Assets: Concepts, Measurement, and Global Trends" (Corrado and Hao 2014). That paper reports average annual spending rate of $\$ 569$ billion in brand investment between 2007 and 2011 (table 7). This is slightly larger than our estimate of $\$ 488$ billion in average spending on advertising and marketing for the same period. However, the similar levels are mostly a coincidence. Corrado and Hao explicitly include telemarketing, market research services and other product lines that we exclude marketing-supported information. Conversely, our paper's estimate of in-house marketing includes an estimate of nonlabor costs and indirect labor costs that Corrado and Hao chose to exclude. As a result of these different

total excludes Internet access charges (\$115 billion in 2016), cell phone data, home computers or other related consumer spending in our total.

${ }^{25}$ In the national accounts, marketing is expensed rather than capitalized. This assumes that marketing does not create future value for the investing firm. If some of it is capitalized as intangible assets, that would be on the basis that marketing expenditures are not fully embedded in current prices, but help the firm to earn money in future periods. Measured GDP would rise to account for this added investment. This treatment would be the same whether or not "free" content is considered part of personal consumption expenditures. 
methodologies, it is not meaningful to directly compare the level of expenditures reported in our paper with the level of expenditures in their paper their paper. However, the similar growth rates found in both papers are more meaningful and provide strong support for our results.

Before we move on to price deflators, it may be useful to summarize the nominal statistics that we have estimated. Table 1 shows that for 2015, total business output of advertising and marketing amounted to $\$ 604$ billion. Of this sum, costs that do not add to household or business entertainment or information were about $\$ 182$ billion. This leaves about $\$ 422$ billion in entertainment and information content. Consumers earn and use $\$ 311$ billion, while businesses earn and use (as intermediate input) $\$ 111$ billion. Thus our methodology would add \$311 billion to measured U.S. GDP in 2015 (\$18,037 billion as of August 2016) for a total expanded GDP total of $\$ 18,348$ billion.

\section{Price Indexes for Content and Experimentally Expanded GDP and PCE}

\subsection{General Discussion on Price Measurement Issues}

Both media and information are difficult services to deflate. Conceptually, the deflators should track production costs for the same item over time and productivity growth. But content users constantly demand original content. Thus, we cannot track the cost of producing the exact same Web site or video over time, for example. In addition, both media and information are nonrival goods with difficult-todefine units of output. A blogger might switch from writing a few long posts to writing many short tweets. Is this change an increase or decrease in total output? Finally, information quality generally depends on its accuracy, yet accuracy is extremely hard to measure.

Complementary goods add more complexity. The user experience depends on the quality of the durable goods used in the production of the entertainment services, and durable-goods quality has risen dramatically. This rise in quality? applies to both the production of entertainment services in the home and of information services outside the home. For example, high-definition televisions (HDTVs) and monitors enhance the quality of videos and television programs being watched, and indeed, the videos have higher production values to take advantage of the improved receiver quality. Similarly, the quality of online experiences is enhanced by improvements in smartphone technology and in better data transmission services over time.

The price indexes that we employ do not account for network effects, positive externalities from content consumption, or other media or information specific factors. We think that these factors probably raise online content quality over time and therefore lower quality-adjusted prices. As a result, the inflation rates shown for online content should be seen as being on the upper end of the true inflation rate. However, the size and direction of bias of other content categories is harder to measure. In addition, the experimental methodology developed in this paper may have secondary implications for measuring parts of the media and information sectors that are paid by subscription fees, government

funding, or other sources. These implications are a topic for future research. For now, we hold all other price indexes in the industry-level production account fixed. 
Next, we provide a basic overview of the price deflators that we have constructed. More information is given in appendix $\mathrm{B}$.

\subsection{Prices for Online Media and Information}

We start by constructing a price index for digital content. The main inputs to online content are software and the computers to run the software. For example, search engines start out with complex algorithms to optimize the search process. They then run the algorithms on server farms every time someone enters a query. For simplicity, we assign each input a 50 percent weight and calculate the price of "free" digital as a geometric average.

Our price index for software is taken from BEA's price index for own-account software (NIPA table 5.6.4, line 3). The price index for computers is a little more complicated. BEA has many price indexes for computers, but they only track the cost of the hardware. Over the past decade, server farms have become much more efficient at using their hardware to produce more computing power. Our price index for computing services is based on the paper "The Rise of Cloud Computing: Minding Your P's and Q's" (Byrne, Corrado, and Sichel 2017). The data in this paper do not start until 2009, and Amazon is the only company tracked until 2014. As a result, the annual changes are somewhat noisy. We used the three indexes reported in the paper to measure cloud computing prices in 2009 and 2016. Between these years and before 2009, we use BEA's price index for business computers (NIPA table 5.5.4, line 4) as an interpolator.

Table 4 shows the combined price index for online content, while figure 8 shows the price index for online content relative to the GDP price index. We find that relative prices have fallen approximately 15 percent per year. This decline is due to plummeting cloud computing prices because own-account software prices increased over the period, reflecting the underlying wages of the programmers that create the unique projects that in-house programmers work on. In contrast, data processing companies have become much more productive in using their servers to provide computing services. We assume the same productivity gains for Internet publishing companies that produce advertising-supported online media and the marketing divisions that produce marketing-supported online information.

\subsection{Prices for Print Content}

Book publishers produce a similar product to print media and therefore wholesale book prices are a good proxy for the costs of writing, editing, printing, and delivering newspapers. We used BEA's price index for entertainment, literary, and artistic originals for books (NIPA table 5.6.4, line 25) as a proxy for all the costs. Note that this is an output price and therefore includes some productivity growth over time. In addition to the writing costs, print media generally requires more outside research than books. For example, journalists generally interview sources before they write an article on a topic. We were not able to find any data specific to journalist research costs, but we believe that those costs are related to communication technology. Accordingly, we use BEA's price index for telecommunications (NIPA table 2.4.4, line 97) as a proxy for outside research costs. For our combined price index, we assign book originals an 85 percent weight and telecommunications a 15 percent weight and construct the price of "free" print content as the geometric average. 
Table 4 and figure 8 show the combined price index for print content. Unlike online media, print content prices have been rising steadily since the early 1980s. It is true that cell phones and search engines make reporting much easier and more efficient. However, the basic job of writing and then editing a story has not changed much, so there is little increase in labor productivity. Furthermore, wages for white collar professionals like authors or journalists have risen substantially over time. The net impact is steady price growth for print content production. Before 1980, the prices for print content changed at about the same rate as the GDP deflator.

\subsection{Prices for Audiovisual Content}

Note that this index is not for the provision of broadcast towers or cable TV connections, but for the underlying audiovisual content. Before 1950, broadcast radio accounted for the vast majority of content and broadcast television became important during the 1950s and 1960s. Cable television connections are now responsible for the majority of content delivery, but online video has been growing recently and may eventually replace cable companies. There are no existing prices for "free" audiovisual content, so we will use a combination of input and output prices that reasonably cover the production of audiovisual content. In particular, the three main inputs to audiovisual content are sports programs to air, nonsports programs to air, and transmission services to send the content to viewers. We use BEA's price index for sporting event tickets (NIPA table 2.4.4U, line 212) as a proxy for the price of sports programs. We use BEA's price index for long-lived television programs (NIPA table 5.6.4, line 24) as a proxy for nonsports program costs. Finally, we use BEA's price index for telecommunications (NIPA table 2.4.4, line 97) as a proxy for transmission costs. We then calculate the price of "free" audiovisual content using a geometric average of the three with 13.3 percent weight on sports programs, 53.3 percent weight on nonsports programs, and 33.3 percent weight on telecommunications. The relative weights for sports versus nonsports are based on genre data purchased from Kantar Media. These data are described in much more detail in Soloveichik (2013b). We were not able to find data tracking the weight for telecommunications, so we use our best judgment instead.

This approach is an oversimplification of the broadcasting and cable industries. Broadcasting stations have implicit ownership of their airwaves, and their transmission costs depend on the shadow price of spectrum as well as the capital costs of transmission equipment. Furthermore, both cable distributors and phone companies are regulated monopolies with prices partially determined by government policy. As a robustness test, we also experimented with developing detailed price indexes tracking the inputs to transmission more closely. That price index is described in much more detail in our previous paper (Nakamura, Samuels, and Soloveichik 2016). In practice, that detailed price index provides similar longterm trends at the cost of much greater computation complexity. We also considered using quantity data to derive prices. The paper "The Random Long Tail and the Golden Age of Television" (Waldfogel 2016) demonstrates a simple methodology to count television show production. We followed his methodology and created a quantity index based on a simple count of all television shows running in the United States from 1949 onwards. Once again, this complex price index matches the simple input-based price index reasonably well.

Table 4 and figure 8 show the combined price index for audiovisual content. Since the early 1990s, prices fell relative to GDP but not nearly as much as the price declines in digital content. Intuitively, 
audiovisual content uses more computers than print media companies and fewer computers than online media companies.

\subsection{The Impact of "Free" Content on GDP, PCE, and Core PCE Prices}

Overall, the introduction of advertising- and marketing-supported consumer content to U.S. national income and product accounts via the experimental methodology that we have introduced has a small but still noticeable impact on the measured inflation rate over the past 20 years. As table 2 shows, from 1929 to 1975, the average annualized inflation rate as measured in the GDP, PCE, and core PCE price indexes is unaffected by consumer content. And from 1975 to 1995, the difference is generally less than 0.01 percentage point. The impact rises after 1995. From 1995 to 2005, the inflation rate falls from 2.02 percent to 1.97 percent for the GDP price index, from 1.91 percent to 1.85 percent for the PCE price index, and from 1.70 percent to 1.63 percent for the core PCE price index. From 2005 to 2015, the inflation rate falls from 1.80 percent to 1.74 percent for the GDP price index, from 1.73 percent to 1.64 percent for the PCE price index, and from 1.67 percent to 1.58 percent for the core PCE price index.

\subsection{The Impact of "Free" Content on Measured Real GDP}

We introduced our results by showing the impact of advertising-supported media in figure 1 and marketing-supported information in figure 2 . In order to save space, we will refer to the same figures in this discussion. Both figures measure real GDP growth from the expenditure side, which we estimate by deflating the nominal estimates with the price deflators described above and constructing a new chained Fisher estimate of real GDP. We find that our experimental methodology raises GDP growth from 1995 to 2005 by 0.07 percentage point per year, and it raises GDP growth from 2005 to 2015 by 0.10 percentage point per year. These increases in real GDP growth are much larger than the increases in nominal GDP growth shown in figure 6. Intuitively, the plummeting price for online information reinforces the explosive nominal growth of online information.

\section{The Impact of "Free" Content on Real Input and Productivity by Industry}

\subsection{Measuring Viewership Quantities over Time}

The analysis up to this point fully measures the impact of "free" content on real GDP (output), but it does not address the impact of "free" content on measured productivity across industries and in the aggregate. Policymakers and researchers are interested in measuring the extent to which private business sector output can be explained by TFP growth relative to input accumulation and the industry origins of the aggregate sources of economic growth. This decomposition is particularly important for analyzing advertising-supported media because the content is produced in a narrow set of industries but is used broadly throughout the economy. The missing pieces in constructing productivity measures that account for both the production and the use of "free" media and information are viewership quantities and prices. To clarify this, for industries that use "free" content (like Waze), this is an input to production, while viewership of advertising and marketing is a new industry output. In this case, we need prices and quantities of the output of viewership. For industries that produce the content, 
viewership is an input, and advertising-supported media and marketing-supported information are the outputs.

In nominal terms for each industry, viewership and content are equal and thus cancel each other out; this is the underlying assumption of the barter transaction model. Because the household viewership sector is outside the private business sector, the household viewership inputs into private business gross output are excluded, by definition, from private business sector value added. Thus even though the private business sector is making a larger contribution to PCE and GDP in real terms, private business sector value added in nominal terms is unchanged. Moreover, fundamental inputs, such as qualityadjusted labor and capital services, into private business sector production, are also unchanged. However, the real value added, and thus TFP, is not unchanged, because the real inflation rates and the real quantities of viewership and content are not the same. In particular, online content in real terms grows substantially faster than the growth of online hours (viewership inputs in the private business sector) as online marketing has accelerated.

We will calculate viewership quantities and implicit prices based on time use. We create quantity indexes tracking viewership of advertising and marketing. By construction, our indexes only track viewership of the advertising and marketing that is viewed during media usage time and that is separated from the media content. For example, a print newspaper might print news articles on one page and paid advertisements on the next page. The cost of the paid advertisements includes not only the cost charged by newspapers to advertisers for the page space, but also the implicit cost incurred by marketers designing the ad and placing it in a relevant location. We then construct price indexes as the ratio of total nominal advertising and marketing content divided by the viewership quantity.

We construct six separate viewership quantity and implicit price indexes for the following categories: (1) Print newspaper readership; (2) Print magazine readership; (3) NonInternet radio listenership; (4) NonInternet television viewership; (5) Desktop Internet search; (6) All other Internet. The data used for each category are described in much more detail in appendix B. We were not able to track viewership quantities for many categories of marketing, so we impute prices for those categories. ${ }^{26}$ In particular, for example, we use viewership prices of desktop search as a proxy for viewership prices of mobile search, viewership prices of audiovisual media as a proxy for viewership prices of audiovisual marketing, and viewership prices for print media as a proxy for viewership prices of print marketing.

Figure 9 shows the implicit price indexes for viewership from 1929 to 2015 relative to the GDP deflator. One way to interpret the implicit price index is as the value of content provided per unit of viewership time. For print viewership, the content per time spent increased up through the early 2000 s relative to the GDP deflator and was flat between that time and the onset of the Great Recession. Starting with the financial crisis, the value of content in newspapers plummeted relative to the readership, and this ratio has continued to fall since then.

\footnotetext{
${ }^{26}$ Some marketing categories are embedded in media programs without any clear separation. For example, a public relations spokesperson for a company might give a television interview defending the company's products. In that case, the cost of embedded marketing is often bias or omitted facts rather than wasted time. Other marketing categories are separated, but we were not able to locate any viewership quantity data.
} 
Between 1936 and 1947 (before the widespread use of home televisions), content provision by radio grew rapidly relative to listenership, implying an increase in the price of exposure to marketing- and advertising-supported information. Between 1960 and 2000, content provision by television grew rapidly relative to viewership, implying a similar increase in the price of exposure to marketing and advertising-supported information. Since the early 2000s, both radio and television content provision costs have declined relative to the overall GDP deflator, most likely because the value of content provision has shifted online and has grown less rapidly relative to the quantity of viewership.

Viewership prices for online content spiked during the dot com bubble. The Silicon Valley business model of "ubiquity first, revenue later" provides one lens to interpret this early spike. Companies spent heavily building Web sites and creating online content to attract early Internet users because the companies believed that later Internet users would gravitate toward products and services with a preexisting network of users. Viewership prices fell rapidly between 1998 and 2002, reflecting the influx of people viewing content online. Since 2002, the price for viewership of online content has increased slightly relative to GDP, reflecting significant growth in spending on online content.

\subsection{The Impact of "Free" Online Content on Measured TFP}

Our experimental methodology treats an increase in Internet surfing by the viewership sector as an increase in inputs and therefore as a reduction in TFP for the content-producing sector, holding real content fixed. If, in fact, quantities of viewership have risen more slowly than the content that has been produced, then TFP for the content-producing industries would rise. For the other industries, an increase in Internet surfing is considered an increase in gross output and therefore an increase in TFP. The intuition for this is that content-producing sectors use "free" content as an input. Advertising and marketing viewership is the implicit payment for the "free" business information that is produced by the content providers, so it is counted as an output of the businesses that use "free" content.

This section incorporates our estimates of "free" content production and use into industry-level statistics for each of the 63 business sector industries tracked in the paper "Long-term Estimates of U.S. Productivity and Growth" (Jorgenson, Ho, and Samuels 2014). Except for the estimates of advertisingsupported media and marketing-supported information, all of our data on labor and on nonlabor inputs by industry are based on this paper's data. Because there are so many industries, it was not feasible to show each one separately; thus, we show the result for the private economy as a whole by aggregating the industries. The results for the individual industries are available upon request.

We note that our data that track the output of marketing-supported information are based on OES's reported earnings for marketing professionals in each of the 63 business sector industries. By construction, nominal output of marketing-supported information is equal to nominal input of marketing viewership for each industry and for each subcategory of "free" content, so we do not need a separate data set to measure the inputs of marketing viewership. Our data that track usage of advertising- and marketing-supported information are based on a survey by Forrester that tracks Internet time usage for work purposes. Appendix B contains more detailed information. 
Figure 10 shows that TFP growth rises when "free" digital content is included in the productivity accounts for the private business sector. In 2014, the level of TFP would have been higher by 0.5 percentage point, and in 1995, it would have been lower by about 0.5 percentage point. Thus, over the period 1995-2014, TFP would have grown by about 0.05 percentage point per year faster than the currently published growth rate; it would have grown 0.10 percentage point per year faster during the recovery period of 2010-2014, 0.05 percentage point per year faster during the jobless recovery period of 2001-2007, and 0.01 percentage point per year between 1995 and 2001.

The revisions to measured TFP from as a result of including "free" digital content shown in figure 10 are much smaller than the revisions suggested in the popular press (Ito 2013; Aeppel 2015). The main cause of this difference is how we weight "free" apps in our TFP numbers. The standard productivity formula assigns weights in proportion to gross output in order to reflect the production-based valuation consistent with GDP. Even in 2014, online consumer content accounts for less than 1 percent of the overall economy. Accordingly, higher TFP growth for digital content creation has little effect on aggregate TFP growth. In contrast, the popular literature assigns weights in proportion to time use. By 2014, Americans spent more than one-sixth of their waking time online. If we used that weight to value digital content creation, private sector TFP growth would increase dramatically, but this estimate would be inconsistent with standard GDP and TFP constructs where weights are based on the economic theory of production.

As a reminder of the issues that we discussed earlier, the price indexes that we use do not include any quality adjustment for network effects, user-generated content, or factors unique to Silicon Valley. As a robustness test, we explore the use bytes of data, which were tracked by the Minnesota Internet Traffic Studies as a potential proxy for quantities of "free" digital content. ${ }^{27}$ Based on the quantity index that we construct, we calculated that quality-adjusted prices could have fallen as fast as 26 percent per year. Using this price index, we calculate that "free" digital content would have increased aggregate TFP growth by 0.13 percentage point per year between 1995 and 2014 (about triple the effect reported above). This upward revision to TFP growth is not trivial, and it suggests that quality growth may be very important when measuring "free" online media. However, even a TFP increase of 0.13 percentage point per year is not nearly enough to reverse the recent productivity slowdown (Syverson 2016).

\subsection{The Impact of TFP from Other "Free" Content}

Even though the Internet receives the most popular attention, it is not the only category of "free" content. Figure 6 shows that "free" digital content represents less than half of total consumer entertainment. Like digital content, our experimental methodology includes "free" print and audiovisual content in final output and GDP. Thus, it is just as important to account for how these content categories affect TFP growth when it is measured using our experimental methodology.

Figure 10 shows the combined effect of all the "free" categories on measured private sector TFP. From 1947 to 2014, adding "free" content to the productivity accounts would raise measured productivity

${ }^{27}$ https://en.wikipedia.org/wiki/Internet traffic\#Internet backbone traffic in the United States provides the primary data. We use Cisco's estimate of global traffic as a proxy after 2011 and for the years without data. 
growth by about 0.04 percentage point per year. To put this in context, Jorgenson, Ho, and Samuels (2016) estimate that aggregate TFP grew by 0.64 percentage point per year over that same period, a substantive difference. ${ }^{28}$ Between 1995 and 2000 (the dot com boom), our imputations add about 0.12 percentage point to per year in comparison with 0.79 percentage point per year for the aggregate economy, but we note that we have not carefully considered the cyclical properties of our estimation methods. After 2000, our experimental accounting for advertising- and marketing-supported content adds about 0.06 percentage point to measured private sector TFP.

However, it is worth noting that adding our barter transaction for "free" content does not necessarily lead to upward revisions to TFP growth. In practice, the revision depends on the productivity effect of producing the new content versus the effect of using the new content. For example, between 2007 and 2014, including the production and use of "free" print media lowered private sector TFP growth. The explanation for this result is that across all industries the contribution of additional viewership inputs exceeded the extra growth due to the production of "free" print content. The large downwards spike in the 2009, in part reflects volatility in estimating prices and content production over the business cycle, but it also reflects the real decline in the production of print content relative to the inputs used in producing the content. Other than this relatively small decline, however, adding "free" content to the production account produces minor upward revisions to private sector TFP growth. Since 1948, including the "free" audiovisual content would add 0.01 percentage point per year to private sector TFP growth, and adding "free" print media would add another 0.01 percentage point per year to private sector TFP growth. Other Effects of the Media Industry on Measured Productivity

The main focus of this paper is to present a method that we think more accurately reflects transactions accompanying "free" content. We have implemented this approach with (mostly) existing price data, but it is worth noting that researchers disagree on how completely BEA's current price indexes capture quality change in the goods and services used to access media. Recent research has focused on Internet access. In the period from 2004 to 2009, Greenstein and McDevitt (2011a, b) take two different routes to measure the price of broadband services. Both studies find very modest declines of 2 percentage points annually in quality-adjusted prices. These studies imply that the implied willingness-to-pay for broadband speeds and rapid increases in data downloads is not very high. However, these studies do not consider the heterogeneity of broadband customers, which appears to be high (Nevo et al. 2015).

Exactly how far quality-adjusted prices should fall is a difficult question to answer. An important issue is that the willingness to pay for characteristics at a point in time is affected by the rapid change in the uses and usefulness of applications. For example, high definition televisions provide very little value for television shows filmed in low resolution, but they provide substantial value for television shows filmed in high resolution. Similarly, smartphones equipped with GPS technology have become much more useful with the introduction of location-based apps like Waze or Uber.

Broadband Internet, televisions, and other media access spending account for a much larger share of GDP than "free" content production. It is possible that the revision to measured TFP from new price

\footnotetext{
${ }^{28}$ The aggregate TFP estimate from Jorgenson, Ho, Samuels (2016) covers total TFP, but our TFP estimates cover only the private sector.
} 
indexes for broadband Internet services, television sets, or other media access technologies could dwarf the revisions to TFP shown in figure 10. However, new price indexes for telecommunications, televisions, and other media-related spending are not directly related to the conceptual question of how to track "free" digital content in GDP. After all, research on hedonic computer prices started long before the Internet (Triplett 1989).

\section{Concluding Remarks}

The "free" digital economy poses a number of challenging questions for the national income and product accounts and productivity measurement. In this paper we have addressed one important difficulty: how to account for advertising- and marketing-supported content when there is no directly measured transaction between the producers and users of the content. An important context for our work is that the content that is provided via the Internet is not the first content category to be subsidized by advertising and marketing. We have demonstrated that many of the measurement issues can be addressed by a relatively simple tweak to the current GDP and productivity measurement methodologies by accounting for "free" content through a barter transaction.

We use the barter transaction methodology to recalculate GDP, GDP growth, aggregate productivity of the business sector, and industry-level productivity growth. We find that including advertisingsupported media and marketing-supported information in final output has a substantive impact on measured real GDP growth and TFP growth, and the impact of including marketing-supported information is larger than the impact of including advertising-supported media. Between 1947 and 2015, adding "free" content to final demand would increase real GDP growth by about 0.03 percentage point per year, of which 0.01 percentage point would be from advertising content and 0.02 percentage point would be from marketing content. Most of this increase in real GDP growth occurred after 1995. From 1996 to 2015, advertising content added 0.02 percentage point, and marketing content added 0.07 percentage point.

Overall, between 1948 and 2014, aggregate measured TFP for the private sector increases by 0.04 percentage point per year when we include the barter transaction in the production account. From 1995 to 2014 , TFP would have grown faster by 0.07 percentage point. The main causes of this are the increase in the share of marketing-supported content in GDP and the amount of the marketing content being produced relative to the viewership inputs being exchanged.

Many previous researchers studying the Internet have focused on advertising-supported online media companies like Google or Facebook. These companies are easier to study because advertising revenue is tracked in the Economic Census and in other government surveys. Yet those companies account for less than one-quarter of "free" online content production. Our research demonstrates that measuring the full value of the Internet requires that one goes beyond Internet publishing companies that produce advertising-supported media to the universe of companies with Web pages and Twitter accounts. 


\section{Bibliography}

Aeppel, Tim, 2015, “Silicon Valley Doesn't Believe U.S. Productivity Is Down," Wall Street Journal, July 16, http://www.wsj.com/articles/silicon-valley-doesnt-believe-u-s-productivity-is-down-

1437100700 ?tesla=y\&cb=logged 0.28855257923714817.

Brynjolfsson, Erik, and Joo Hee Oh, 2012, "The Attention Economy: Measuring the Value of Free Digital Services on the Internet, "MIT Working Paper.

Brynjolfsson, Erik, Felix Eggers and Avinash Gannamaneni, 2017a, "Using Massive Online Experiments to Measure Changes in Well-being," MIT Working paper.

Brynjolfsson, Erik, Felix Eggers and Avinash Gannamaneni, 2017b, "Using Massive Online Experiments to Measure Changes in Well-being," Slides presented at the Society of Economic Measurement. These slides discuss the paper, but include additional material.

Bughin, Jacques, Laura Corb, James Manyika, Olivia Nottebohm, Michael Chui, Barbat Borja de Muller, and Remi Said, 2011, "The Impact of Internet Technologies: Search" McKinsey Institute Working Paper.

Byrne, David, and Carol Corrado, 2015, “Prices for Telecommunications Equipment: Rewriting the Record," FEDS Working Paper 2015-69, September.

Byrne, David and Carol Corrado, 2016, "ICT Prices and ICT Services: What Do They Tell Us About Productivity and Technology?" http://scholar.harvard.edu/files/jorgenson/files/1.1.pdf?m=1463778496.

Byrne, David, Carol Corrado and Dan Sichel, 2017, “The Rise of Cloud Computing: Minding Your P's and Q's" https://bea.gov/about/pdf/acm/2017/the-rise-of-cloud-computing-minding-your-ps-and-qs.pdf.

Byrne, David and Eugenio Pinto, 2015, "The Recent Slowdown in High-Tech Equipment Price Declines and Some Implications for Business Investment and Labor Productivity," FEDS Notes, March 26, http://www.federalreserve.gov/econresdata/notes/feds-notes/2015/recent-slowdown-in-high-techequipment-price-declines-some-implications-for-business-investment-labor-productivity20150326.html.

Coase, Ronald H, 1959, "The Federal Communications Commission" Journal of Law and Economics, 3, 140. 
Cox, Jim, 2013, "Radio After the Golden Age: The Evolution of American Broadcasting Since 1960" McFarland Publishers.

Chen, Yan, Grace YouJoo Jeon, and Yong-Mi Kim, 2014, “A Day without a Search Engine: An

Experimental Study of Online and Offline Search," Experimental Economics 17, December, 512-536.

Corrado, Carol and Janet Hao, 2014, "Brands as Productive Assets: Concepts, Measurements and Global Trends" http://www.wipo.int/edocs/pubdocs/en/wipo_pub_econstat_wp_13.pdf

Corrado, Carol, Charles Hulten, and Daniel Sichel, 2009, "Intangible Capital and U.S. Economic Growth," Review of Income and Wealth, 55 (3), 661-685.

Cremeans, John, 1980, “Consumer Services Provided by Business Through Advertising-Supported Media in the United States," Review of Income and Wealth, 26 (2), 151-174.

Danaher, Peter J., 1995, "What Happens to Television Ratings During Commercial Breaks?" Journal of Advertising Research, 35 (1), 37-47.

Dean, David, Digrande, Sebastian, Field, Dominic, Lundmark, Andreas, O’Day, James, Pineda, John and Zwillenberg, Paul, 2012, "The Internet Economy in the G-20: The \$4.2 Trillion Growth Opportunity" https://www.bcgperspectives.com/content/articles/ media entertainment strategic planning 42 trillion opportunity internet economy g20/.

Dogtiev, Artyom, 2017, “App Revenues 2017” http://www.businessofapps.com/data/app-revenues/. Accessed October $16^{\text {th }}, 2017$.

Dorfman, Robert and Peter O. Steiner, 1954, "Optimal Advertising and Optimal Quality," American Economic Review 44, 826-836.

Eisner, Robert, 1978, "Total Incomes in the United States, 1959 and 1969," Review of Income and Wealth, 24 (1), 41-70.

Fisher, Jonathan and Christina Houseworth, 2012, "Occupation Inflation in the Current Population Survey", CES Working Paper 12-26, https://www2.census.gov/ces/wp/2012/CES-WP-12-26.pdf.

Galbi, Douglas, 2008, "Coen Structured Advertising Expenditure Dataset" Available at https://www.purplemotes.net/2008/09/14/us-advertising-expenditure-data/.

Goolsbee, Austin and Peter J. Klenow, 2006, "Valuing Consumer Products by the Time Spent Using Them: An Application to the Internet," American Economic Review Papers and Proceedings, 96(2): 108113. 
Greenstein, Shane, and Ryan McDevitt, 2011a, "Evidence of a Modest Price Decline in US Broadband Services," Information Economics and Policy 23, 200-211.

Greenstein, Shane and Ryan McDevitt, 2011b, "The Broadband Bonus: Estimating Broadband Internet's Economic Value", Telecommunications Policy 35, 617-632.

Ito, Aki, November 21, 2013, "The Free Web Has Economists Puzzled." www.businessweek.com/articles/2013-11-21/economists-gdp-calculations-may-miss-impact-of-freeinternet-services; accessed April 9, 2014.

Holmes, Linda, May 30, 2013, "Theaters and Studios Squabble Over Shortening Movie Trailers" NPR Morning Edition http://www.npr.org/sections/monkeysee/2013/05/30/187096839/as-trailers-eat-upmovie-time-theaters-and-studios-squabble-over-shortening-them.

Hulten, Charles and Nakamura, Leonard, 2017, "Accounting for Growth in the Age of the Internet: The Importance of Output-Saving Technical Change" https://www.aeaweb.org/conference/2017/preliminary/paper/TzriretB.

Jaszi, George, 1971, “An Economic Accountant's Ledger," Survey of Current Business, 51 (7) Part II, 183227.

Jaszi, George and Schwartz, Charles, 1954, “National Income - 1954 Edition” Survey of Current Business, supplement. Discussion of "free" content on page 38. https://fraser.stlouisfed.org/files/docs/publications/nipab/nipa_1929_1954.pdf.

Jorgenson, Dale, 2001, "Information Technology and the U.S. Economy." American Economic Review 91 (1), 1-32

Jorgenson, Dale W, Mun S.Ho, and Jon D. Samuels, 2014, "Long-term Estimates of U.S. Productivity and Growth." Unpublished Manuscript. http://www.worldklems.net/conferences/worldklems2014/worldklems2014_Ho.pdf.

Jorgenson, Dale W, Mun S.Ho, and Jon D. Samuels, 2016, "Education, Participation and the Revival of U.S. Economic Growth." NBER Working Paper 22453.

Juster, Thomas, 1973, "A Framework for Measurement of Economic and Social Performance," The Measurement of Economic and Social Performance, Milton Moss, ed., National Bureau of Economic Research. 
Kendrick, John, 1979, "Expanding Imputed Values in the National Income and Product Accounts," Review of Income and Wealth, 25 (4), 349-363.

Kohut, Andrew, Carroll Doherty, Michael Dimock, and Scott Keeter, 2012, “In Changing News Landscape, Even Television is Vulnerable" http://www.people-press.org/files/legacypdf/2012\%20News\%20Consumption\%20Report.pdf.

Lichty, Lawrence and Topping, Malachi, 1975, “American Broadcasting”, Hastings House Publishers.

Matsa, Katerina Eva, Olmstead, Kenneth, Mitchell, Amy and Rosenstiel, Tom, 2012, “Digital Advertising and News" PewResearchCenter http://assets.pewresearch.org/wpcontent/uploads/sites/13/legacy/Advertising\%20Study-FINAL.pdf.

Miller, Chance, 2016, "iOS App Store brings in 75\% more revenue than Play Store despite difference in downloads" 9to5Mac https://9to5mac.com/2016/01/20/app-store-ios-downloads-vs-android-revenue/.

Nakamura, Leonard I., 2014, "Hidden Value: How Consumer Learning Boosts Output," Federal Reserve Bank of Philadelphia Business Review, Third Quarter.

Nakamura, Leonard, 2015 “Advertising, Intangibles, and Unpriced Entertainment," in Ahmed Bounfour and Tsutomo Miyagawa, eds., Intangibles, Market Failure and Innovation Performance, Springer, 11-26.

Nakamura, Leonard and Rachel Soloveichik, "Valuing 'Free' Media Across Countries in GDP," Federal Reserve Bank of Philadelphia Working Paper 15-25, July 2015.

Nakamura, Leonard, Jon Samuels, and Rachel Soloveichik, "Valuing Free Media in GDP: An Experimental Approach," BEA Working paper 2016-3, June 2016.

Nakamura, Leonard, Jon Samuels, and Rachel Soloveichik, "Bartering for Free Information: Implications for Measured GDP and Productivity" Working Paper, April 2017.

Nerlove, Marc, and Arrow, Kenneth, 1962, "Optimal Advertising Policy Under Dynamic Conditions" Economica 29(114), pages 129-142.

Nevo, Aviv. John L. Turner and Jonathan W. Williams, 2015, "Usage-Based Pricing and Demand for Residential Broadband," NBER Working Paper 21321, July. 
Nielsen, 2015, "Video Consumer Mapping Study: Additional Data Mining" http://www.researchexcellence.com/files/pdf/2015-

02/id126_video_consumer_mapping_study_data_mining.pdf.

Noll, Roger G., Merton J. Peck and John G. McGowan, 1973, Economic Aspects of Television Regulation, Washington DC: Brookings Institution.

Okun, Arthur (1971), "Social Welfare Has No Price Tag," Survey of Current Business, 51 (Part II), 129-133.

Reisinger, Don, 2016, "Here's How Much You Spend on iPhone Apps Each Year" Fortune Magazine http://fortune.com/2016/03/29/spend-on-iphone-apps/.

Rose, Bill, Philippe Generali and Jon Coleman, 2006, "What Happens When the Spots Come On: The impact of Commercials on the Radio Audience." http://colemaninsights.com/wpcontent/uploads/2013/07/The-Impact-of-Commercials-on-the-Radio-Audience-September-2006.pdf. Ruggles, Nancy and Richard (1970), The Design of Economic Accounts, Columbia University Press.

Soloveichik, Rachel (2013a, b, c, d, and e), "Music Originals as Capital Assets," "Long-Lived Television Programs as Capital Assets," "Theatrical Movies as Capital Assets," "Miscellaneous Artwork as Capital Assets," "Books as Capital Assets." www.bea.gov/research/bio/soloveichik rachel h.htm.

Soloveichik, Rachel and Wasshausen, David, 2013, "Copyright-Protected Assets in the National

Accounts" Available at: https://blogs.commons.georgetown.edu//copyrightnrc/files/NRC-CopyrightSoloveichik-draft-5-11.pdf.

Sponsor Magazine, 1949, “More Power!", October 24, pages 28-29 and 35-36

http://www.americanradiohistory.com/Archive-Sponsor-Magazine/1949/Sponsor-1949-10-2.pdf

Sponsor Magazine, 1961, "Radio Declares: Compare Me", November 13, pages 35-37

https://archive.org/stream/sponsormagazine-1961-11/Sponsor-1961-11-3 djvu.txt

Sterling, Christopher and Kittross, John, 1978, "Stay Tuned: A Concise History of American Broadcasting" Wadsworth Publishing Company.

Stevens, Ruth, 2005, "Trade Show \& Event Marketing" South-Western Educational Pub.

Syverson, Chad, 2016, "Challenges to Mismeasurement Explanations for the U.S. Productivity Slowdown," NBER Working Paper 21974. 
Triplett, Jack, 1989 "Prices and Technological Change in a Capital Good: A Survey of Research on Computers." Technology and Capital Formation. Edited by D.W. Jorgenson and R. Landau, pp. 127-213. Cambridge, MA: MIT Press, 1989.

TVWeek, 2014, "How Many Minutes of Commercials Are Shown in an Average TV Hour? The Number Has Been Steadily Climbing," http://www.tvweek.com/tvbizwire/2014/05/how-many-minutes-ofcommercial/.

United Nations Statistics Division. (2008). Updated System of National Accounts 2008. Accessed May 20, 2013. http://unstats.un.org/unsd/nationalaccount/sna2008.asp

Varian, Hal, (2009), “Economic Value of Google,"

http://cdn.oreillystatic.com/en/assets/1/event/57/The\%20Economic\%20Impact\%20of\%20Google\%20Pr esentation.pdf.

Von Hippel, Paul T., Samuel V. Scarpino, and Igor Holas, "Robust Estimation of Inequality from Binned Incomes," Sociological Methodology, forthcoming.

Waldfogel, Joel (2016), "The Random Long Tail and the Golden Age of Television" available online at http://conference.nber.org/confer/2016/IPEs16/IPEs16prg.html. 
Figure 1: Impact of Advertising-Supported Media on Real GDP, Percent

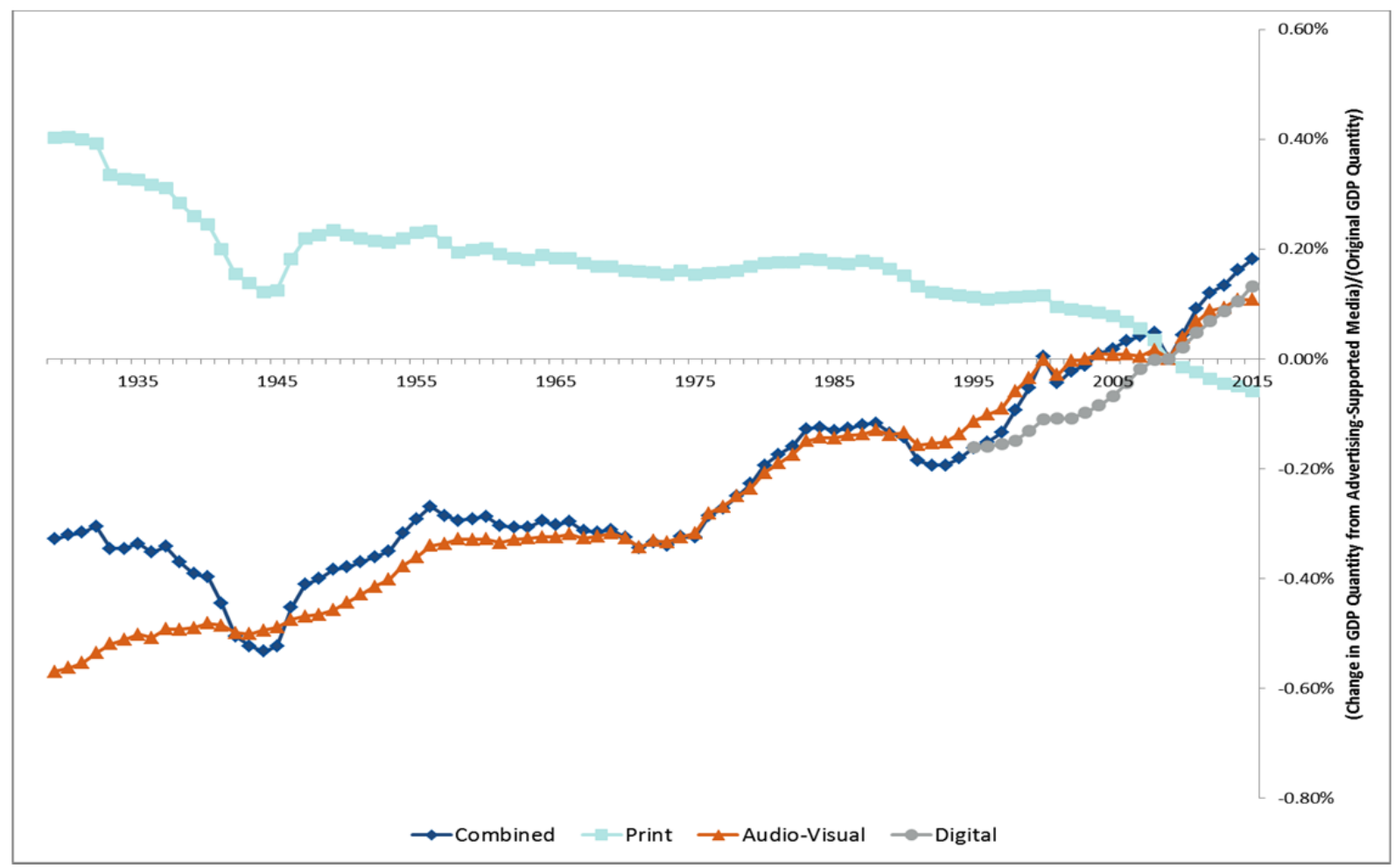

Figure 2: Impact of Marketing-Supported Information on Real GDP, Percent

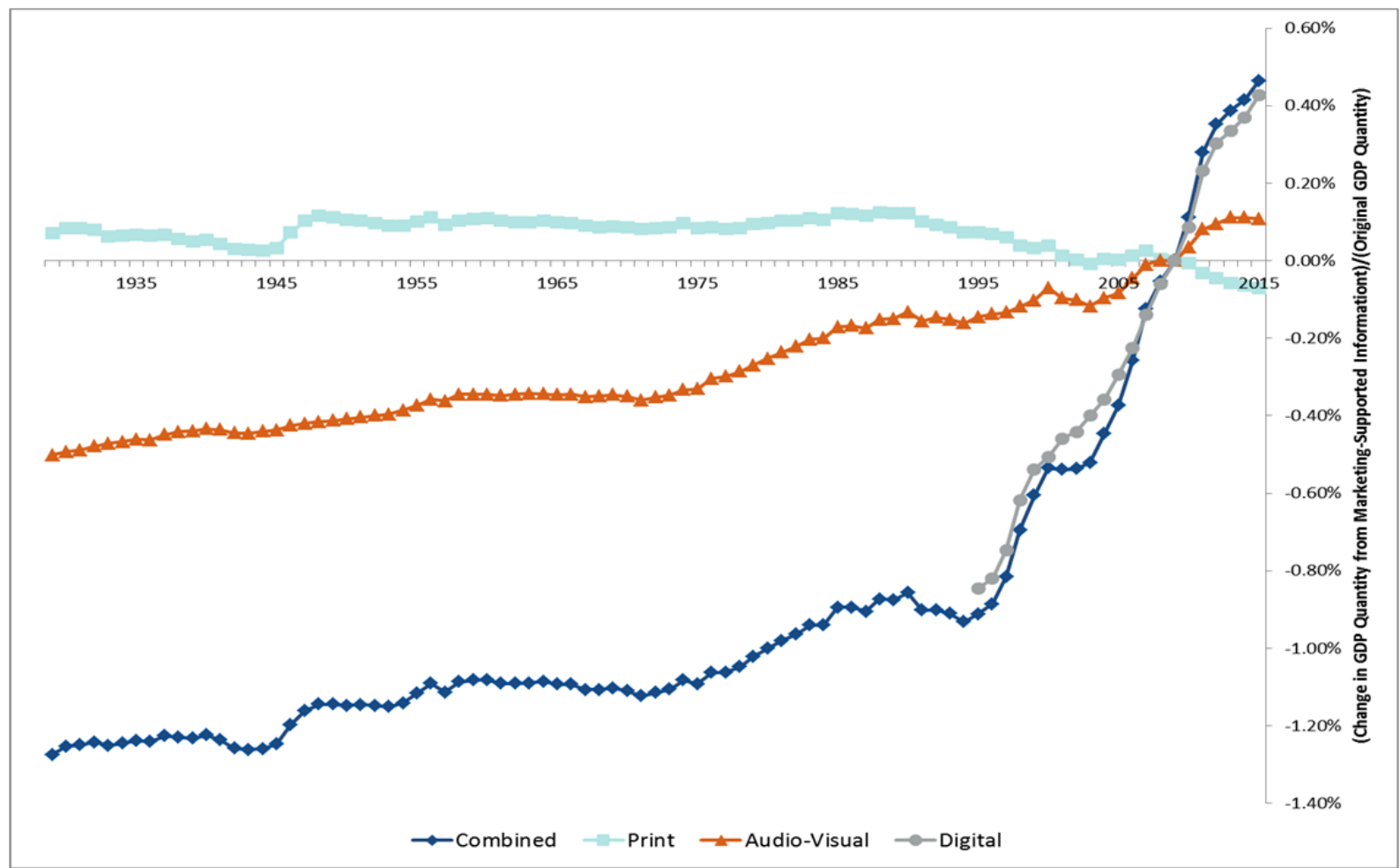


Figure 3: Advertising Revenue as a Share of GDP, Percent

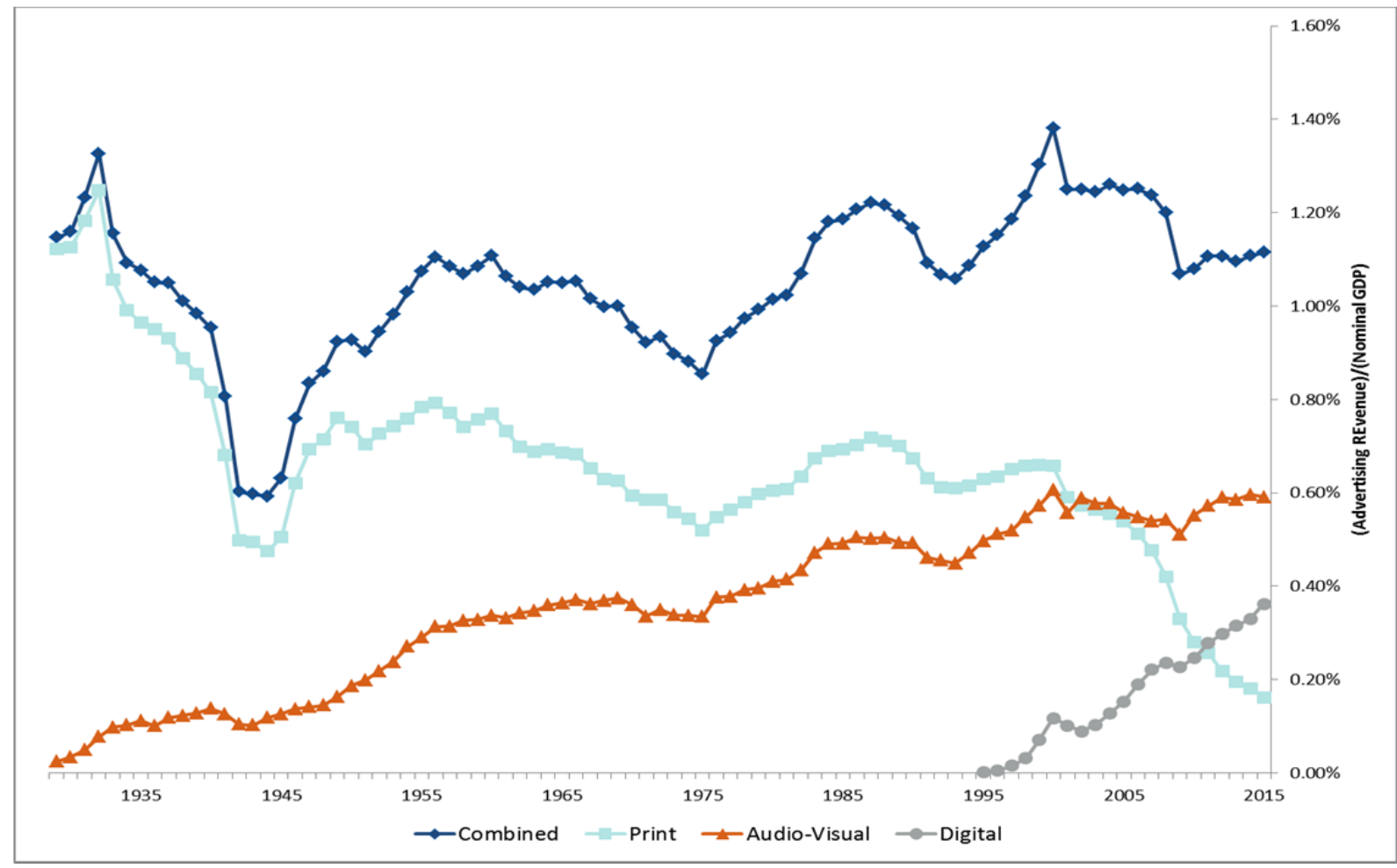

Figure 4: Opportunity Cost of In-House Advertising as a Share of GDP, Percent

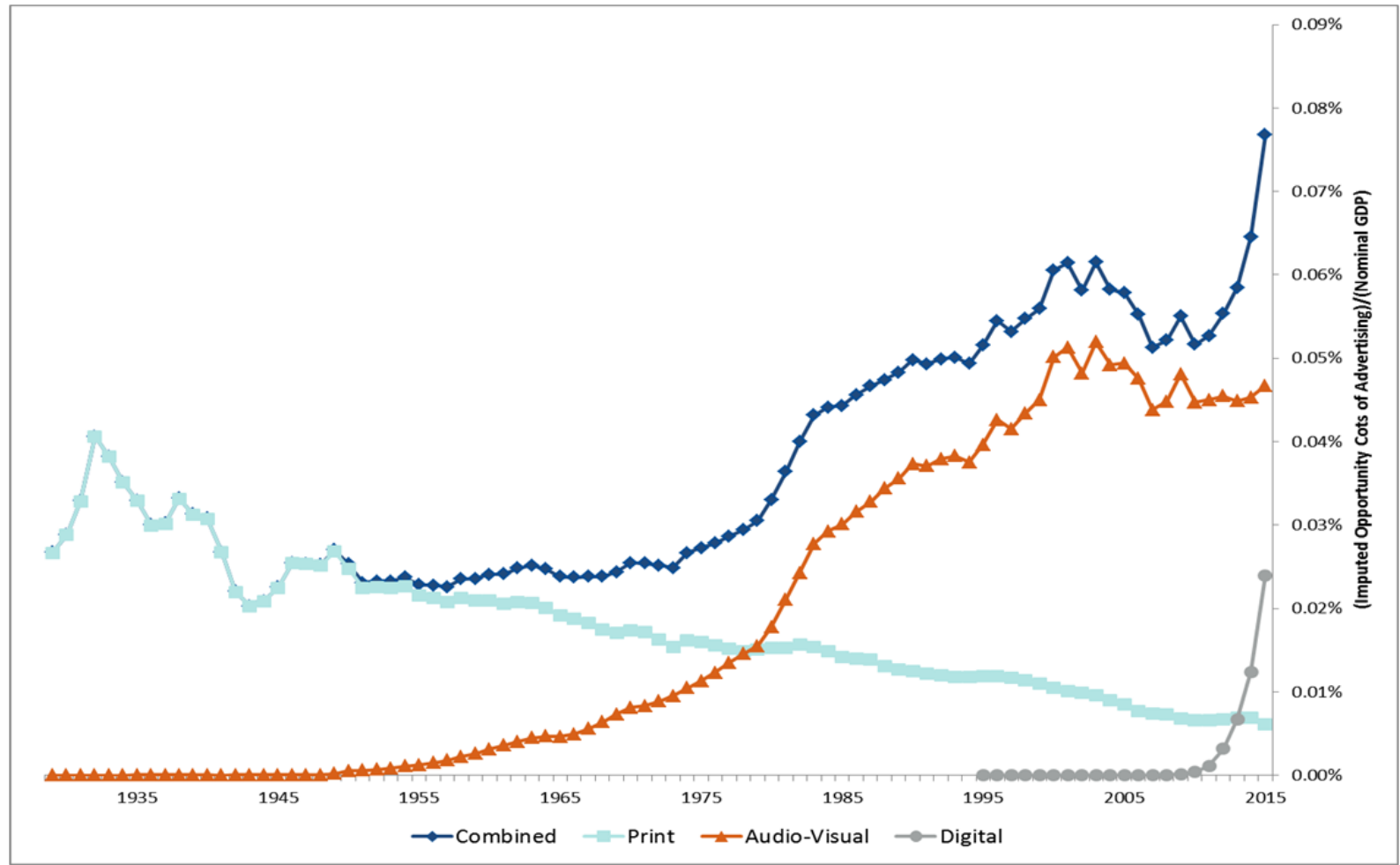


Figure 5: Consumer Media Content as a Share of GDP, Percent

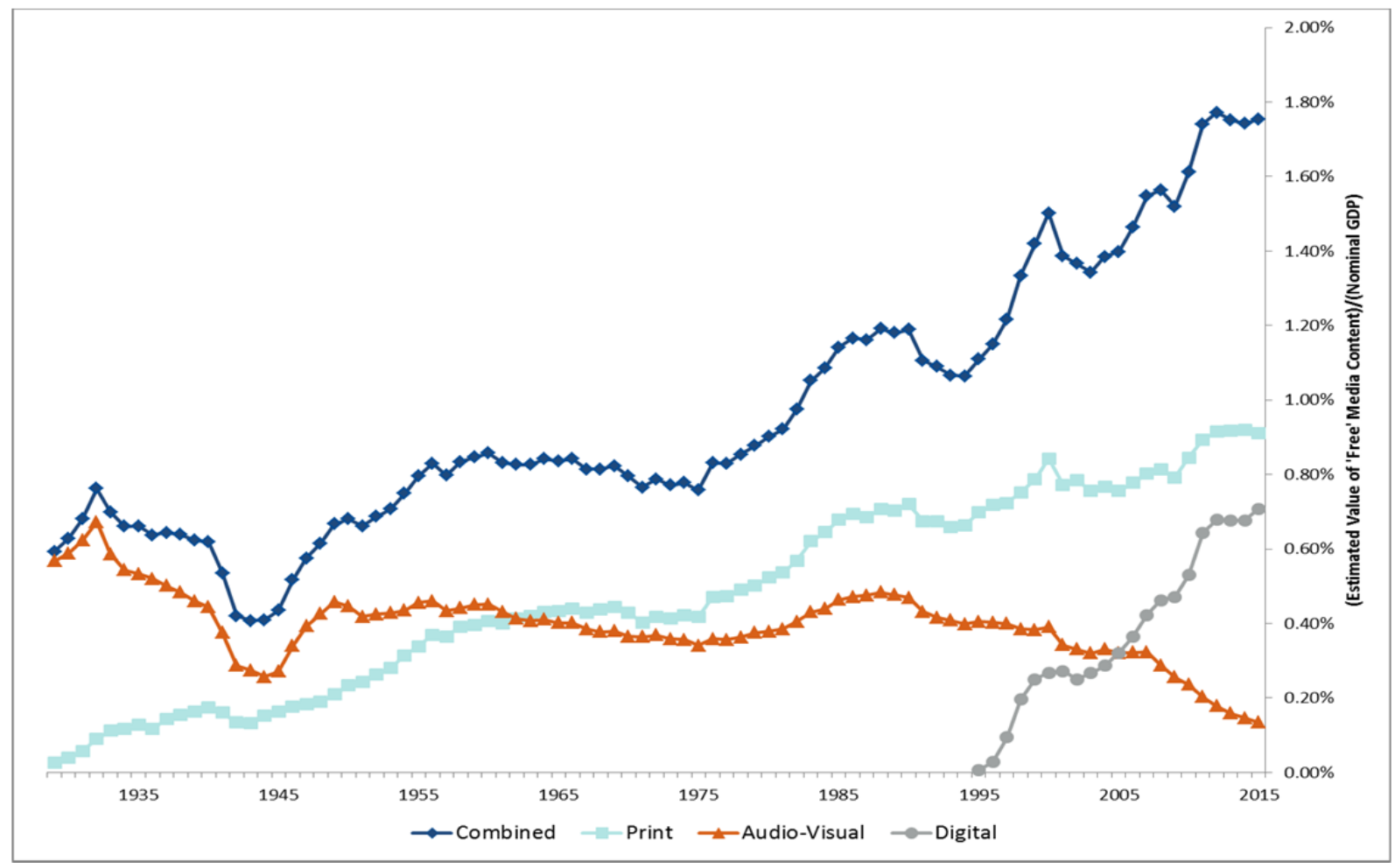

Figure 6: Marketing Output as a Share of GDP, Percent

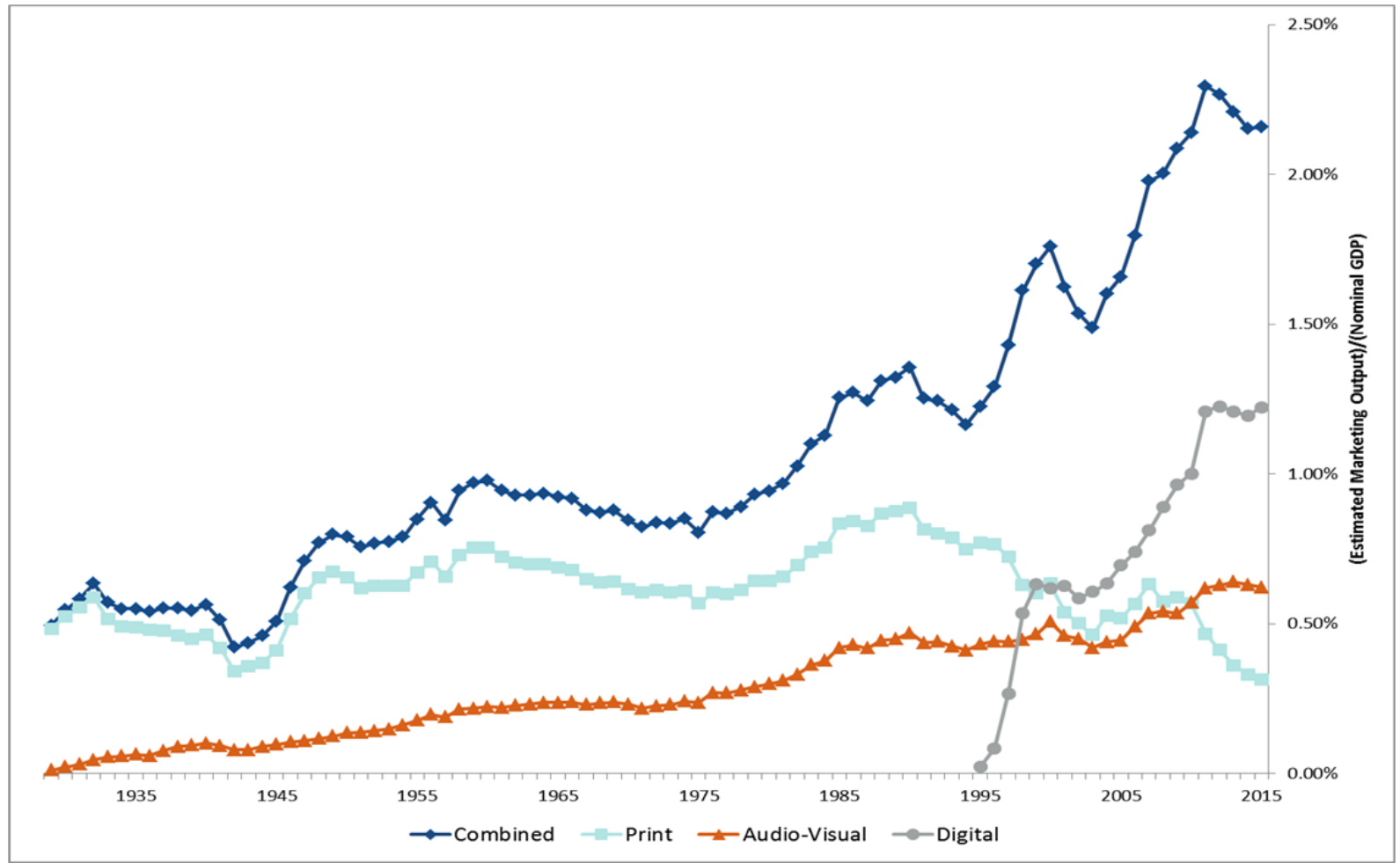


Figure 7: Consumer Information Content as a Share of GDP, Percent

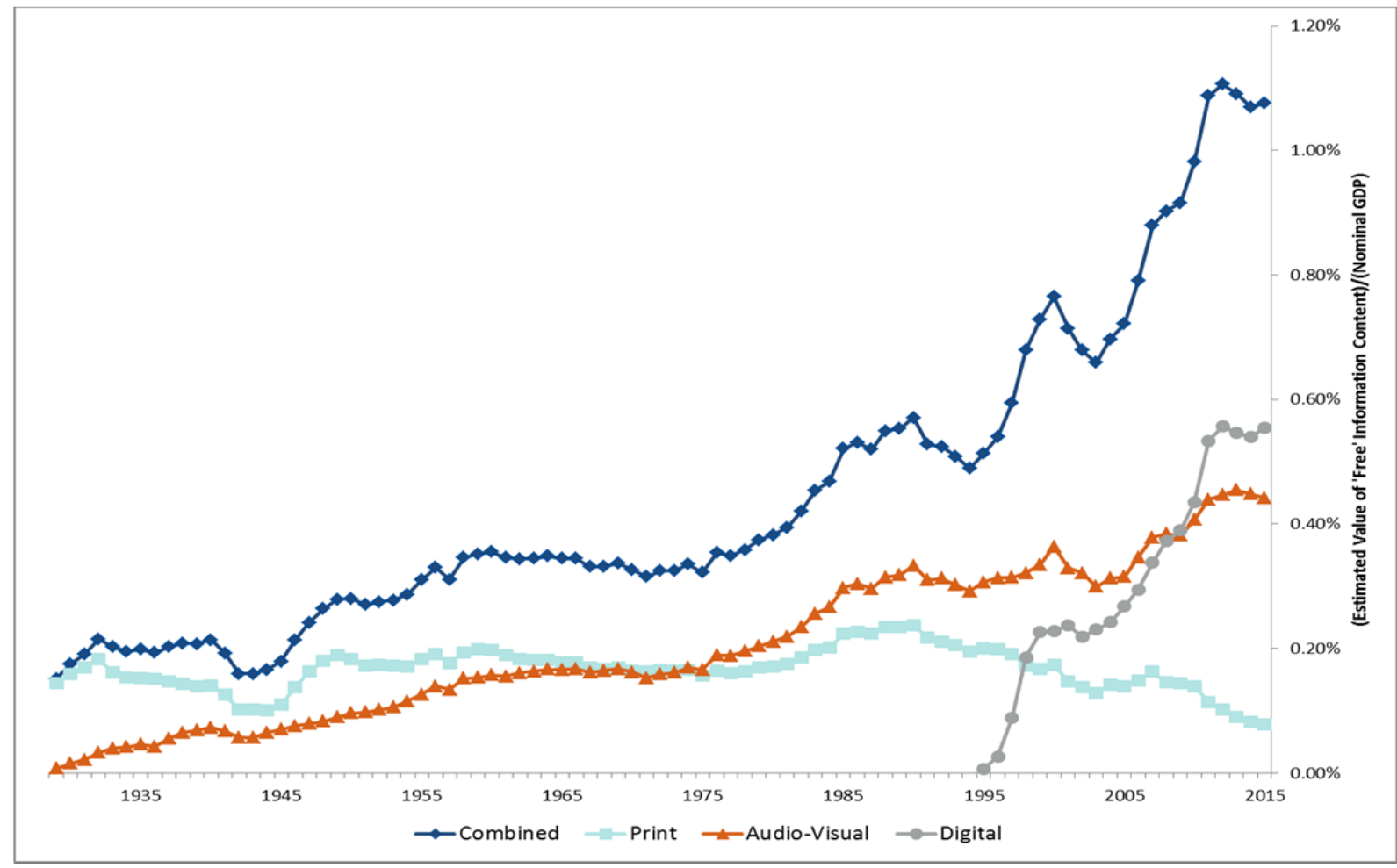

Figure 8: Content Prices Relative to the GDP Deflator

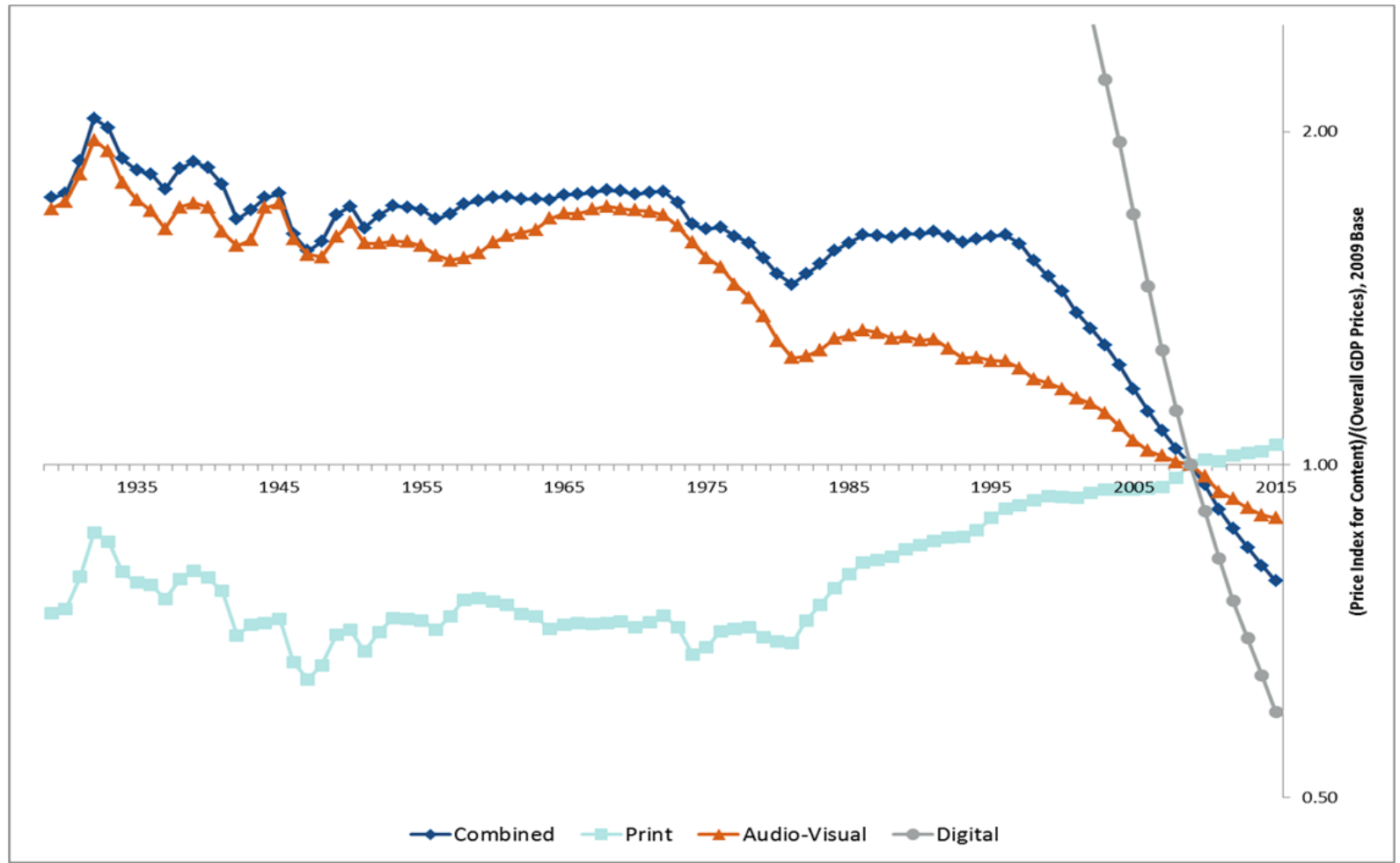


Figure 9: Viewership Prices Relative to the GDP Deflator

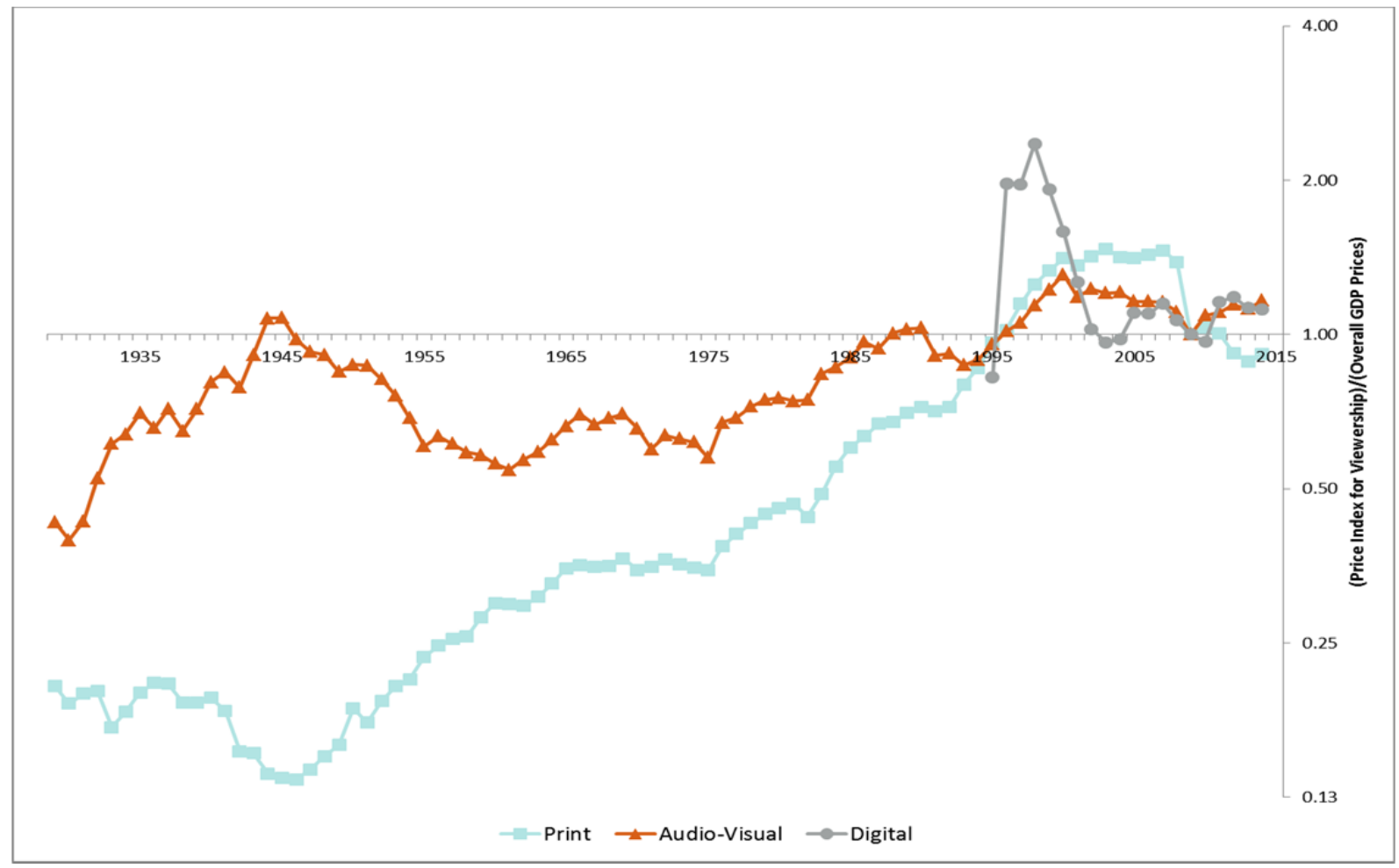

Figure 10: Impact of "Free" Content on TFP, Percent

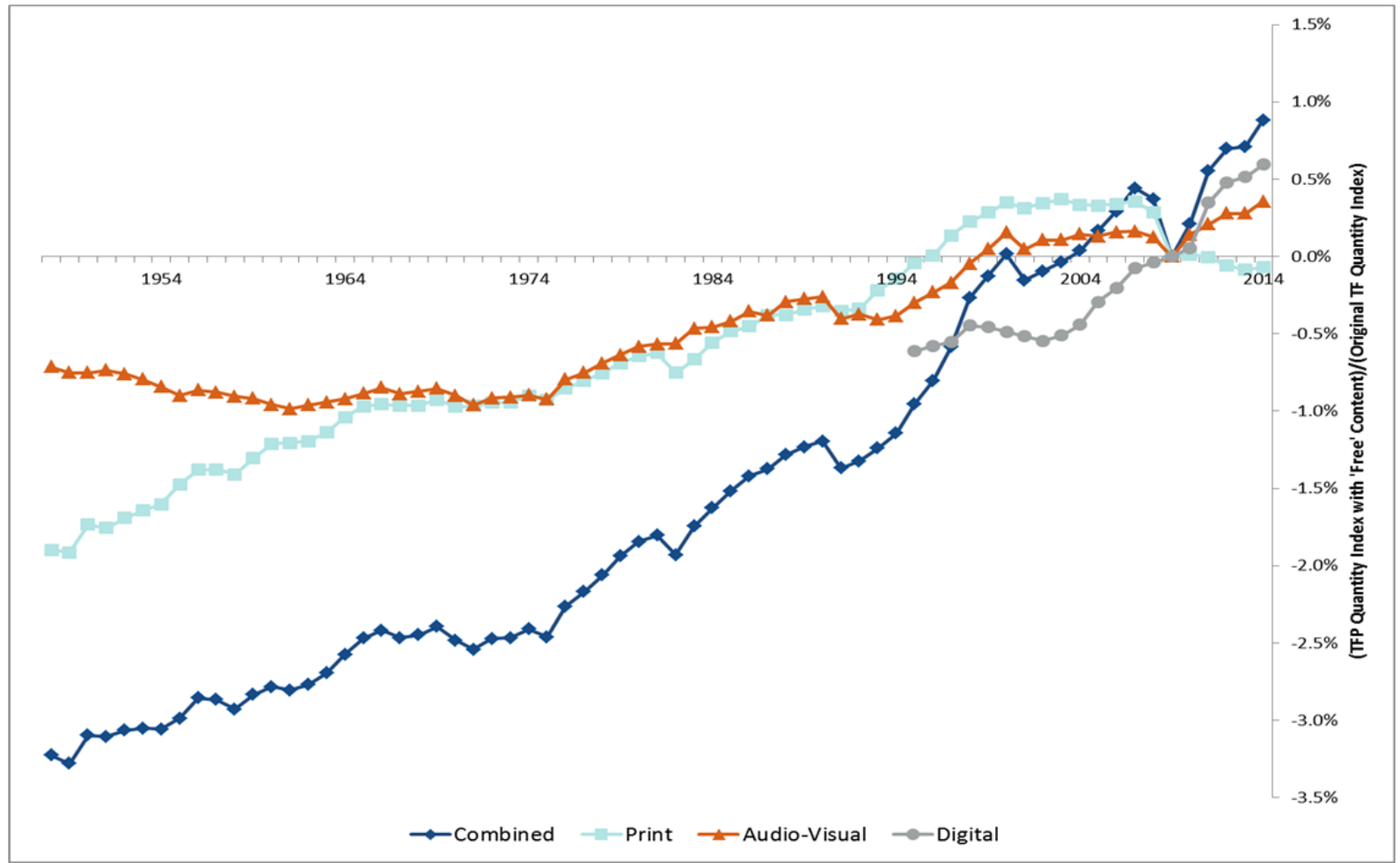


Table 1. Summary Nominal Experimental Estimates, 2015

\begin{tabular}{|c|c|c|c|}
\hline & Advertising & Marketing & Total \\
\hline Total Output & 214.9 & 389.2 & 604.1 \\
\hline Costs & 64.4 & 117.4 & 181.8 \\
\hline Total Content & 150.4 & 271.8 & 422.2 \\
\hline Consumers & 122.4 & 189.0 & 311.4 \\
\hline Business & 28.1 & 82.7 & 110.8 \\
\hline
\end{tabular}

Table 2. Summary Deflator Experimental Estimates, 1929-2015

\begin{tabular}{|l|c|c|c|c|}
\hline & 1929 to 1975 & 1975 to 1995 & 1995 to 2005 & 2005 to 2015 \\
\hline GDP plus Free Content & $2.54 \%$ & $4.48 \%$ & $1.97 \%$ & $1.74 \%$ \\
\hline BEA GDP & $2.54 \%$ & $4.48 \%$ & $2.02 \%$ & $1.80 \%$ \\
\hline Difference in GDP Prices & $0.00 \%$ & $0.00 \%$ & $-0.04 \%$ & $-0.07 \%$ \\
\hline PCE plus Free Content & $2.46 \%$ & $4.72 \%$ & $1.85 \%$ & $1.64 \%$ \\
\hline BEA PCE & $2.46 \%$ & $4.72 \%$ & $1.91 \%$ & $1.73 \%$ \\
\hline Difference in PCE Prices & $0.00 \%$ & $0.00 \%$ & $-0.06 \%$ & $-0.09 \%$ \\
\hline Core PCE plus Free Content & $2.44 \%$ & $4.81 \%$ & $1.63 \%$ & $1.58 \%$ \\
\hline BEA Core PCE & $2.44 \%$ & $4.82 \%$ & $1.70 \%$ & $1.67 \%$ \\
\hline Difference in Core PCE Prices & $0.00 \%$ & $-0.01 \%$ & $-0.07 \%$ & $-0.10 \%$ \\
\hline
\end{tabular}


TABLE 3: Nominal “Free" Consumer Content, Billions of US \$

\begin{tabular}{|c|c|c|c|c|c|c|c|c|}
\hline & \multirow{2}{*}{$\begin{array}{c}\text { GDP } \\
\text { +"Free" }\end{array}$} & \multirow{2}{*}{ BEA GDP } & \multicolumn{3}{|c|}{ Advertising-Supported Media } & \multicolumn{3}{|c|}{ Marketing-Supported Information } \\
\hline & & & Print & Audio-Visual & Digital & Print & Audio-Visual & Digita \\
\hline 2015 & $18,353.0$ & $18,036.6$ & 10.1 & 84.5 & 27.7 & 14.1 & 79.8 & 100.1 \\
\hline 2014 & $17,696.2$ & $17,393.1$ & 11.0 & 82.1 & 23.8 & 14.3 & 77.9 & 93.9 \\
\hline 2013 & $16,984.0$ & $16,691.5$ & 11.4 & 77.4 & 21.6 & 15.0 & 75.9 & 91.2 \\
\hline 2012 & $16,441.6$ & $16,155.3$ & 12.4 & 75.5 & 19.6 & 16.5 & 72.2 & 90.0 \\
\hline 2011 & $15,788.0$ & $15,517.9$ & 13.7 & 70.5 & 17.1 & 17.7 & 68.2 & 82.9 \\
\hline 2010 & $15,205.6$ & $14,964.4$ & 14.5 & 65.6 & 14.2 & 20.8 & 60.9 & 65.2 \\
\hline 2009 & $14,637.8$ & $14,418.7$ & 16.1 & 59.2 & 11.8 & 20.8 & 55.0 & 56.2 \\
\hline 2008 & $14,948.7$ & $14,718.6$ & 20.9 & 63.2 & 13.1 & 21.4 & 56.6 & 54.9 \\
\hline 2007 & $14,701.6$ & $14,477.6$ & 23.2 & 61.3 & 12.2 & 23.6 & 54.8 & 49.0 \\
\hline 2006 & $14,058.7$ & $13,855.9$ & 23.9 & 59.8 & 9.6 & 20.7 & 48.0 & 40.8 \\
\hline 2005 & $13,276.7$ & $13,093.7$ & 23.9 & 57.6 & 7.1 & 18.2 & 41.3 & 35.0 \\
\hline 2004 & $12,444.9$ & $12,274.9$ & 23.2 & 55.9 & 5.5 & 17.4 & 38.4 & 29.8 \\
\hline 2003 & $11,665.2$ & $11,510.7$ & 21.9 & 52.6 & 4.2 & 14.9 & 34.5 & 26.5 \\
\hline 2002 & $11,127.4$ & $10,977.5$ & 21.1 & 50.9 & 3.4 & 15.2 & 35.2 & 24.1 \\
\hline 2001 & $10,769.2$ & $10,621.8$ & 20.7 & 47.0 & 3.8 & 15.7 & 35.0 & 25.2 \\
\hline 2000 & $10,439.3$ & $10,284.8$ & 22.3 & 49.3 & 4.1 & 17.8 & 37.4 & 23.5 \\
\hline 1999 & $9,797.7$ & $9,660.6$ & 20.9 & 43.6 & 2.3 & 16.1 & 32.3 & 21.9 \\
\hline 1998 & $9,210.4$ & $9,089.2$ & 19.4 & 39.2 & 0.9 & 15.6 & 29.2 & 16.9 \\
\hline 1997 & $8,713.2$ & $8,608.5$ & 18.0 & 35.2 & 0.4 & 16.4 & 27.1 & 7.7 \\
\hline 1996 & $8,193.3$ & $8,100.2$ & 16.6 & 32.8 & 0.1 & 16.1 & 25.4 & 2.2 \\
\hline 1995 & $7,749.2$ & $7,664.1$ & 15.7 & 30.0 & 0.0 & 15.3 & 23.5 & 0.5 \\
\hline 1994 & $7,386.6$ & $7,308.8$ & 14.9 & 27.1 & 0.0 & 14.3 & 21.4 & 0.1 \\
\hline 1993 & $6,952.1$ & $6,878.7$ & 13.9 & 24.5 & - & 14.2 & 20.8 & - \\
\hline 1992 & $6,610.6$ & $6,539.3$ & 13.4 & 23.6 & - & 13.8 & 20.5 & - \\
\hline 1991 & $6,242.3$ & $6,174.0$ & 13.3 & 22.5 & - & 13.4 & 19.1 & - \\
\hline 1990 & $6,050.7$ & $5,979.6$ & 13.9 & 23.1 & - & 14.2 & 19.9 & - \\
\hline 1985 & $6,029.2$ & $4,346.7$ & 10.4 & 16.5 & - & 9.7 & 12.9 & - \\
\hline 1980 & $2,888.3$ & $2,862.5$ & 5.9 & 8.9 & - & 4.9 & 6.0 & - \\
\hline 1975 & $1,701.7$ & $1,688.9$ & 3.1 & 4.2 & - & 2.6 & 2.8 & - \\
\hline 1970 & $1,084.5$ & $1,075.9$ & 2.2 & 2.9 & - & 1.8 & 1.7 & - \\
\hline 1965 & 749.9 & 743.7 & 1.7 & 2.0 & - & 1.3 & 1.2 & - \\
\hline 1960 & 548.0 & 543.3 & 1.4 & 1.4 & - & 1.1 & 0.9 & - \\
\hline 1955 & 429.6 & 426.2 & 1.2 & 0.9 & - & 0.8 & 0.5 & - \\
\hline 1950 & 302.2 & 300.2 & 0.8 & 0.4 & - & 0.6 & 0.3 & - \\
\hline 1945 & 229.2 & 228.2 & 0.4 & 0.2 & - & 0.2 & 0.2 & - \\
\hline 1940 & 103.5 & 102.9 & 0.3 & 0.1 & - & 0.1 & 0.1 & - \\
\hline 1935 & 74.8 & 74.3 & 0.3 & 0.1 & - & 0.1 & 0.0 & - \\
\hline 1930 & 92.8 & 92.2 & 0.4 & 0.0 & - & 0.1 & 0.0 & - \\
\hline 1929 & 105.2 & 104.6 & 0.4 & 0.0 & - & 0.2 & 0.0 & - \\
\hline
\end{tabular}




\section{TABLE 4: Deflator for “Free" Content, 2009 Base Year}

\begin{tabular}{|c|c|c|c|c|c|c|c|c|c|}
\hline & \multirow[b]{2}{*}{$\begin{array}{l}\text { GDP + } \\
\text { "Free" }\end{array}$} & \multirow[b]{2}{*}{ BEA GDP } & \multicolumn{4}{|c|}{ Content Creation } & \multicolumn{3}{|c|}{ Viewership } \\
\hline & & & Combined & Print & $\mathrm{AV}$ & Digital & Print & $\mathrm{AV}$ & Digital \\
\hline 2015 & 109.6 & 110.0 & 86.3 & 114.6 & 98.4 & 65.7 & - & - & - \\
\hline 2014 & 108.4 & 108.8 & 88.2 & 111.9 & 97.9 & 70.1 & 99.7 & 130.4 & 109.4 \\
\hline 2013 & 106.6 & 106.9 & 90.0 & 109.6 & 97.7 & 74.5 & 94.7 & 123.1 & 110.1 \\
\hline 2012 & 105.0 & 105.2 & 92.1 & 107.2 & 98.0 & 79.2 & 96.8 & 122.5 & 116.0 \\
\hline 2011 & 103.2 & 103.3 & 94.1 & 104.1 & 97.6 & 85.0 & 103.7 & 115.1 & 112.9 \\
\hline 2010 & 101.2 & 101.2 & 97.1 & 102.3 & 98.8 & 91.9 & 104.5 & 111.4 & 95.6 \\
\hline 2009 & 100.0 & 100.0 & 100.0 & 100.0 & 100.0 & 100.0 & 100.0 & 100.0 & 100.0 \\
\hline 2008 & 99.3 & 99.2 & 102.5 & 96.6 & 99.8 & 111.1 & 137.4 & 106.9 & 106.2 \\
\hline 2007 & 97.4 & 97.3 & 104.5 & 92.9 & 99.2 & 123.5 & 142.0 & 107.4 & 114.1 \\
\hline 2006 & 95.0 & 94.8 & 105.9 & 90.2 & 97.5 & 137.6 & 135.6 & 104.7 & 107.0 \\
\hline 2005 & 92.2 & 92.0 & 107.7 & 87.3 & 96.8 & 154.9 & 129.8 & 101.3 & 106.8 \\
\hline 2004 & 89.4 & 89.1 & 109.7 & 84.6 & 96.6 & 174.7 & 126.3 & 102.4 & 94.4 \\
\hline 2003 & 87.0 & 86.7 & 111.1 & 82.3 & 96.5 & 193.2 & 127.5 & 99.0 & 93.2 \\
\hline 2002 & 85.4 & 85.0 & 113.0 & 80.1 & 96.6 & 217.1 & 120.9 & 98.4 & 98.9 \\
\hline 2001 & 84.1 & 83.8 & 115.0 & 78.1 & 96.2 & 249.1 & 114.1 & 92.4 & 121.8 \\
\hline 2000 & 82.3 & 81.9 & 117.4 & 76.5 & 95.9 & 289.3 & 115.3 & 100.2 & 152.4 \\
\hline 1999 & 80.5 & 80.1 & 118.4 & 75.0 & 94.9 & 322.7 & 106.7 & 91.7 & 182.2 \\
\hline 1998 & 79.3 & 78.9 & 120.5 & 73.2 & 94.3 & 383.6 & 98.8 & 83.7 & 221.6 \\
\hline 1997 & 78.5 & 78.0 & 123.6 & 71.7 & 95.4 & 475.3 & 89.6 & 75.6 & 187.3 \\
\hline 1996 & 77.2 & 76.7 & 123.7 & 70.0 & 95.2 & 577.5 & 78.3 & 71.0 & 187.6 \\
\hline 1995 & 75.8 & 75.3 & 121.2 & 67.5 & 93.5 & 708.0 & 72.6 & 64.5 & 77.1 \\
\hline 1994 & 74.3 & 73.8 & 118.0 & 64.4 & 92.2 & - & 63.5 & 57.5 & - \\
\hline 1993 & 72.7 & 72.2 & 114.9 & 62.2 & 90.1 & - & 57.7 & 54.1 & - \\
\hline 1992 & 71.0 & 70.6 & 113.6 & 60.7 & 89.8 & - & 51.0 & 55.7 & - \\
\hline 1991 & 69.5 & 69.0 & 112.0 & 58.9 & 89.6 & - & 48.9 & 53.6 & - \\
\hline 1990 & 67.2 & 66.8 & 107.9 & 56.5 & 86.5 & - & 48.1 & 58.1 & - \\
\hline 1985 & 57.6 & 57.2 & 90.8 & 45.6 & 74.9 & - & 34.4 & 41.1 & - \\
\hline 1980 & 44.6 & 44.4 & 66.0 & 30.7 & 57.4 & - & 20.4 & 23.1 & - \\
\hline 1975 & 31.6 & 31.4 & 51.2 & 21.4 & 48.2 & - & 10.9 & 12.3 & - \\
\hline 1970 & 22.9 & 22.8 & 40.0 & 16.2 & 38.7 & - & 7.9 & 10.7 & - \\
\hline 1965 & 18.8 & 18.7 & 32.8 & 13.4 & 31.6 & - & 6.5 & 8.9 & - \\
\hline 1960 & 17.6 & 17.5 & 30.5 & 13.1 & 27.8 & - & 5.2 & 7.4 & - \\
\hline 1955 & 15.7 & 15.6 & 26.5 & 11.2 & 24.5 & - & 3.7 & 6.8 & - \\
\hline 1950 & 13.8 & 13.7 & 23.5 & 9.7 & 22.8 & - & 2.6 & 8.5 & - \\
\hline 1945 & 10.4 & 10.3 & 18.1 & 7.5 & 17.7 & - & 1.4 & 8.0 & - \\
\hline 1940 & 8.2 & 8.1 & 15.1 & 6.4 & 13.9 & - & 1.6 & 5.2 & - \\
\hline 1935 & 8.0 & 7.9 & 14.6 & 6.2 & 13.7 & - & 1.6 & 4.3 & - \\
\hline 1930 & 9.6 & 9.5 & 16.8 & 7.1 & 16.5 & - & 1.8 & 2.8 & - \\
\hline 1929 & 10.0 & 9.9 & 17.3 & 7.3 & 16.9 & - & 2.0 & 4.3 & - \\
\hline
\end{tabular}


TABLE 5: GDP Quantity Indexes, 2009=100

\begin{tabular}{|c|c|c|c|c|c|c|c|c|c|c|}
\hline & \multirow[b]{2}{*}{$\begin{array}{l}\text { GDP+ } \\
\text { "Free" }\end{array}$} & \multirow{2}{*}{ BEA GDP } & \multicolumn{4}{|c|}{ Advertising-Supported Media } & \multicolumn{4}{|c|}{ Marketing-Supported Information } \\
\hline & & & Combined & Print & $\mathrm{AV}$ & Digital & Combined & Print & AV & Digital \\
\hline 2015 & 114.4 & 113.7 & 150.6 & 55.0 & 145.1 & 358.0 & 178.6 & 59.2 & 147.4 & 271.1 \\
\hline 2014 & 111.5 & 110.8 & 142.7 & 61.3 & 141.6 & 288.6 & 166.4 & 61.5 & 144.7 & 238.0 \\
\hline 2013 & 108.8 & 108.3 & 133.7 & 64.6 & 134.0 & 246.5 & 158.4 & 65.7 & 141.4 & 217.7 \\
\hline 2012 & 107.0 & 106.5 & 128.7 & 71.7 & 130.3 & 210.4 & 150.8 & 73.9 & 134.0 & 202.2 \\
\hline 2011 & 104.6 & 104.2 & 120.5 & 82.1 & 122.0 & 170.9 & 138.2 & 81.9 & 127.0 & 173.4 \\
\hline 2010 & 102.7 & 102.5 & 110.2 & 88.1 & 112.3 & 130.9 & 115.5 & 97.4 & 112.1 & 126.1 \\
\hline 2009 & 100.0 & 100.0 & 100.0 & 100.0 & 100.0 & 100.0 & 100.0 & 100.0 & 100.0 & 100.0 \\
\hline 2008 & 102.8 & 102.9 & 111.1 & 134.5 & 107.0 & 100.4 & 96.9 & 106.5 & 103.2 & 87.8 \\
\hline 2007 & 103.1 & 103.2 & 110.3 & 155.1 & 104.4 & 84.0 & 89.9 & 121.8 & 100.5 & 70.5 \\
\hline 2006 & 101.1 & 101.4 & 107.0 & 164.7 & 103.5 & 59.2 & 75.1 & 110.0 & 89.5 & 52.8 \\
\hline 2005 & 98.4 & 98.7 & 101.9 & 170.0 & 100.6 & 38.8 & 62.6 & 99.9 & 77.5 & 40.2 \\
\hline 2004 & 95.1 & 95.5 & 97.3 & 170.2 & 97.7 & 26.6 & 54.7 & 98.7 & 72.2 & 30.3 \\
\hline 2003 & 91.6 & 92.0 & 90.8 & 165.7 & 92.1 & 18.3 & 47.1 & 86.7 & 64.9 & 24.4 \\
\hline 2002 & 89.0 & 89.5 & 87.1 & 163.8 & 89.0 & 13.3 & 44.7 & 90.9 & 66.4 & 19.7 \\
\hline 2001 & 87.4 & 88.0 & 82.9 & 164.7 & 82.6 & 12.8 & 43.8 & 96.3 & 66.1 & 18.0 \\
\hline 2000 & 86.6 & 87.1 & 87.8 & 181.2 & 86.9 & 12.2 & 43.6 & 111.9 & 70.9 & 14.4 \\
\hline 1999 & 83.1 & 83.7 & 78.0 & 173.0 & 77.6 & 6.0 & 38.1 & 103.3 & 61.9 & 12.1 \\
\hline 1998 & 79.3 & 79.9 & 70.0 & 164.2 & 70.3 & 2.0 & 32.0 & 102.6 & 56.3 & 7.8 \\
\hline 1997 & 75.8 & 76.5 & 62.9 & 155.7 & 62.3 & 0.7 & 25.4 & 110.2 & 51.6 & 2.9 \\
\hline 1996 & 72.5 & 73.2 & 58.5 & 147.0 & 58.2 & 0.2 & 21.4 & 110.5 & 48.5 & 0.7 \\
\hline 1995 & 69.8 & 70.6 & 55.4 & 144.5 & 54.2 & 0.0 & 19.6 & 109.1 & 45.7 & 0.1 \\
\hline 1994 & 67.9 & 68.7 & 52.2 & 143.5 & 49.7 & 0.0 & 18.3 & 106.3 & 42.1 & 0.0 \\
\hline 1993 & 65.3 & 66.0 & 49.0 & 139.1 & 45.9 & 0.0 & 18.4 & 109.3 & 41.9 & 0.0 \\
\hline 1992 & 63.6 & 64.3 & 47.7 & 137.3 & 44.3 & 0.0 & 18.3 & 109.2 & 41.4 & 0.0 \\
\hline 1991 & 61.4 & 62.1 & 46.8 & 140.0 & 42.5 & 0.0 & 17.6 & 109.4 & 38.9 & 0.0 \\
\hline 1990 & 61.5 & 62.1 & 50.2 & 152.5 & 45.2 & 0.0 & 19.2 & 120.9 & 41.9 & 0.0 \\
\hline 1985 & 52.1 & 52.7 & 43.5 & 142.3 & 37.3 & 0.0 & 15.1 & 102.7 & 31.4 & 0.0 \\
\hline 1980 & 44.2 & 44.7 & 32.9 & 120.4 & 26.3 & 0.0 & 10.1 & 76.7 & 19.1 & 0.0 \\
\hline 1975 & 36.8 & 37.4 & 20.9 & 90.5 & 14.9 & 0.0 & 6.5 & 59.0 & 10.6 & 0.0 \\
\hline 1970 & 32.3 & 32.7 & 18.3 & 82.8 & 12.6 & 0.0 & 5.4 & 52.3 & 8.2 & 0.0 \\
\hline 1965 & 27.2 & 27.6 & 16.2 & 77.3 & 10.7 & 0.0 & 4.8 & 47.5 & 7.1 & 0.0 \\
\hline 1960 & 21.3 & 21.6 & 13.0 & 65.2 & 8.2 & 0.0 & 3.9 & 39.3 & 5.6 & 0.0 \\
\hline 1955 & 18.7 & 19.0 & 11.4 & 64.2 & 6.2 & 0.0 & 3.1 & 33.4 & 4.0 & 0.0 \\
\hline 1950 & 14.9 & 15.1 & 7.4 & 50.3 & 3.1 & 0.0 & 2.2 & 27.2 & 2.3 & 0.0 \\
\hline 1945 & 15.1 & 15.4 & 4.7 & 30.7 & 2.0 & 0.0 & 1.4 & 16.1 & 1.6 & 0.0 \\
\hline 1940 & 8.6 & 8.8 & 4.0 & 30.1 & 1.3 & 0.0 & 0.9 & 10.8 & 1.0 & 0.0 \\
\hline 1935 & 6.4 & 6.5 & 3.4 & 28.4 & 0.8 & 0.0 & 0.6 & 8.8 & 0.4 & 0.0 \\
\hline 1930 & 6.6 & 6.7 & 3.6 & 34.8 & 0.2 & 0.0 & 0.6 & 10.0 & 0.2 & 0.0 \\
\hline 1929 & 7.2 & 7.3 & 3.9 & 37.9 & 0.2 & 0.0 & 0.6 & 10.0 & 0.1 & 0.0 \\
\hline
\end{tabular}




\section{Appendix A: Primer on the Experimental Accounting for "Free” Content}

The basic premise of the economic accounting framework experimented with above is that values for "free" content can be imputed in the Input-Output tables based on the marketing expenditures that fund "free" content. Conceptually, the idea of imputing components of current production that are not paid out-of-pocket is not new to GDP accountants. The largest imputed estimate in the national income and product accounts is owner occupied housing services. Other examples include food furnished to employees and financial intermediation services indirectly measured (FISIM).

The purpose of this section is to provide details and discussion of the experimental accounting framework for "free" content and how it relates to the current treatment in BEA's accounts. We demonstrate our experimental approach to measuring advertising-supported media and marketingsupported information by presenting a series of input-output tables that include the pertinent transactions. An advantage of viewing this through the input-output accounts is that these accounts form the foundation both for measuring GDP by industry and also for measuring productivity at the industry level.

We begin with a stylized example with four sectors: a sector (C) that produces content (e.g. viral videos or television programs), a sector that produces advertising/marketing (AM), an everything else sector (EE), ${ }^{29}$ and a household viewership sector (HV). GDP is measured two equivalent ways: 1) the sales to final demand (FD) and 2) the sum of value added generated by industry. Value added is comprised of payments to factor services and taxes, but can be thought of as payments to labor services in this example.

We start with the case of direct sales of content to final demand, compare this to the case of "free" content under our current methodology and then proceed to "free" content under our experimental methodology. In all of our initial examples with "free" content, the full value of the content is supported by advertising/marketing, so that the viewer pays zero for the content. Partially supported content can be treated within the same framework, but the free information highlights the conceptual issues involved.

\section{Direct sales of content}

Table A1 depicts the input-output table for this stylized economy with direct sales of the information to final demand. Nominal GDP is $\$ 1,000$, comprised of $\$ 800$ of industry EE sales to final demand and $\$ 200$ sales of content directly to final demand. Total final sales equal $\$ 1,000$, the value added generated by the four sectors. In this economy, advertising is required to sell industry EE's output (Industry EE purchases $\$ 250$ worth of advertising services, think of this as direct mailings) and industry EE supplies $\$ 200$ worth of product used in producing the advertising. In this example, the $\$ 200$ of output of the content company $\mathrm{C}$ is sold directly to final demand. We imagine that this information comprises $\$ 100$ of print content, like recipes, and $\$ 100$ of digital content, like video games. The household viewership sector (HV) has no role in this economy.

\footnotetext{
${ }^{29}$ Companies sometimes produce market-supported information entirely in-house. As a result, the current inputoutput tables will not show any flow of either marketing or information. But this stylized example shows separate industries in order to make the accounting easier to follow.
} 
Table A1.

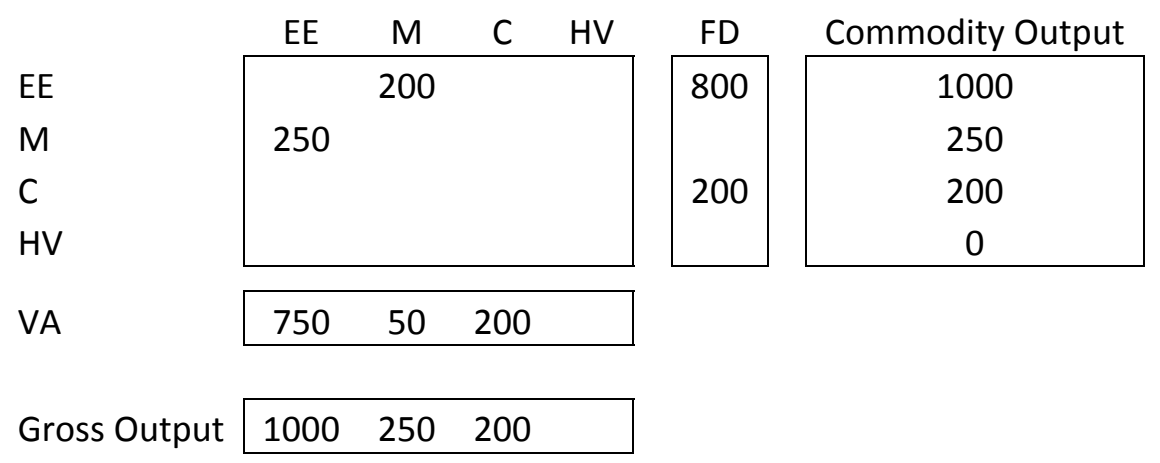

\section{Current treatment of "Free" Content}

To produce an input-output table with "free" content, we impose the following assumptions. First, actual consumption of the output of industry EE is unchanged from the case of direct sales. Second, real consumption and the price of digital content is unchanged from the case of direct sales. Third, by substituting the direct mailing with content-based marketing. industry EE is able to save on labor dollar for dollar. ${ }^{30}$ In this example, we imagine print content is used to distribute marketing, but the two are basically equivalent in this stylized model.

Table A2 lays out an example of an economy with "free" content and demonstrates some of the measurement drawbacks of the current approach to accounting for content's role in the economy. ${ }^{31}$ Because the consumer values this print content at $\$ 100$, the $M$ industry must pay the content company at least $\$ 100$ for the content company to be willing to make the content free to consumers. We assume that the $M$ industry pays exactly $\$ 100$. In this economy, industry EE switches between direct marketing and marketing bundled with the print content. For this privilege, industry EE pays $M \$ 350$, reflecting the value of the content and other marketing-related services. The viewership sector has no explicit role in this representation, even though the $M$ sector is implicitly serving as an intermediary in delivering viewership to sector EE.

\footnotetext{
${ }^{30}$ This precise assumption is made for modeling convenience. It ensures that GDP prices remain fixed. This may seem like a strong assumption, and it is, but it is relatively innocuous since the pertinent comparison is between the current treatment "free" content and our proposed treatment with the barter transaction. When comparing those two approaches, we need not make this assumption. We impose this here to make a broad comparison between how the input-output accounts would look with direct sales of content to make the point that the value of the content to the consumer must be bid away. We do not make use of any evidence to tell us how industries adjust when with the introduction of "free" content. We could have alternatively chosen to allow the value of the output of industry EE to increase, for example.

${ }^{31}$ We do not consider the underlying reason for the advertising/marketing supported approach to selling content or the role of content in selling industry output, but our approach allows for it to be used as a productive input.
} 
Table A2.

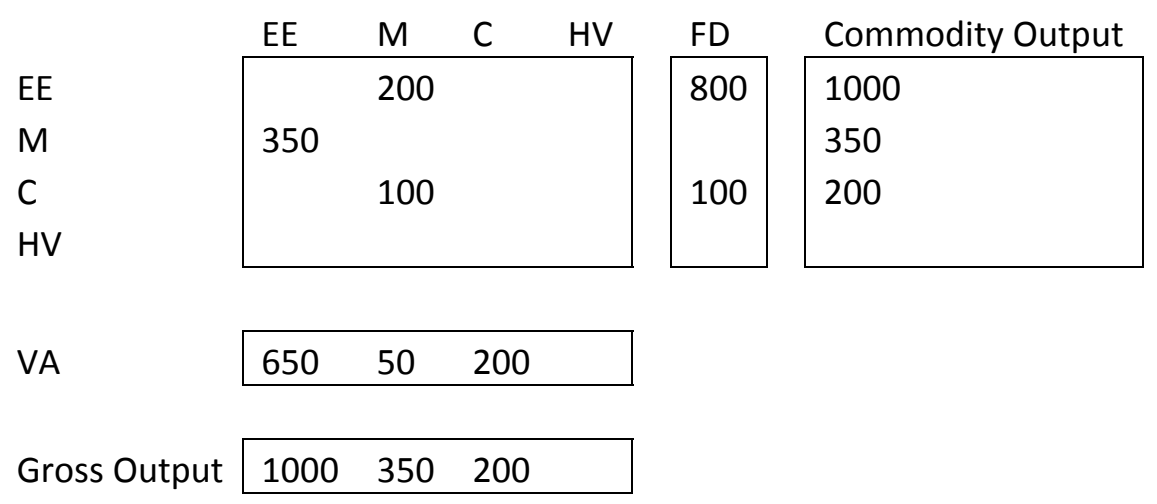

It is worthwhile to compare the aggregate economy measured in Table A1 to Table A2 even though this comparison embeds the assumptions imposed above. Imposing fixed prices allows for an easy comparison of aggregate nominal and real GDP. By assumption, the "free" content does not increase the final sales of industry $E E$, thus consumption of industry EE's output is unchanged from the example of direct sales. Similarly, the consumption of digital content and its price is the same. It is obvious from Table A2 that real measured GDP is lower than the economy measured in Table A1 because the same quantity of industry EE output is consumed, while only the digital content measured in final consumption. Under this set of assumptions, the consumer is indifferent between the economy in Table $A 1$ and $A 2$ (the same level of real consumption) and real production measured from final demand is the same, but measured GDP is lower. This is the crux of the measurement issue.

\section{Content consumption as a barter transaction}

Our experimental treatment recognizes the barter transaction that is implicit in the above example of advertising-supported media or marketing-supported information. The role of our imputed barter transaction is highlighted in Table A3. One way to think about the exchange is that the consumer was spending $\$ 100$ for the print content (the direct sales case), but the current accounting does not capture this. Thus, we impute $\$ 100$ to consumption of the content, which in this case is provided by the $M$ industry to final consumers. How does the consumer fund this consumption? This $\$ 100$ of consumption is funded by an implicit payment from the $M$ industry, which in exchange for this payment gets exposure to the household viewership sector (people watching advertising/marketing). Thus, the $M$ sector generates "free" content (to be viewed by the household viewership sector) in addition to primary marketing services (which are purchased by the EE sector). Finally, the household viewership sector produces viewership output. Note that the digital content still is sold directly to consumers in this example. 
Table A3.

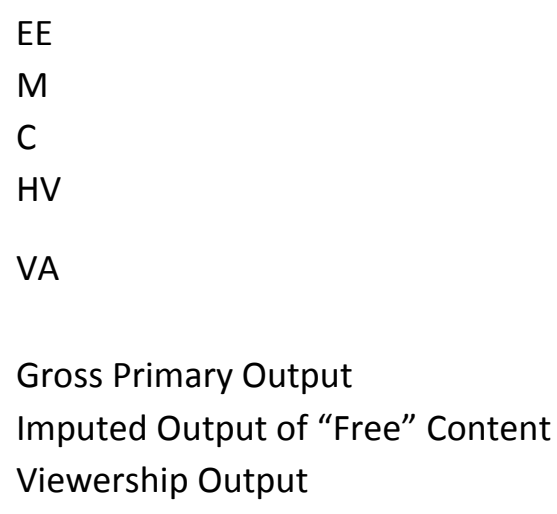

\begin{tabular}{|llll|}
\multicolumn{1}{|l}{ EE } & M & C & HV \\
\hline & 200 & & \\
350 & & & \\
& 100 & & \\
& 100 & & \\
\hline 650 & 50 & 200 & 100 \\
\hline & & & \\
\hline 1000 & 350 & 200 & \\
& 100 & & \\
& & & 100 \\
\hline
\end{tabular}

A complementary interpretation of the barter transaction in Table A3 is that the M industry needs to deliver viewership to the EE industry. To deliver this viewership, the $M$ industry must compensate the HV sector. In this framework, the $M$ industry compensates the viewership sector exactly the amount that the viewer is willing to pay for the content.

At this point, we highlight that in our application we do not observe the amount that the consumer is willing to pay for the information if it was sold directly. To estimate these values, we use observed advertising revenue and imputed marketing output. That is, we use observations on the output of the advertising/marketing industry (the $\$ 350$ in Table A3) to estimate the value of content to consumers and use this estimate as the value of the barter transaction. It is instructive to compare the measurement framework with the imputed barter transaction to the current treatment. First, value added across the private industries is the same in the two treatments. The implication of this is that the additional imputed consumption is balanced by the additional value added produced by the viewership sector.

It is immediately apparent that conditional on the assumptions listed above, our experimental approach produces the same nominal and real GDP as would have occurred under the direct sales model. This is the fundamental justification for our experimental approach. Conceptually, we believe that "free" content is a very close substitute for directly purchased content, so the two content types should be handled similarly in the national income and product accounts. Under the current GDP formula, "free" content is entirely excluded from final expenditures and contributes to GDP only indirectly. In contrast, our experimental approach includes both directly purchased content and also "free" content in final expenditures. Furthermore, we argue that this is a useful feature since a significant portion of content consumed is through "free" content.

\section{Viewership sector as part of the broader household sector}

In these stylized examples, and in the analysis in the main text, we have introduced a viewership sector that is beyond the scope of BEA's current set of economic accounts. To minimize the deviation of our analysis from BEA's official accounts, we do not consider the production process for this viewership. Presumably, viewership requires capital inputs, such as a television, a mobile phone, or a kitchen table to read the magazine. On the other hand, we do impose the assumption that intermediate inputs are 
minimal, so gross output is equal to value added. Measuring the output and inputs of this process is entangled with measuring overall household production and productivity in the household sector. We intentionally avoid this due to the plethora of issues involved in measuring household production. Our estimates of TFP at the industry level, however, are separable from measuring the inputs to household viewership, thus our focus is on the role of "free" content in industry TFP measurement.

\section{Content Use by Business}

Our examples in Tables A1-A3 assumed that information content was valuable only to consumers. Tables A4-A6 revisit the same conceptual issues when the content is valuable to business. In Table A4, the content produced by industry I is purchased directly by industry EE. To clarify, we imagine a situation where the content itself is directly relevant to the production process of industry EE, for example an accounting manual for a financial industry, or cooking apps for a restaurant. This is distinct from the case above where the industry only valued the content as a conduit to reach marketing viewers. Just like the earlier consumer entertainment example, businesses provide viewership in return for information content.

Table A4.

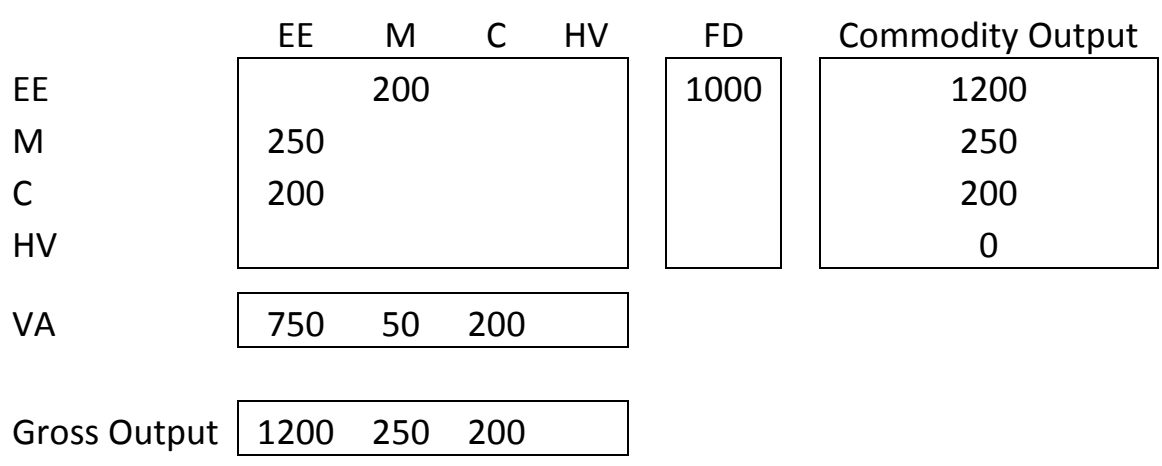

In this example economy with direct sales of information to business, nominal GDP is $\$ 1,000$. Like the case above, industry EE requires $\$ 250$ worth of marketing to sell its output and the content producer makes $\$ 200$ worth of content. Unlike the case above, this content is purchased as an intermediate input into the production of $\mathrm{EE}$.

Table A5 provides a demonstration of what happens to the 10 account with "free" content. Again, we imagine that $\$ 100$ of content is provided by the $C$ industry, and as above whether it is the digital or print content, the input-output accounting is the same. In this case, the industry EE values the information at $\$ 100$ so the $M$ industry must pay the content producer, $C, \$ 100$ to bid this away. Given the value of the "free" content embedded in the marketing services produced by the $M$ industry, industry EE pays the marketing industry $\$ 350$ for the marketing services including the "free" content. Under this model, industry EE is indifferent between the direct sales model and the "free" content because it receives the same quantity of intermediate inputs for the same prices as under the direct sales. Because content is used as an intermediate input, aggregate GDP is unchanged with the "free" content model in comparison to the case where the content is purchased directly as an intermediate input. 
Table A5.

\begin{tabular}{|c|c|c|c|c|}
\hline & $\mathrm{EE}$ & $\mathrm{M}$ & $\mathrm{C}$ & $\mathrm{HV}$ \\
\hline $\mathrm{EE}$ & & 200 & & \\
\hline$M$ & 350 & & & \\
\hline C & 100 & 100 & & \\
\hline HV & & & & \\
\hline VA & 750 & 50 & 200 & \\
\hline ross Output & 1200 & 350 & 200 & \\
\hline
\end{tabular}

\begin{tabular}{|c|c|}
\multicolumn{1}{c|}{ FD } & Commodity Output \\
\hline 1000 & 1200 \\
& 350 \\
& 200 \\
& \\
\hline
\end{tabular}

Like the case with "free" content consumed by households, the advertising/marketingsupported content model leaves out the implicit transaction between the viewer and producer of the marketing. Table A6 highlights these barter transactions. In this case, industry EE produces viewership in addition to its primary output. Like in the case of consumers, the $M$ industry implicitly compensates the viewers $\$ 100$, which funds the business consumption of "free" content in sector EE. The $M$ industry has $\$ 100$ of imputed output of "free" content, so that a total of $\$ 450$ of input from the $M$ industry is purchased by industry EE. The intuition for this is that the since industry M paid $\$ 100$ to obtain the rights to use the content, this must be worth at least $\$ 100$ to the $M$ industry. This value accounts for an implicit payment that must be made to the viewers of the marketing. The account in Table A6 makes this payment explicit and produces an internally consistent accounting for "free" content that reflects both the recorded and implicit payments for the content as an output and an input. ${ }^{32}$

Table A6.

\begin{tabular}{|c|c|c|c|c|}
\hline & $\mathrm{EE}$ & $M$ & C & HV \\
\hline $\mathrm{EE}$ & & \multicolumn{3}{|l|}{200} \\
\hline$M$ & 450 & & & \\
\hline C & \multirow[t]{2}{*}{100} & 100 & & \\
\hline HV & & 100 & & \\
\hline VA & 750 & 50 & 200 & \\
\hline \multirow{3}{*}{$\begin{array}{l}\text { Gross Primary Output } \\
\text { Imputed Output of "Free" Content } \\
\text { Viewership Output }\end{array}$} & \multirow[t]{2}{*}{1200} & 350 & \multirow{3}{*}{\multicolumn{2}{|c|}{200}} \\
\hline & & 100 & & \\
\hline & 100 & & & \\
\hline
\end{tabular}

\footnotetext{
32 The household viewership sector is uninvolved in this example. The payment for viewership goes to the business sector, which produces viewership as a secondary product. Thus, there is no entry in value added for HV.
} 


\section{Industry and Aggregate Productivity measurement with our Experimental Approach}

Given our reconstructed input-output table, measures of industry growth and productivity that reflect our experimental approach are relatively straightforward. Productivity measures require prices and quantities for the outputs and inputs of each sector. Productivity growth is defined as the growth rate of the ratio of the output quantity index to the input quantity index.

On the output side of each industry's production account there potentially six new outputs discussed in the main text: 1) "free" print content; 2) "free" audio-visual content; 3) "free" digital content; 4) print viewership; 5) audio-visual viewership; 6) online viewership. We construct new measures of the price and quantity of industry output as the Tornqvist index of the original industry output with these six new outputs. Data for the prices and quantities for each of these is described in the body of the paper and Appendix B.

At first glance, it seems surprising create so many new outputs for each industry. In fact, having a single industry produce multiple outputs is common in productivity measures. The official BEA-BLS integrated industry-level accounts employs this approach and industries are classified by their primary production. When a single industry produces multiple outputs in the official BEA accounts, industry output growth is a chained index over multiple outputs. On the input side of the production account, each industry has these same six potentially new inputs.

We reiterate that by construction the nominal value of new outputs equals the nominal value of new inputs by industry. However, the price of each of these is different on the output side and the input side of the account, thus the barter transaction has implications for measured industry TFP. The government and viewership sectors complicate aggregation across industries. Thus, we focus on the measured productivity impact on the private economy.

\section{Free information in the 200710 accounts}

Table A7 demonstrates how the barter transactions impact the 2007 BEA input output table (modified to include a viewership sector) for fifteen broad sectors that encompass U.S. GDP. We reiterate that the starting point for these values is data on marketing expenditures. In the main text and Appendix B, we describe how we estimate the value of each form of information embedded in marketing viewership.

Table A7a shows the production and use of marketing-supported information content, that is, our estimate of the value of information content embedded in marketing expenditures. In 2007, print, audio-visual and online content combined for $\$ 300$ billion in content. We estimate that $\$ 228$ billion accrued to the household viewership sector. The remainder of the value was used by U.S. businesses and government. To be clear, by construction, the sum of the value added generated by the viewership sector plus the intermediate use of the content equals the estimated value of "free" content. Table A7b highlights that the value of "free" content equals the value of viewership output across the economy, that is, the total value of output from viewership across all sectors equals the value of "free" content. The table makes it clear that within industries, the value of content being used equals the secondary production value of viewership. 
Table A7a

\begin{tabular}{|c|c|c|c|c|c|c|c|c|c|c|c|c|c|c|c|c|}
\hline Commodities/Industries & 11 & 21 & 22 & 23 & $31 G$ & 42 & $\begin{array}{c}\mathbf{4 4 R} \\
\mathbf{T}\end{array}$ & $\begin{array}{l}48 T \\
W\end{array}$ & 51 & FIRE & $\begin{array}{l}\text { PRO } \\
\text { F }\end{array}$ & 6 & 7 & 81 & $\mathbf{G}$ & HV \\
\hline $\begin{array}{l}\text { 11: Agriculture, forestry, fishing, and } \\
\text { hunting }\end{array}$ & .71 .1 & 0.1 & 0.0 & 1.7 & 202.9 & 1.5 & 1.6 & 0.1 & 0.0 & 0.0 & 1.1 & 0.5 & 5.7 & 0.1 & 1.8 & \\
\hline 21: Mining & 2.1 & 54.7 & 74.7 & 12.3 & 422.2 & 0.1 & 0.2 & 4.6 & 0.3 & 4.8 & 1.3 & 0.6 & 1.3 & 0.5 & 18.6 & \\
\hline 22: Utilities & 5.2 & 4.9 & 5.2 & 3.3 & 80.2 & 6.9 & 16.1 & 6.4 & 3.8 & 80.7 & 11.5 & 19.8 & 15.3 & 4.3 & 26.5 & \\
\hline 23: Construction & 2.3 & 7.2 & 7.4 & 0.2 & 13.9 & 1.5 & 2.9 & 4.3 & 2.2 & 111.5 & 2.1 & 2.2 & 2.5 & 3.0 & 57.0 & \\
\hline 31G: Manufacturing & 70.6 & 37.2 & 31.5 & 364.0 & 1897 & 40.7 & 44.7 & 162.0 & 82.3 & 82.5 & 131.1 & 149.5 & 119 & 47.6 & 337.1 & \\
\hline 42: Wholesale trade & 21.6 & 5.7 & 5.2 & 51.0 & 257.3 & 28.0 & 17.0 & 22.0 & 12.9 & 11.6 & 17.8 & 31.7 & 16.7 & 7.0 & 37.0 & \\
\hline 44RT: Retail trade & 0.2 & 0.2 & 0.5 & 76.8 & 11.4 & 0.6 & 5.0 & 4.2 & 0.3 & 7.4 & 2.0 & 1.0 & 6.2 & 4.1 & 0.5 & \\
\hline 48TW: Transportation and warehousing & 10.3 & 9.0 & 23.1 & 21.4 & 123.2 & 46.4 & 54.7 & 93.8 & 16.6 & 28.1 & 35.2 & 16.2 & 11.0 & 4.2 & 48.8 & \\
\hline 51: Information & 0.4 & 0.9 & 2.1 & 3.8 & 22.8 & 12.2 & 13.3 & 5.4 & 164.4 & 65.0 & 56.2 & 22.6 & 9.2 & 8.1 & 72.3 & \\
\hline $\begin{array}{l}\text { FIRE: Finance, insurance, real estate, } \\
\text { rental, and leasing }\end{array}$ & 15.5 & 13.8 & 19.4 & 29.2 & 92.6 & 92.6 & 140.9 & 76.8 & 61.3 & 928.5 & 222.6 & 231.9 & 83.5 & 80.2 & 1115.6 & \\
\hline $\begin{array}{l}\text { PROF: Professional and business } \\
\text { services }\end{array}$ & 4.2 & 22.7 & 28.5 & 44.0 & 339.6 & 146.0 & 124.0 & 51.0 & 124.2 & 420.3 & 419.0 & 166.2 & 106 & 31.9 & 254.2 & \\
\hline $\begin{array}{l}\text { 6: Educ. services, health care, and social } \\
\text { assist. }\end{array}$ & 0.2 & 0.0 & 0.1 & 0.0 & 0.1 & 0.5 & 2.2 & 0.1 & 0.2 & 0.1 & 0.5 & 20.4 & 1.3 & 1.5 & 13.8 & \\
\hline $\begin{array}{l}\text { 7: Arts, entertain., rec., accomm.., and } \\
\text { food service }\end{array}$ & 0.4 & 0.6 & 3.6 & 2.1 & 15.5 & 5.1 & 3.7 & 3.2 & 26.4 & 45.7 & 45.6 & 19.3 & 22.0 & 2.9 & 26.5 & \\
\hline 81: Other services, except government & 0.8 & 0.5 & 1.0 & 4.4 & 16.1 & 15.0 & 10.5 & 4.8 & 7.7 & 30.3 & 27.2 & 22.5 & 10.3 & 6.1 & 23.4 & \\
\hline G: Government & 0.1 & 0.0 & 0.8 & 0.0 & 5.2 & 11.5 & 6.4 & 18.7 & 3.7 & 9.2 & 8.7 & 5.7 & 6.1 & 1.8 & 8.1 & \\
\hline Original Intermediate & 205 & 157 & 203 & 614.4 & 3500 & 409 & 443 & 457 & 506 & 1826 & 982.0 & 710 & 416 & 203 & 1041 & \\
\hline "Free” Print Content & 0.3 & 0.5 & 0.7 & 3.4 & 4.8 & 3.3 & 2.1 & 1.7 & 3.3 & 21.9 & 10.3 & 5.3 & 2.2 & 1.8 & 5.8 & \\
\hline "Free" Audio-Visual Content & 0.1 & 0.0 & 0.0 & 0.1 & 0.6 & 0.0 & 0.1 & 0.1 & 0.0 & 4.3 & 0.0 & 0.0 & 0.0 & 0.0 & 0.0 & \\
\hline "Free” Digital Content & 0.0 & 0.0 & 0.0 & 0.1 & 0.1 & 0.1 & 0.1 & 0.0 & 0.1 & 0.3 & 0.3 & 0.1 & 0.1 & 0.0 & 0.2 & \\
\hline Print Viewership & 0.4 & 0.2 & 1.2 & 0.7 & 7.5 & 6.4 & 4.5 & 0.8 & 75.5 & 12.1 & 43.8 & 5.1 & 2.9 & 0.4 & 0.0 & \\
\hline Audio-Visual Viewership & 0.2 & 0.1 & 0.5 & 0.3 & 3.7 & 3.8 & 2.5 & 0.4 & 2.7 & 5.2 & 21.4 & 2.2 & 1.4 & 0.2 & 0.0 & \\
\hline Online Viewership & 0.4 & 0.7 & 2.1 & 1.1 & 12.2 & 14.2 & 3.7 & 2.1 & 38.0 & 7.5 & 60.0 & 6.1 & 0.6 & 0.8 & 0.0 & \\
\hline Total Intermediate & 206.4 & 158.5 & 207.6 & 620.2 & 3529 & 436.9 & 456.0 & 462.1 & 625.6 & 1877.2 & 1117.8 & 728.9 & 423.2 & 206.3 & 1046.9 & \\
\hline V001: Compensation of employees & 41.5 & 62.7 & 63.1 & 439.8 & 944.4 & 429.2 & 506.1 & 255.8 & 260.4 & 730.0 & 1183.3 & 895.8 & 324.7 & 231.1 & 1541.0 & \\
\hline $\begin{array}{l}\text { V002: Taxes on production and imports, } \\
\text { less subsidies }\end{array}$ & -2.5 & 33.6 & 54.6 & 7.9 & 60.2 & 175.3 & 184.3 & 24.6 & 43.1 & 247.9 & 49.8 & 32.0 & 70.5 & 17.3 & -18.7 & \\
\hline V003: Gross operating surplus & 103.0 & 217.7 & 117.4 & 267.3 & 849.7 & 256.3 & 187.2 & 129.1 & 398.8 & 1899.2 & 424.1 & 136.8 & 137.0 & 82.1 & 382.9 & \\
\hline Total Value Added & 142.0 & 314.0 & 235.1 & 715.0 & 1854.3 & 860.8 & 877.6 & 409.6 & 702.4 & 2877.1 & 1657.2 & 1064.6 & 532.1 & 330.5 & 1905.2 & \\
\hline
\end{tabular}


Table A7b

\begin{tabular}{|c|c|c|c|c|c|c|c|c|c|c|c|c|c|c|c|c|}
\hline Commodities/Industries & 11 & 21 & 22 & 23 & $31 G$ & 42 & $\begin{array}{c}44 R \\
T\end{array}$ & $\begin{array}{l}48 T \\
W\end{array}$ & 51 & FIRE & $\begin{array}{c}\text { PRO } \\
\text { F }\end{array}$ & 6 & 7 & 81 & $\mathbf{G}$ & HV \\
\hline Original Industry Output & 346.9 & 471.4 & 438.2 & 1329.4 & 5354.4 & 1269.5 & 1320.7 & 866.9 & 1208.6 & 4702.8 & 2639.2 & 1774.7 & 948.0 & 533.8 & 2946.7 & \\
\hline \multicolumn{17}{|l|}{ Media Related Output } \\
\hline "Free" Print Content & 0.4 & 0.2 & 1.2 & 0.7 & 7.5 & 6.4 & 4.5 & 0.8 & 75.5 & 12.1 & 43.8 & 5.1 & 2.9 & 0.4 & 0.0 & \\
\hline "Free" Audio-Visual Content & 0.2 & 0.1 & 0.5 & 0.3 & 3.7 & 3.8 & 2.5 & 0.4 & 2.7 & 5.2 & 21.4 & 2.2 & 1.4 & 0.2 & 0.0 & \\
\hline "Free" Digital Content & 0.4 & 0.7 & 2.1 & 1.1 & 12.2 & 14.2 & 3.7 & 2.1 & 38.0 & 7.5 & 60.0 & 6.1 & 0.6 & 0.8 & 0.0 & \\
\hline Print Viewership & 0.3 & 0.5 & 0.7 & 3.4 & 4.8 & 3.3 & 2.1 & 1.7 & 3.3 & 21.9 & 10.3 & 5.3 & 2.2 & 1.8 & 5.8 & 94.3 \\
\hline Audio-Visual Viewership & 0.1 & 0.0 & 0.0 & 0.1 & 0.6 & 0.0 & 0.1 & 0.1 & 0.0 & 4.3 & 0.0 & 0.0 & 0.0 & 0.0 & 0.0 & 151.8 \\
\hline Online Viewership & 0.0 & 0.0 & 0.0 & 0.1 & 0.1 & 0.1 & 0.1 & 0.0 & 0.1 & 0.3 & 0.3 & 0.1 & 0.1 & 0.0 & 0.2 & 148.0 \\
\hline Total Industry Output & 348.4 & 473.0 & 443.4 & 1335.8 & 5386.0 & 1299.3 & 1335.1 & 872.3 & 1414.9 & 4759.4 & 2791.9 & 1796.3 & 956.5 & 537.4 & 2953.4 & 394.1 \\
\hline
\end{tabular}




\section{Appendix B: Detailed Discussion of Datasets Used}

The line between advertising-supported media and marketing-supported information is often very thin. Media companies frequently collaborate with marketers to produce content. Furthermore, the jointly produced content is sometimes published without fully informing users of its funding. In this paper, we will use the Economic Census's industry classifications to distinguish between the categories in our discussion. "Free" content produced by the information sector (NAICS 51) is considered advertising-supported media and "free" content produced by the rest of the private business sector is considered marketing-supported information. Both advertising-supported media and marketingsupported information have the same impact on final output, so measured GDP does not depend on how we classify an item.

It is common for sellers to bundle information with a purchased good or service without charging separately for the information. For example, electronics generally come with a detailed manual that helps new owners set up and use the product. The value of this manual is already counted in the price of the electronics and so it would be double-counted if we included it in "free" content as well. The crucial distinction between "free" content and bundled information is that advertisingsupported media and marketing-supported information are both available without any purchase requirement. For example, General Mills provides recipes to the general public at BettyCrocker.com and these recipes work for any brand of flour. In contrast, many software and electronics companies restrict their product upgrades and telephone support to individuals with proof of purchase.

\section{Nominal Expenditures on Advertising-Supported Media, 1929-2015}

Our primary dataset is the 2012 Economic Census. All of the numbers reported in this paper are benchmarked to that Census. The 2012 Economic Census reports advertising revenue for newspaper publishers (NAICS 51111), magazine publishers (NAICS 51112), directory publishers (NAICS 51114), radio broadcasters (NAICS 51511), television broadcasters (NAICS 51512), cable networks (NAICS 5152) and Internet publishers (NAICS 516 in 2002 and 51913 in 2007 and 2012). We also use the 2002 and 2007 Economic Censuses to get advertising revenue by industry for those years.

For print media, our historical data are mostly taken from the Coen Structured Advertising Expenditure Dataset (Galbi 2008). That dataset tracks newspaper and directory advertising consistently back to 1919, so we use the dataset without adjustment. The CS Ad Expenditure Dataset is available for public use online ${ }^{33}$ and was also published periodically in the Statistical Abstract of the United States. Unfortunately, the CS Ad Expenditure Dataset does not track magazine advertising consistently. So, we used the Service Annual Survey (SAS) as a proxy from 2005 until 2013 and the Economic Census as a proxy from 1947 until 2005. We use the CS Ad Expenditure Dataset before 1947 and as an interpolator between Economic Census years.

For radio, we use a variety of sources. The SAS reports radio advertising revenue back to 1998 and the Communications Survey reports radio advertising revenue from 1989 to 1998 . Between 1935 and 1988, we use the broadcast radio revenue reported periodically in the Statistical Abstract of the United States. ${ }^{34}$ Finally, we use the CS Ad Expenditure dataset to track revenue from 1929 until 1934.

\footnotetext{
${ }^{33}$ https://www.purplemotes.net/2008/09/14/us-advertising-expenditure-data/

${ }^{34}$ This volume was also called the Historical Statistics. Much of our data is taken from the volume 'Historical Statistics of the United States: Colonial Times Until 1970'
} 
For television, the SAS provides our time series from 2011 onwards. Before 2011, we use data collected earlier for a previous paper on long-lived television programs (Soloveichik 2013b). Unlike the print media and radio, advertising-supported television shows up in two NAICS codes: 5151 for broadcast television and 5152 for cable television. We add the two categories of television advertising to get total advertising.

For Internet publishing, we use the Internet Advertising Bureau (IAB) as a proxy. Since 1996, that organization has estimated Internet advertising revenue and published their results online. ${ }^{35}$ Internet advertising was very small in 1996, and so little data exists before then. We assume that Internet advertising was negligible and grew 240 percent from 1995 to 1996 and was negligible before then.

The datasets listed above all track production, not consumption. We were not able to find any data on exports or imports of advertising-supported media. We believe that virtually all print newspapers, magazines, radio and television are consumed domestically, so there is no effect on the balance of payments from those media categories. ${ }^{36}$ The situation for online media is much more complicated. Unlike the other media categories, individuals in one country can easily view foreign websites. In theory, our experimental methodology requires that Internet use by foreigners should be treated as an export of advertising-supported media content and an import of advertising viewership. By construction, the nominal export value of media content equals the nominal import value of advertising viewership - and so advertising revenue earned from foreign Internet users does not increase nominal GDP. Conversely, nominal GDP rises if US residents view foreign websites even if the associated advertising revenue is not tracked in the US Economic Census. We were not able to find any data on net exports of online media. For simplicity, our current calculations assume that imports are precisely equal to exports and therefore net exports are zero.

\section{Advertising-Supported Media By Category, 1929-2015}

Before the Internet, the mapping between media categories and industries was straightforward: publishers (NAICS 511) produced print media and networks (NAICS 5151 and 5152) produced audiovisual media. The Internet makes the situation more complicated. The majority of online media is produced by Internet-only publishers like Google or Yahoo (NAICS 519). However, print media publishers also produce online content like digital news stories or blogs. Conversely, Internet publishers like Youtube or Castbox host audio-visual content. ${ }^{38}$ Unfortunately, the 2012 Economic Census does not report online advertising revenue for print publishers or video revenue for Internet publishers. The only data tracked are total advertising revenue for each industry. So, we are forced to use a variety of private datasets to split media by industry.

To start out, we estimate the digital content produced by publishers. Between 2001 and 2004, the SAS tracked online advertising revenue for publishers. Accordingly, it is straightforward to calculate digital advertising in those years. After 2005, we are forced to use a variety of proxies. For newspapers,

\footnotetext{
${ }^{35}$ https://www.iab.com/insights/iab-internet-advertising-revenue-report-conducted-by-pricewaterhousecooperspwc-2/

${ }^{36}$ In many cases, the domestic media company buys content from foreign media companies or sells its content abroad. These transactions are already tracked as imports and exports in the Balance of Payments account. One might think that the U.S. exports far more online media than it imports. After all, the U.S. is a world leader in online media technology. However, most large Internet companies have foreign branches which handle their non U.S. customers. Only small websites are likely to have foreign viewers coming directly.

${ }^{38}$ Many of the YouTube networks earn minimal advertising revenue. Nevertheless, we include them in advertisingsupported media if the producers aspire to earn advertising revenue eventually.
} 
the Newspaper Association of America (NAA) published estimates of print advertising and digital advertising from 2003 until 2012. From 2012 onwards, the Pew Research Center has published a fact sheet reporting digital advertising for a selection of publicly traded newspapers. Based on those two sources, we are able to estimate the digital share of newspaper advertising relatively precisely. We were not able to find similar data on magazines or directories, but the Service Annual Survey does track the share of overall revenue earned online from 2005 until 2012. We use this overall digital share as a proxy for the digital share of advertising. After 2012, we use digital newspaper advertising as a proxy for digital magazine and director advertising revenue. Based on all of these sources, we calculate that the online advertising share grew from 2 percent in 2001 to more than 10 percent in 2015 . As a result, print advertising revenue has been falling even faster than overall advertising revenue for the publishing industry.

Next, we estimate the audio-visual content produced by Internet publishers. Our main dataset is from the Internet Advertising Bureau. Since 2008, they have tracked the share of online advertising attributed to digital video. ${ }^{39}$ We supplement this with estimates of digital radio advertising provided by XAPPMedia for 2014 and 2015. Before 2014, we use XAPPMedia's estimate of digital radio listening time as a proxy for digital advertising revenue. ${ }^{40}$ Based on all of these sources, we calculate that the audio-visual advertising share grew from 4 percent in 2008 to nearly 14 percent in 2015. As a result, the explosive growth in Internet publishing revenue slightly overstates the true growth in digital content. ${ }^{41}$ In other words, some Internet advertising is really just people canceling their cable subscription and watching the same shows online. This digital delivery of audio-visual content may offer valuable convenience to viewers - but it probably doesn't create nearly as much consumer surplus as entirely new products like Internet search.

\section{Nominal Opportunity Costs of In-House Advertising, 1929-2015}

Our data are taken from a variety of industry sources. For newspapers and magazines, we rely on the Pew article "Digital Advertising and News" (Matsa, Olmstead, Mitchell and Rosenstiel 2012), which estimated that 9-10 percent of print advertising is promoting the newspaper or magazine. For cable television, we used data from Kantar Media that directly tracks own-account television advertising time from 1995 to 2010. Those data are described in much more detail in a previous paper "Long-Lived Television Originals as Capital Assets" (Soloveichik 2013b). For theatric movie trailers, we rely on the NPR article "Theaters and Studios Squabble Over Shortening Movie Trailers" (Holmes 2013). That article does not give a precise value for movie trailers, but it estimates they average 20 minutes per movie. If a typical movie is 2 hours, then movie trailers account for approximately 14 percent of active theater time. For freemium games, we rely on two separate news articles: "Here's How Much You Spend on Iphone Apps Each Year" (Reisinger 2016) and "iOS App Store Brings in 75\% More Revenue than Play Store Despite Difference in Downloads" (Miller 2016) to estimate total expenditures by US consumers on freemium games in 2015. We were not able to find any articles that track US expenditures over time, but the article "App Revenue Statistics" (Dogtiev 2017) gives global expenditures on in-app purchases from 2011 onwards. We use those global revenues as a proxy for US freemium game revenue.

\footnotetext{
${ }^{39}$ Their digital video statistics do not include mobile video. We assume that mobile advertising has the same video share as desktop advertising.

${ }^{40} \mathrm{http}: / / x a p p m e d i a . c o m / w p-c o n t e n t / u p l o a d s / 2015 / 01 / I n t e r n e t-R a d i o-T r e n d s-R e p o r t-2015$ january.pdf

${ }^{41}$ Conversely, radio networks and television networks earn approximately 1 percent of their advertising revenue from online content. This revenue source is too small to affect results much.
} 
We only count a portion of in-house ads in our category of opportunity cost advertising. Broadcast radio and online search engines both earn the vast majority of their revenue from paid advertising. If we counted their in-house ads as opportunity cost advertising, then we would need to subtract those imputed advertising costs from their revenue when calculating content share. The end result would be a reclassification between types of "free" media with no aggregate change. In order to avoid this problem, we will only count in-house ads that promote subscription content. In many cases, the same newspaper or cable show earns revenue from both subscribers and advertisers. When that is the case, we split in-house ads in proportion to the revenue share. Broadcast television shows are frequently re-run on cable, and so we consider in-house broadcast ads to be partially marketing for cable subscriptions in the future. Taken as a whole, the television industry earns half of its revenue from subscriptions, and so we allocate approximately half of the opportunity cost of in-house ads to "free" content.

The opportunity costs calculated above represent an upper bound. For movie theaters, television networks and print media, we assume a perfectly competitive market. Because of that assumption, we can use the average price for sold advertising viewership or movie theaters tickets to estimate the potential revenue from selling that advertising viewership in the market sector. If perfect competition does not hold, then the estimated opportunity cost for in-house advertising may be significantly lower. For freemium games, we assume that the production cost for premium items like extra lives is nearly zero. As a result, the entire revenue earned from in-app purchases can be allocated to the game development costs. In practice, Figure 4 shows that even the upper bound of opportunity cost advertising is much lower than the advertising expenditures tracked in Figure 3. Accordingly, adjusting our opportunity cost estimates has little aggregate effect.

\section{Nominal Expenditures on Marketing-Supported Information, 2002-2014}

Because marketing-supported information is produced and used in-house, it is much harder to track than advertising-supported media. In this paper, we use a two step process to estimate expenditures on marketing-supported information. We start out by identifying six product lines that are associated with marketing-supported information and the primary industries that produce those product lines for sale. We will list those product lines later. We start with the reported product line revenue in the Economic Census and then adjust for non-employers, underreporting and misreporting. ${ }^{42}$ Our adjusted Economic Census product line sales yield the aggregate value of marketing produced and sold by primaries industries in the U.S. economy. The Economic Census data are only available in 2004, 2007 and 2012. Between Census years, we use the Service Annual Survey (SAS) to interpolate revenue. Next, we use occupation data to estimate expenditures on marketing that is produced outside the primary industry. In our discussion, we will call marketing produced outside the primary industry "inhouse" marketing. In practice, it is possible that some industries may sell marketing as a secondary product. This potential sales do not affect our aggregate estimates of overall marketing expenditures but might bias estimates of marketing output and productivity growth for individual industries.

We use the following procedure to estimate total marketing expenditures. First, we identify the occupations that are primarily responsible for its production. We then focus on industries that produce sold marketing, and calculate the ratio of gross output to earnings for specialist workers for each marketing category. Finally, we use that ratio to estimate the value of in-house marketing produced by

\footnotetext{
${ }^{42}$ According to BEA's calculations, NAICS 51 has very few non-employers, underreporting or misreporting. As a result, we do not bother adjusting the numbers for advertising-supported media.
} 
specialty workers employed in the broader economy. ${ }^{43}$ For example, suppose that a public relations firm (NAICS 54182) sells $\$ 1$ billion worth of public relations services, employs one thousand people in public relations (occupation codes 11-2031 and 27-3031) and pays each person an average salary of $\$ 100,000 .^{44}$ In the rest of the industries studied, we observe ten thousand individuals employed in public relations with an average salary of $\$ 80,000$ each. Based on those hypothetical numbers, we calculate that in-house expenditures on public relations are approximately $\$ 8$ billion [ $\$ 1$ billion/ $(1,000 * \$ 100,000)]^{*}[(10,000 * \$ 80,000)] .{ }^{45}$ Note that we exclude public relations specialists employed by the government or charitable institutions because the current GDP methodology already counts expenditures on public relations in measured output. ${ }^{46}$ Below is a list of the seven categories:

1) Media representation services in NAICS 5418 (product line 37720). For this product, we use advertising sales agents (occupation code 41-3011) as a proxy.

2) Public relations services in NAICS 5418 (product line 37700). For this product, we use public relation specialists (occupation code 27-3031) and public relations managers (occupation code 11-2031) as proxies.

3) Commercial planning, creation and placement services in NAICS 5418 (product lines 37710,37670 and 37680). For these products, we use art directors (occupation code 27-1011), graphic designers (occupation code 27-1024), editors (occupation code 27-3041), writers/authors (occupation codes 273043), multimedia artists (occupation code 27-1014) and producers/directors (occupation code 272012) as proxies.

4) Remaining marketing in NAICS 5418. This category includes a variety of small product lines that appear to marketing-supported information together with our best split for the ambiguous product lines. For proxies, we use all the occupation codes previously mentioned and the additional occupations of marketing managers (occupation code 11-2011), proofreaders (occupation code 43-9081) and all other media workers (occupation codes 27-3099).

5) Website development and hosting in NAICS 5415 (product line 37411 and 36120). For this product, we use system administrators (occupation code 15-1142) as a proxy.

\footnotetext{
${ }^{43}$ This formula misses the in-house marketing produced by industries which sell marketing as their primary product. In addition, we were forced to exclude some industries for some marketing categories because we felt that the occupation proxies might not be reliable for those industries. Furthermore, the OES does not cover the farm sector. For all of those missing industries, we assume the ratio of in-house marketing to total wages matches the broader economy. Aggregate results are robust to changing assumption for these specific industries.

${ }^{44}$ In practice, there are many self-employed individuals working in marketing. These individuals are not tracked in the OES, so we cannot observe precise occupations for the self-employed. However, BEA does have data on the self-employment rate by industry. We use that data to impute aggregate earnings for self-employed public relations specialists and add those imputed earnings to the wages discussed above. In-house production of marketing is assumed to be carried out by employees, so we do not adjust for self-employment there.

${ }^{45}$ Even though this is a hypothetic example, the ten-fold markup from specialty worker earnings to gross output is not unusual. Public relations specialists generally require an IT staff to help them research and write press releases, a travel department to schedule interviews, etc. None of these support staff are identifiable in the OES, so we can't add their earnings to the public relations specialist earnings to get total output. Instead, we are forced to infer their contribution from the reported earnings for specialty workers.

${ }^{46}$ Non-profit hospitals generally receive the majority of their revenue from product sales and behave similarly to for-profit institutions in the same industries. We treat these sectors as if they were entirely in the private sector.
} 
6) Commercial photography in NAICS 5419 (product line 37870). For this product, we use photographers as a proxy (occupation code 27-4021).

7) Corporate sponsorship of events. For this product, we took our data directly from the IEG's annual reports. Those reports are available at http://www.sponsorship.com/report.aspx. Unlike the earlier six categories, we do not distinguish between purchased marketing services and in-house production.

For all of these seven marketing categories, we use the formula described earlier to calculate inhouse production. ${ }^{47}$ Adding up these seven categories, we estimate that U.S. businesses purchased $\$ 119$ billion of marketing services and spent another $\$ 257$ billion on in-house production. The precise level of in-house marketing calculated is somewhat sensitive to the exact product categories tracked and the occupations used as proxies for each category. Just like advertising-supported media, we assume that net exports are negligible. We also assume that marketing-supported information is consumed in the same year it is produced. However, the general growth rate for marketing-supported information is robust to alternative product categories, occupation codes, assumptions about trade and assumptions about marketing capital.

\section{Nominal Expenditures on Marketing-Supported Information, Before 2002}

Unfortunately, we cannot use the formulas and data described above to track marketingsupported information before 2002. Between 2001 and 2002, the OES changed from SIC codes to NAICS codes. This change makes it very difficult to identify which industries are producing marketing as their primary product - so we cannot calculate either purchased marketing or in-house marketing reliably. Furthermore, the OES changed its occupation codes dramatically between 1998 and 1999. Instead, we use a variety of datasets to proxy for marketing expenditures in each of the categories described earlier:

1) Media representation services. For this category, we use the total income reported by media buying agencies (NAICS 54184 and SIC 7313) in the Economic Census and similar surveys. This data is available periodically back until 1948. Before 1948 and between years with data, we use total expenditures on advertising-supported media as an interpolator.

2) Public Relations services. For this category, we use the total income reported by public relations agencies (NAICS 54182, SIC 8743 in 1987 \& 1992 and SIC 7392 for 1963-1982). Before 1963, the Economic Census did not track public relations agencies at all. Accordingly, we cannot use that survey before 1963. However, the decennial population Census does provide some data on self-reported occupation. IPUMS published a crosswalk which allows us to calculate that employment in public relations grew 64 percent between 1950 and 1960. ${ }^{48}$ IPUMS also publishes the exact occupation string reported to the Census up until 1940. Based on that occupation string, we calculate that employment in public relations grew 77 percent between 1930 and 1940. Between 1940 and 1950, we assume that public relations grew at the same rate as other marketing categories. We also use other marketing categories as an interpolator between years with data.

\footnotetext{
${ }^{47}$ Note that our formula might not match internal company calculations. A particular issue is that advertising agencies (NAICS 5418) appear to earn extremely high rates of return on their capital. We assume that companies producing in-house marketing would earn those same rates, so the opportunity cost of in-house marketing is equal to the purchase cost. However, companies calculating marketing expenditures may assume a more normal rate of return on the associated capital.

${ }^{48}$ https://usa.ipums.org/usa/resources/chapter4/occ_50-60.pdf
} 
3) Commercial planning, creation and placement services. For this category, we use the net billing reported by advertising agencies (NAICS 54181 and SIC 7311) in the Economic Census and similar surveys. This data are available periodically back until 1935. The Service Annual Survey also tracks advertising billing back until 1972. We use the SAS data as an interpolator when it is available. Before 1935 and between years with data, we use total expenditures on advertising-supported media as an interpolator. Finally, we adjust the advertising agency revenue to remove expenditures on audio-visual programs produced in-house. Those expenditures will be studied separately. As a robustness test, we also explored using self-reported employment in the decennial Census to track in-house production of media planning, creation and placement. We found that this method produced similar long-term trends, but the imputed ratio of in-house production to purchased production was noisy from one Census to the next.

4) Remaining marketing. The category is relatively small and diverse. For simplicity, we did not try to collect data back to 1929. Instead, we use the previous four categories of marketing-supported information as proxies.

5) Website development and hosting. We use OES tracking employment of system administrators as a proxy. This gives us spending back to 1998 . Before 1998, this category was small and so new that the 1997 Economic Census did not even have product codes for it. We were not able to find any official data tracking website development costs during the 1990s. For now, we use online advertising expenditures as a proxy.

6) Commercial stock photography. This product was studied earlier in the paper "Miscellaneous Artwork as Capital Assets" (Soloveichik 2013d). We took the existing estimate of revenue from commercial stock photography and use that as a proxy back until 1929.

7) Corporate sponsorship of events. The IEG reports described earlier provide sponsorship expenditures back until 2001. Between 1988 and 2000, we use the Olympic Committee's reported revenue from corporate sponsorship as a proxy for overall sponsorship expenditures. These two proxies suggest that sponsorship has grown rapidly, from 2.75 percent of expenditures on advertising-supported media in 1988 to 6.89 percent of expenditures on advertising-supported media in 2000. Before 1988, we were not able to find any data on corporate sponsorship. We use its growth rate after 1988 and the growth rate of advertising-supported media as a proxy.

\section{Nominal Expenditures on Marketing-Supported Information in $\mathbf{2 0 1 5}$}

It might seem that the OES data track marketing up until 2016. After all, the last publicly available dataset is labeled May 2016. In fact, the OES data are based on a three year rolling panel - so the 2016 dataset actually tracks employment for 2014-2016. We use the 2015 OES data to measure marketing expenditures in 2014, and so on. At the time this research project was started, the May 2016 OES data were not yet available. Accordingly, we were only able to carry out the detailed calculations described earlier up to 2014. Shortly before publication, we downloaded the May 2016 data and calculated earnings growth for selected professions across the private sector economy. We use this aggregate growth rate as a proxy the growth rate of marketing between 2014 and 2015. 


\section{Marketing-Supported Information by Category, 1929-2015.}

In this paper, we track three separate categories of marketing-supported information: a) print marketing; b) audio-visual marketing and c) digital marketing. Unfortunately, it is often very hard to allocate product lines between print, audio-visual and digital. For example, a writer might write a column for a print newsletter, contribute to a corporate blog or write dialogue for a filmed ad. Many writers do all three simultaneously. In this paper, we combine a variety of datasets with out best judgment to split spending. Our methodology for allocating the various product lines is given below:

1) Media representation in NAICS 5418 (product line 37720). Between 1997 and 2012, the Economic Census reports separate product lines for each media category (37721-37725). Between 1963 and 1997, the Economic Census reports revenue separately for publishers' representatives (print marketing) and radio/television representatives (audio-visual marketing). Before 1963 and between census years, we use advertising-supported media as a proxy for media representation services.

2) Public relations services in NAICS 5418 (product line 37700). Neither the Economic Census nor the industry literature gives much guidance for this product line. We will use our best judgment instead. Public relations agencies typically work to push favorable news stories and rebut unfavorable news stories about their clients. Therefore, it seems likely that public relations specialists allocate their time in proportion to news consumption. According to a 2011 Pew survey, print newspapers provided 19 percent of news information, the Internet provided 25 percent and the remainder was supplied by radio or television. ${ }^{49}$ The Pew surveys provide data from 2001 until 2010. Before 2001 and after 2010, we use media consumption time as an extrapolator. That media consumption time will be described in more detail in our section calculating viewership prices.

3) Purchased commercial planning, creation and placement services in NAICS 5418 (product lines 37710, 37670 and 37680). Our primary dataset is the industry group Ad Age. They first report on digital marketing in 2007, when it accounted for 8.74 percent of total marketing services sold. By 2015, digital marketing had grown to 41 percent of total marketing services sold. We were not able to find any data splitting print marketing from audio-visual marketing. For simplicity, we will generally split these two categories in proportion to media representation services. The only exception is that advertising agencies before 1960 sometimes created shows like "The Kraft Television Hour" rather than simply buying commercial time on existing media programs. We allocate those shows entirely to the audiovisual sector. We also use digital media representation services as a proxy for digital marketing before 2007.

3b, 4, 5 and 6) In-house commercial planning, creation and placement services; remaining marketing services; website development; website hosting; and commercial photography. For these categories, we use reports from the research firm Outsell. That firm has tracked marketing by category since 2006. Before 2006, we use earnings for systems administrators and computer workers (occupation codes 15$1131,15-1132,15-1133,15-1134$ and $15-1142$ ) as a proxy for digital marketing. We were not able to

\footnotetext{
${ }^{49}$ Individuals were allowed to volunteer two main news sources, so the reported totals sum up to well over $100 \%$. The survey did not ask about magazines news. We assume magazine news equaled half of newspaper news. We smoothed across three years and divide by the total to get shares. http://www.peoplepress.org/2011/01/04/internet-gains-on-television-as-publics-main-news-source/.
} 
find such direct proxies for print marketing. For now, we use the print media as a proxy for print marketing.

7) Corporate sponsorship of events. The IEG reports split spending between sports sponsorship and other events like live music concerts. We allocate 75 percent of sports sponsorship towards television viewers (audio-visual sector) and 25 percent towards the fans in the stadium (in-person sector). We are not studying in-person marketing in this paper, so we will drop all spending in that category from our analysis.

\section{Price Index for “Free” Content: 1929-2015}

Below is a brief description of each category:

a) Print Media. Book publishers produce a very similar product to print media and therefore wholesale book prices are a good proxy for the costs of writing, editing, printing, and delivering newspapers. We use the BEA's price index for book originals (Table 5.6.4, line 25) as a proxy for all those costs. In addition to the writing costs, print media generally requires more outside research than books do. For example, journalists generally interview sources before they write an article on a topic. We were not able to find any data specific to journalist research costs, but we believe that those costs are related to communication technology. Accordingly, we use BEA's pre-existing price index for telecommunications (Table 2.4.4, line 97) as a proxy for outside research costs. For our combined price index, we assign book originals an 85 percent weight and telecommunications a 15 percent weight. We then calculate the price of "free" digital content with the simple formula:

$$
(\text { Price of Print Content })=(\text { Price of Book Originals })^{0.85} *(\text { Telecommunications Price })^{0.15}
$$

b) Audio-Visual Content. The three main inputs to audio-visual content are sports programs to air, nonsports programs to air and transmission services to send the content to viewers. We use BEA's preexisting price index for sporting event tickets (Table 2.4.4U, line 212) as a proxy for the price of sports programs. We use BEA's pre-existing price index for long-lived television programs (BEA Table 5.6.4, line 24) as a price index for non-sports programs. ${ }^{51}$ Finally, we use BEA's pre-existing price index for telecommunications (Table 2.4.4, line 97) as a proxy for transmission costs. We then calculate the price of "free" audio-visual content with the formula:

(Price of Audio-Visual Content $)=(\text { Price of Sports Programs })^{0.133} *($ Price of Non-Sports Programs $)^{0.533} *{\text { (Telecommunications Price })^{0.333}}^{0.133}$

The formula given above simplifies the broadcasting and cable industries immensely. Broadcasting stations have implicit ownership of their airwaves, and their transmission costs depend on the shadow price of spectrum as well as the capital costs of transmission equipment. Furthermore, both cable distributors and phone companies are regulated monopolies with prices partially determined by

\footnotetext{
${ }^{51}$ It might seem overly complicated to create two separate price indexes. However, the inflation rate for sports programs averaged 1.1 percentage points than the inflation rate for non-sports programs. This higher inflation rate is likely caused by the extraordinary wage growth for athletes. BEA's price index only goes back to 1959 . Before then, we use MLB wages as a proxy.
} 
government policy. As a robustness test, we also experimented with developing detailed price indexes tracking the inputs to transmission more closely. That price index is described in much more detail in our previous paper (Nakamura, Samuels and Soloveichik 2016). In practice, that detailed price index provides similar long-term trends at the cost of much greater computation complexity. We also considered using quantity data to derive prices. The paper 'The Random Long Tail and the Golden Age of Television' (Waldfogel 2016) demonstrates a simple methodology to count television show production. We followed his methodology and created a quantity index based on a simple count of all television shows running in the United States from 1949 onwards. Once again, this complex price index matches the simple input based price index reasonably well.

c) Digital Content. The two main inputs to digital content are software to provide the content and computers to run the software. For simplicity, we assign each input a 50 percent weight and calculate the price of "free" digital content with the simple formula:

$($ Price of Digital Content $)=(\text { Price of Software })^{0.5} *(\text { Cloud Computing Prices })^{0.5}$

Our price index for software is taken from BEA's pre-existing price index for own-account (Table 5.6.4, line 3). The price index for computers is a little more complicated. BEA has many separate price indexes for computers, but they only track the cost of the hardware. Over the past decade, server farms have become much more efficient at using their hardware to produce more computing power. Our price index for computing services is based on the paper, 'The Rise of Cloud Computing: Minding Your P's and Q's' (Byrne, Corrado and Sichel 2017) to develop a price index for cloud computing services. The data in that paper did not start until 2009 and only cover Amazon's prices until 2014. As a result, the annual changes are somewhat noisy. ${ }^{52}$ We used the three indexes reported in that paper to measure cloud computing prices in 2009 and 2016. Between those years and before 2009, we use BEA's preexisting price index for business computers (Table 5.5.4, line 4) as an interpolator.

\section{Price Indexes for Advertising/Marketing Viewership}

We measure viewership prices indirectly. First, we create quantity indexes tracking viewership of advertising/marketing. By construction, our indexes only track viewership of the advertising/marketing which is viewed during media usage time and which is separated from the media content. For example, a print newspaper might print news articles on one page and paid advertisements in the next page. The cost of those paid advertisements includes not only the cost charged by newspapers to advertisers for the page space, but also the implicit cost incurred by marketers designing the ad and placing it in a relevant location. We then construct price indexes with the formula:

(Viewership Price) $=[($ Advertising \$) $+($ Separated Marketing \$) $/($ Viewership Quantity)

We construct six separate viewership quantity indexes for the following categories;

\footnotetext{
${ }^{52}$ Amazon's prices started dropping much faster in 2014. These faster declines appear to be caused by increased competition in the cloud computing industry rather than a true cost change. As a result, the short-term price changes are an imperfect proxy of the in-house cost of running server farms.
} 
a) Print newspaper readership. For this category, we are able to measure both the time spent reading newspapers and the share of newspaper content devoted to advertising. We then multiply to get our quantity index.

b) Print magazine readership. For this category we are only able to measure the time spent reading magazines. We assume that the share of magazine content devoted to advertising is fixed, so we can use readership time as a quantity index.

c) Non-Internet radio listenership. For this category, we are able to measure both the time spent listening to the radio offline and the share of broadcast time devoted to advertising. We multiply to get our quantity index.

d) Non-Internet television viewership. For this category, we are able to measure both viewership time offline and the share of television network time devoted to advertising. We multiply to get our quantity index.

e) Desktop Internet search. This category covers traditional searches on Google and other search engines. We are able to measure the total number of searches in the United States. We use that as our quantity index.

f) All other Internet. For this category, we are only able to measure the total time spent online. Just like magazines, we assume that advertising exposure per hour is fixed and so we can use online time as our quantity index.

We were not able to track viewership quantities for many categories of marketing. Some marketing categories are embedded in media programs without any clear separation. For example, a public relations spokesperson might give a television interview defending a company's products. In that case, the cost of embedded marketing is often bias or omitted facts rather than wasted time. Other marketing categories are separated, but we were not able to locate any viewership quantity data. In those cases, we impute viewership prices by assuming that viewership prices for unmeasurable print marketing is the same as the average viewership prices for measurable print marketing, the viewership prices for unmeasureable audio-visual marketing are the same as the average viewership prices for unmeasureable audio-visual marketing, etc

\section{Quantity Indexes of Media Viewership Time, 2007-2014}

Our primary data on time use is provided by Forrester, a survey company. They have been surveying Americans about their media time use since 1999. Our paper will use data from their questions on weekly time use for "reading newspapers (not online)", "reading magazines (not online)", "listening to the radio (not online)", "Using the Internet for personal purposes" and "Using the Internet for work purposes". Like most surveys, Forrester relies on self-reported data and does not attempt to check their answers against objective source data like Internet cookies. We do not know either the size or direction of the possible misreporting. For now, we will use Forrester's data on newspaper readership, magazine readership, radio listenership and total Internet usage without adjustment.

Forrester's survey does not ask respondents for the exact amount of media usage. Instead, they are asked to check boxes giving the time use category. The lowest category is "none" and the highest category is "30 or more hours". In some of their published reports, Forrester creates a continuous variable by replacing each box with the midpoint of the range. In particular, the mapping is "none" $=0$, "less than 1 hour" = 0.5, "1-4 hours" = 2.5, "5-9 hours" = 7, "10-14 hours" = 12, "15-19 hours" = 17, "2024 hours" $=22$, " $25-29$ hours" $=27$ and "30 or more hours" $=32$. This average usage is held fixed over time. In this paper, we have used a statistical methodology described in Von Hippel et al (forthcoming) to estimate the mean for the top-coded bin, using a Pareto distribution for the top-coded bin ( $30+$ 
hours per week) and the next-to-top-coded bin (25-29). For the non-top-coded bins, we used midpoints, as Forrester does. In future work, we plan to use a parametric methodology for estimating the mean using the generalized beta distribution to model the entire distribution of binned data. This has the advantage of not throwing away any information, but it leans more heavily on distributional assumptions. Having two methods should enable us to have some notion of how sensitive our estimates are to the statistical methodology employed. Our imputed numbers should not be attributed to Forrester.

\section{Other Data on Media Time and Media Consumption: 1929-2014}

For television, we use Nielsen data to track viewership back to its beginning. We did not buy Nielsen's full data for this purpose, but rely on the summaries prepared by the non-profit trade association TVB. All of our Nielsen data were taken from their website, tvb.org, and are available for free. Forrester also tracks television viewing time, and we could use their data from 2007 onwards. However, the Forrester data are much noisier than the Nielsen data and so our annual TFP numbers are a little more volatile.

We use a variety of datasets to track radio listenership. From 2007 to 2014, we use Forrester's survey question on "radio listening (not online)". ${ }^{53}$ From 1980 until 2007, we use Arbitron data. Like the Nielsen data, we did not buy Arbitron's full dataset. Instead, we rely on a summary prepared by the Corporation for Public Broadcasting which reports total radio listenership for each year from 1980 to $2010 .^{54}$ We also found Arbitron data for 1972 cited on page 523 of the book "American Broadcasting" (Lichty and Topping 1975). Before 1972, we could not find any systematic ratings for radio. However, we found an article "More Power" (Sponsor 1949) that reports radio listenership in 1949, 1946 and 1943. Before 1943, we could not find any useable data on listenership time. As a rough proxy, we use the percentage of households who own radio and the percentage of cars equipped with radios (Sterling and Kittross 1978). ${ }^{55}$

For the Internet, we use a variety of sources. The UK regulator Ofcom surveyed Internet users in 2005 and 2007 about personal Internet and work Internet. ${ }^{56}$ Their 2007 time use numbers are similar to Forrester's 2007 numbers, so it seems reasonable to use their 2005 time use numbers as a proxy. Before 2005, we use data from the Statistical Abstract of the United States to track Internet usage. ${ }^{57}$

Newspapers and magazines are the hardest media category to track. From 2007 to 2014, we use Forrester's survey on time usage. From 1991 until 2007, we use readership data from Pew surveys conducted periodically and reported in "In Changing News Landscape, Even Television is Vulnerable" (Kohut et al 2012). Before the Pew survey data, we use the article "Radio declares: Compare Me"

\footnotetext{
${ }^{53}$ Forrester reports a very small decline in offline listening between 2007 and 2014 . Over the same time period, Arbitron's data show a much larger decline. This decline may be associated with measurement changes http://rainnews.com/radio-aqh-decline-ppm/ rather than competition from online radio.

54 In particular, we use the series ' $6 a-$ Mid, $12+$ Persons Using Radio AQH Rating'. That series reports the \% of people who are listening to the radio at any given time.

${ }^{55}$ For now, we give home radios and car radios an equal weight when calculating listenership. We multiply both proxies by population to get an estimate of total listenership.

${ }^{56}$ https://www.ofcom.org.uk/_data/assets/pdf_file/0020/102755/adults-media-use-attitudes-2017.pdf

${ }^{57}$ Taken from Table 1094 of the 2010 Statistical Abstract, Table 1089 of the 2009 Statistical Abstract, Table 1110 of the 2007 Statistical Abstract, Table 1119 of the 2004 Statistical Abstract, Table 1125 of the 2003 Statistical Abstract and Table 1102 of the 2002 Statistical Abstract. All of these tables explicitly focus on leisure Internet usage and do not include on-the-job Internet. We adjust for the on-the-job share to get total Internet usage.
} 
(Sponsor 1961) ${ }^{58}$ to get a snapshot of readership in 1961 and the article "More Power" (Sponsor 1949) to get a snapshot of readership in 1949. Between the years with data, we use newspaper and magazine circulation to interpolate annual readership. We also use newspaper and magazine circulation to extrapolate readership before $1949 .{ }^{59}$

\section{Quantity of Internet Searches}

Our data on desktop searches is taken from Comscore. It tracks a representative sample of computer uses and uses that sample to estimate usage across the entire population. ${ }^{60}$ We were not able to buy Comscore's data. Instead, we rely on publicly available news reports to construct a quantity index back until 2003. Before then, we use overall Internet viewership prices as a proxy for search engine prices.

It is important to note that BLS does publish a price index for search engines (PCE 519130519130101). Unlike our indirect price index, it shows rapid declines in search costs from 2009 to 2016. We believe that BLS's price declines are caused by a composition shift. Advertising prices are much lower in developing countries. Between 2009 and 2016, Internet usage has spread rapidly in the developing world. As a result, average revenue per click could have fallen even if viewership prices in the U.S. remained steady. For the same reason, we also chose not to use BLS's price index for banner advertising or other Internet space.

\section{Advertising/Marketing Share for Media, 1929 to 2015}

In 1979, the Statistical Abstract reports that advertising accounted for 64 percent of total newspaper content. Accordingly, we assume that newspaper readers spent 60 percent of their time reading advertising. We are able to track advertising share back to 1929 with data from the Statistical Abstract of the United States ${ }^{61}$ and the Historical Statistics of the United States Colonial Times Until $1970 .^{62}$ Unfortunately, the Statistical Abstract stopped tracking advertising linage after 1980 . We use BLS's producer price index for newspaper advertising (WPU361102) to construct a quantity index of print advertising content. ${ }^{63}$ We use data from the Economic Census and FAO tracking newsprint usage

\footnotetext{
${ }^{58}$ This article gives an estimate for radio listenership. However, their estimate is much lower than Arbitron's numbers. We believe that this difference is caused by survey respondents underreporting background radio while driving or doing other activities. Forrester's survey shows the same underreporting relative to Arbitron.

${ }^{59}$ The two cities tracked in 1949 were both more highly educated than the broader public and might be unrepresentative (Des Moines, lowa and Springfield, Massachusetts).

${ }^{60}$ https://www.statista.com/statistics/265796/us-search-engines-ranked-by-number-of-core-searches/ http://ir.comscore.com/releasedetail.cfm?ReleaselD=362732

http://ir.comscore.com/releasedetail.cfm?releaseid=290856

http://blog.ineedhits.com/search-news/google-yahoo-dominate-search-in-december-2006-15052309.html https://books.google.com/books?id=QVcsBgAAQBAJ\&pg=PA76\&lpg=PA76\&dq=growth+rate+for+search+2005+co mscore\&source=bl\&ots=E-A60e91z\&sig=|0NXWr7pzJvpiOvEfVhbFaQ DXM\&hl=en\&sa=X\&ved=0ahUKEwju5bz39evVAhVLzoMKHSI_AmwQ6AEI $\underline{\mathrm{SzAH \# v}=\text { onepage } \& \mathrm{q} \& \mathrm{f}=\text { false }}$ https://www.informationweek.com/google-widens-search-lead-as-growth-slows/d/d-id/1040924

${ }^{61}$ Table 1080 of the 1980 Statistical Abstract and Table 897 of the 1975 Statistical Abstract.

62 Series T-220 and T-221. Before 1940, we use the newspaper advertising linage from T-485 as a proxy.

${ }^{63}$ That series starts in 1981. We use the broader PPI PCU511110511110 to extend the price index back to 1979. Newspaper advertising prices are generally quoted on a per edition basis, so the number of readers reach has been gradually falling with the decline of print newspapers. We use circulation data from the Newspaper Association of America to adjust for this quality decline. Our precise advertising share numbers are sensitive to the adjustment method, but the general result of falling advertising content is not. BLS did not split digital advertising
} 
to construct a quantity index of total newspaper content. ${ }^{64}$ Based on those two quantity indexes, we are able to infer the advertising share of newspaper linage.

Between 1948 and 1980, advertising hovered around 60 percent of total newspaper content. After 1980, advertising gradually shrank. By 2015, we estimate that advertising accounted for only 37 percent of total content. We assume that advertising readership time has followed the same trends. Accordingly, the decline in print advertising readership is even faster than the decline in print newspaper readership documented by Pew earlier.

For audio-visual media, we use the time share devoted to commercial content. Between 1950 and 2010, we use data from IMDB.com to split viewership between programs and advertising. IMDB does not directly report the amount of advertising viewership - but it does report the run-time for individual episodes. Between 1950 and 2010, the time devoted to commercials grew from 15 percent of broadcast time to 28 percent of broadcast time. After 2010, we use the online article 'How Many Minutes of Commercials Are Shown in an Average TV Hour? The Number Has Been Steadily Climbing' published by TV Week in 2014 as a proxy. We could not find similar data for radio, but the book 'Radio After the Golden Age: The Evolution of American Broadcasting Since 1960' (Cox 2013) suggests that radio commercial time grew at approximately the same rate as television advertising time.

For online media, we could not track advertising shares very precisely. We did locate data tracking Netflix viewership over time. ${ }^{65}$ Between 2009 and 2015, Netflix viewership grew from almost nothing to 7 percent of online time. Netflix is a subscription supported website that shows very few ads - so time spent watching Netflix is unlikely to be spent watching ads. But we could not locate any other data on advertising viewership. In the absence of any other data, we will assume that the advertising share for non-Netflix time is constant. ${ }^{66}$ In theory, it might make sense to subtract time devoted to online search because that search is already tracked in a separate price index. In practice, search is generally a quick process that occupies a small fraction of online time. For simplicity, we will not subtract that time.

\section{Calculating Content Production by Industry}

Advertising-supported media is produced by the information sector (NAICS 51). For simplicity, our current TFP calculations assume that all print media are produced by the publishing sector (NAICS 511), all audio-visual media are produced by the broadcasting and telecommunications sector (NAICS 515) and all online media are produced by the Internet publishing sector (NAIC 518).

It is often quite difficult to determine which industries are bartering marketing-supported information for marketing viewership. Unlike advertising-supported media, virtually all industries produce some marketing-supported information. In addition, most industries outsource a portion of their marketing to specialty industries like computer consultants. We have not been able to find any data tracking expenditures on marketing-supported information by industry or category. In this paper,

from print advertising until very recently. We adjust the combined PPI's for advertising prices in the Internet publishing industry to derive prices for print advertising alone.

${ }^{64}$ The FAO's data is available annually online. The Economic census directly reports newsprint consumption for newspaper publishers in 1977, 1982, 1987, 1992 and 1997. After 1997, we use the Economic Census to measure newsprint consumption by other industries. The residual is assumed to be for newspapers.

${ }^{65} \mathrm{http}: / /$ time.com/4186137/netflix-hours-per-day/. http://tdgresearch.com/tdg-netflix-streaming-volume-up-350-in-10-quarters/. They don't give total U.S. hours for 2012 and 2013, so I interpolate between them based on hours per subscriber.

https://techcrunch.com/2010/07/12/netflix-hulu 
we use OES data tracking employment for computer related occupations as a proxy for total expenditures on online marketing; and OES data tracking advertising and creative occupations as a proxy for total expenditures on print and audio-visual marketing. In order to reduce the random variation, we combine all of the OES sample waves into one and use that as a snapshot of marketing-supported information output in 2009. Finally, we extrapolate expenditures on marketing-supported information from 1948 until 2014 based on pre-existing estimates of gross output by industry. As a robustness check, we have also calculated TFP using alternative allocations. We find nearly identical results for aggregate TFP.

\section{Splitting "Business Information" and "Consumer Entertainment": 1929-2014}

Forrester's reported split between "work Internet" and "personal Internet" is not equivalent to our split between "business information" and "consumer entertainment". Our paper is focused on measuring productivity by industry in the private business sector, so we consider "business information" to be Internet used on-the-job for job related purposes. "Consumer entertainment" covers both leisure activities like YouTube and household production like scheduling medical procedures or paying bills. In contrast, Forrester's respondents appear to have a broader definition of "work Internet". Approximately two thirds of full time students report using the Internet for work and many of those students report very high usage. These students are almost certainly reporting their homework and other study time as "work Internet". In addition, retirees and other individuals not employed also frequently report using the Internet for work. These individuals are probably reporting household production activities as work. We calculated the true "business information" share by replacing reported "work Internet" with zero for all individuals not employed.

Forrester does not ask respondents to split print media readership, television viewing or radio listening between work and personal. In the absence of reliable time use data, we will use a variety of proxies to split "business information" and "consumer entertainment". For print media, we use genre data reported in the Economic Census and other sources. For example, we assume that scientific journals are used for work rather than leisure. Very few of the shows on broadcast radio or television are targeted towards business information. For now, we assume that on-the-job users account for only 1 percent of audio-visual advertising.

Finally, we adjust for a conceptual difference between the NIPA's and everyday conversation. In BEA's GDP statistics, owner-occupied housing is treated as if it were part of the business sector. Consistent with that treatment, "free" media products that help people buy, finance or maintain their homes should be treated as intermediate inputs rather than final consumption. However, the Forrester survey respondents and the Economic Census almost certainly define home purchases as a personal activity rather than a work activity. We use data from the Historical Statistics of the United States tracking advertising genre and our best judgement to adjust for this difference in definition.

\section{Usage of Media By Industry: 1929-2014}

Our primary data are the same Forrester survey described earlier. In 2013 and 2014, Forrester asked respondents "In which industry/field do you work?" They provided only 30 codes for this question and a few of codes do not represent industries. ${ }^{68}$ We used our best judgment to match the

\footnotetext{
${ }^{68}$ For example, one answer was nonprofit, which could correspond with many industries. We do not match those codes to any of the NAICS codes. In addition, many Forrester codes are matched to multiple NAICS codes.

Some individuals report multiple industry/field codes to Forrester. We drop all these individuals from our sample.
} 
Forrester codes with the 63 private sector industries tracked in the joint BLS-BEA production accounts. Reassuringly, reported time usage in the Forrester survey is highly correlated with reported Internet access in the CPS. ${ }^{69}$

We were not able to find any data tracking usage of print media or audio-visual media by industry. For now, we use Internet usage by industry as a proxy for those media categories. We were also unable to find any data on media usage by industry before 2013. For now, we use total industry output and total work Internet usage as extrapolators. For example, agriculture is assumed to use a very small share of print media output in 2013 - but it accounted for a much larger share of business information in 1948. Our aggregate TFP numbers are robust to changing the industry allocation procedure, but TFP numbers for individual industries are more sensitive.

\footnotetext{
${ }^{69}$ The relationship between Internet access and usage is not one-to-one. In the CPS data, Internet access ranged from 15 percent for industries like agriculture to 70 percent for industries like publishing. The Forrester data show a much more compressed range of "work Internet" time. We believe that this compression is caused by employees without work-provided Internet using their personal smartphones for work.
} 